ORNL/TM-11916

Health and Safety' Research Division

\title{
Improving Neutron Dosimetry Using Bubble Detector Technology
}

\author{
M. A. Buckner
}

Date Issued-February 1993

\author{
Prepared for \\ U.S. Department of Energy \\ Office of Health \\ under budget and reporting code HA0118000 \\ Prepared by \\ OAK RIDGE NATIONAL LABORATORY \\ Oak Ridge, Tennessee 37831-6285 \\ managed by \\ MARTIN MARIETTA ENERGY SYSTEMS, INC. \\ for the \\ U.S. DEPARTMENT OF ENERGY \\ under contract DE-AC05-84OR21400
}




\begin{abstract}
Author Affiliations
M. A. Buckner is a member of tile Assessment Technology Section of the Health and Safety Research Division, Oak Ridge National Laboratory, Martin Marietta Energy Systems, Inc., Oak Ridge, Tennessee. This work was originally published as a thesis in partial fulfillment of requirements for a master's degres in nuclear engineering at The University of Tennessee.
\end{abstract}




\section{CONTENTS}

FIGURES $\ldots \ldots \ldots \ldots \ldots \ldots \ldots \ldots \ldots \ldots \ldots \ldots \ldots \ldots \ldots \ldots \ldots$

TABLES $\ldots \ldots \ldots \ldots \ldots \ldots \ldots \ldots \ldots \ldots \ldots \ldots \ldots \ldots \ldots \ldots \ldots \ldots \ldots \ldots$

NOMENCLATURE $\ldots \ldots \ldots \ldots \ldots \ldots \ldots \ldots \ldots \ldots \ldots \ldots \ldots \ldots \ldots$

ACKNOWLEDGMENTS $\ldots \ldots \ldots \ldots \ldots \ldots \ldots \ldots \ldots \ldots \ldots \ldots \ldots \ldots \ldots$

ABSTRACT $\ldots \ldots \ldots \ldots \ldots \ldots \ldots \ldots \ldots \ldots \ldots \ldots \ldots \ldots \ldots \ldots \ldots \ldots$

1. INTRODUCTION $\ldots \ldots \ldots \ldots \ldots \ldots \ldots \ldots \ldots \ldots \ldots \ldots \ldots \ldots \ldots$

1.1 NECESSITY OF ACCURATE NEUTRON DOSIMETRY $\ldots \ldots \ldots \ldots \ldots 1$

1.2 JNHERENT DIFFICULTIES ASSOCIATED WITH

NEUTRON DOSIMETRY $\ldots \ldots \ldots \ldots \ldots \ldots \ldots \ldots \ldots \ldots \ldots$

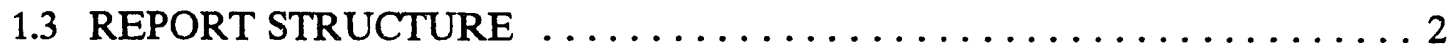

1.4 ADVENT OF SPECTRAL INFORMATION:

THRESHOLD DETECTORS $\ldots \ldots \ldots \ldots \ldots \ldots \ldots \ldots \ldots \ldots \ldots$

1.5 BUBBLE CHAMBER ........................ 4

1.6 BUBBLE DETECTOR (BD) OR SUPERHEATED DROP

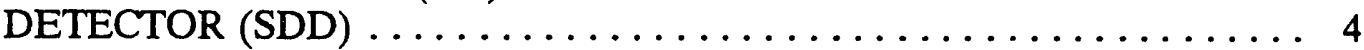

1.6.1 BTI and Post-Event Detection ................... 4

1.6.2 Apfel and Active Detection ................... 5

1.7 THEORY OF INTERACTION AND BUBBLE FORMATION . . . . . . . 5

1.7.1 Ion Production ........................ 6

1.7 .2 Energy Transfer ........................... 7

1.7.3 Bubble Formation $\ldots \ldots \ldots \ldots \ldots \ldots \ldots \ldots \ldots \ldots$

1.8 COMBINATION PERSONNEL NEUTRON DOSIMETER (CPND) $\ldots \ldots \quad 8$

2. IMPROVEMENT AND MODIFICATION OF THE CPND . . . . . . . . 9

2.1 INTRODUCTION AND DESCRIPTION OF AREAS TO BE

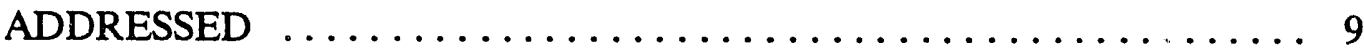

2.2 REFINEMENT OF THE BD-100R AND BDS-1500R(E)S . . . . . . . 9

2.2 .1 Monoenergetic Irradiations $\ldots \ldots \ldots \ldots \ldots \ldots \ldots \ldots \ldots$

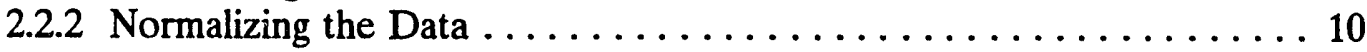

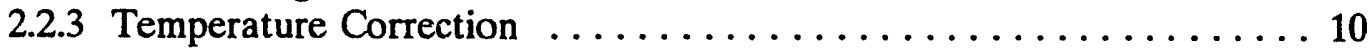

2.3 REEVALUATION OF THE TLD-600 THERMAL

NEUTRON SENSITTVITY $\ldots \ldots \ldots \ldots \ldots \ldots \ldots \ldots \ldots \ldots \ldots$

2.4 REDEFINITION OF ENERGY INTERVAIS (EIs) $\ldots \ldots \ldots \ldots \ldots \ldots \ldots$

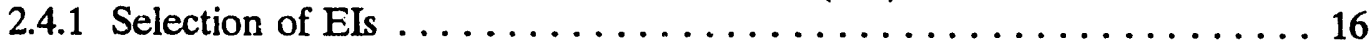

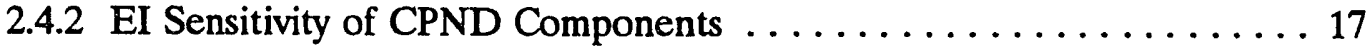

2.5 MATRIX ALGORITHM AND SPECTRUM DECONVOLUTION . . . . . 17

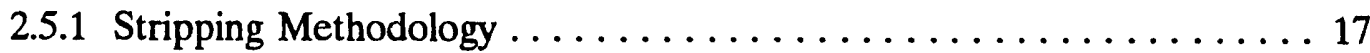

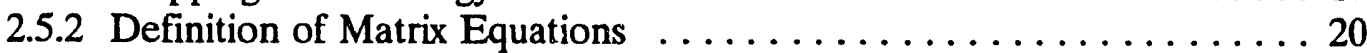

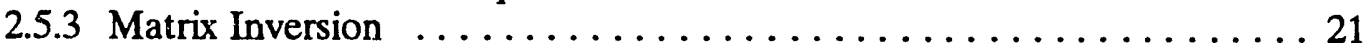

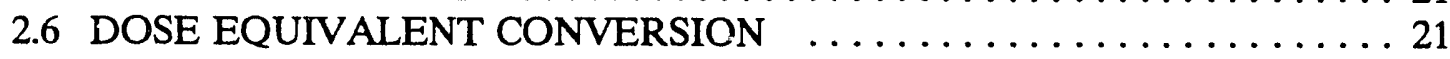


3. PERFORMANCE EVALUATION AND ANALYSIS OF RESULTS $\ldots \ldots \ldots 22$

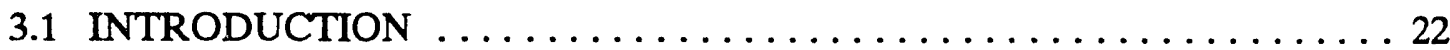

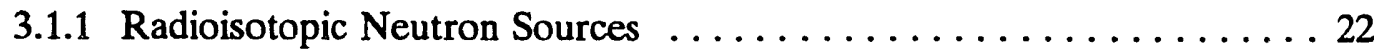

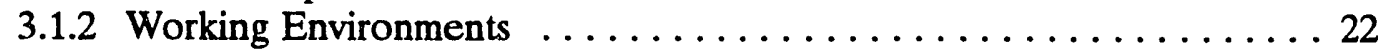

3.1.3 Reference Dosimetry ........................ 23

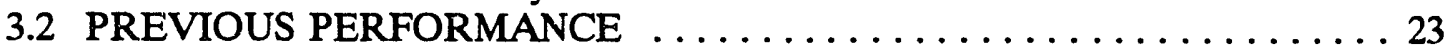

3.2.1 Dose Equivalent Performance Utilizing the Liu Method ... . . . . . 24

3.2.2 Spectrometric Performance Performance

Utilizing the Liu Method . . . . . . . . . . . . . . . 24

3.3 REASSESSMENT OF REFERENCE SPECTRA AND

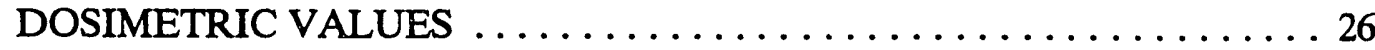

3.4 PERFORMANCE REEVALUATION $\ldots \ldots \ldots \ldots \ldots \ldots \ldots \ldots \ldots \ldots$

3.4.1 Dose Equivalent Performance .................. 28

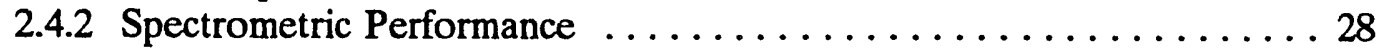

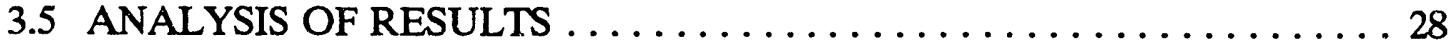

4. SOME CURRENT ASSUMPTIONS AND ALTERNATIVE

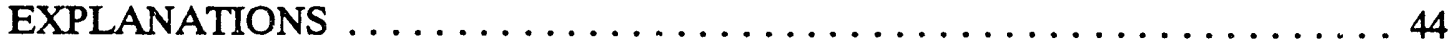

4.1 USEABLE LIFETIME $\ldots \ldots \ldots \ldots \ldots \ldots \ldots \ldots \ldots \ldots \ldots \ldots \ldots \ldots$

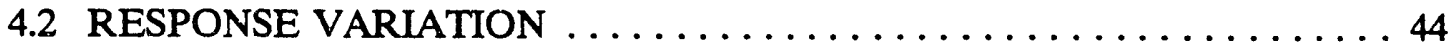

4.3 TEMPERATURE EFFECTS AND COMPENSATION METHODS $\ldots \ldots 45$

4.3.1 How Temperature Affects Response . . . . . . . . . . . . 45

4.3.2 Pressure Compensation ....................... 47

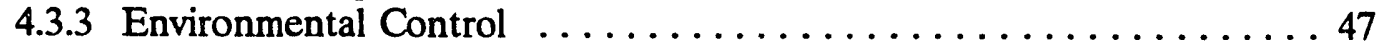

4.3.4 Computational Compensation $\ldots \ldots \ldots \ldots \ldots \ldots \ldots \ldots \ldots \ldots \ldots$

4.3.5 Heat Induced Alteration ..................... 48

4.4 BUBBLE FORMATION, GROWTH, AND MEMORY $\ldots \ldots \ldots \ldots \ldots \ldots 48$

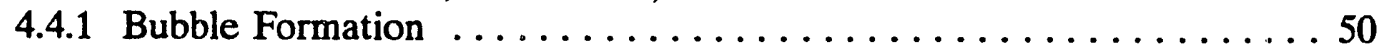

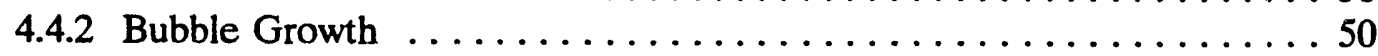

4.4.3 Bubble Memory ...................... 51

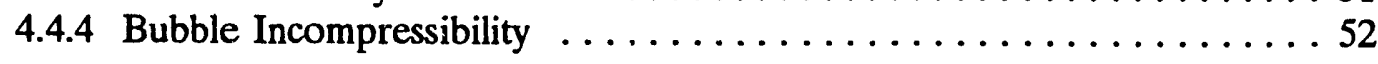

5. FUTURE DIRECTIONS AND APPLICATIONS $\ldots \ldots \ldots \ldots \ldots \ldots \ldots \ldots$

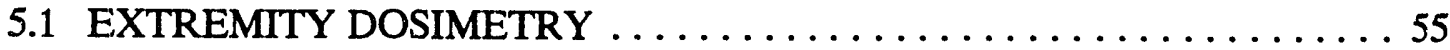

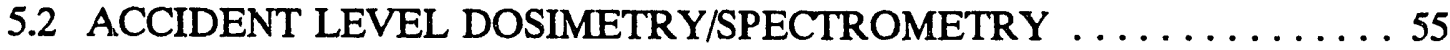

5.3 A "DO-IT-YOURSELF" BUBBLE READER ............... 57

5.4 DEVELOPMENT OF A COMBINATION AREA NEUTRON

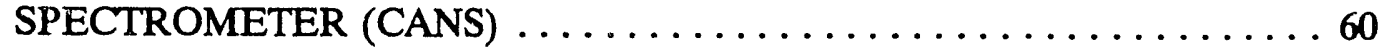

5.4 .1 Redesigned TLD . . . . . . . . . . . . . . . . . 60

5.4 .2 Additional BDs . . . . . . . . . . . . . . . . 60

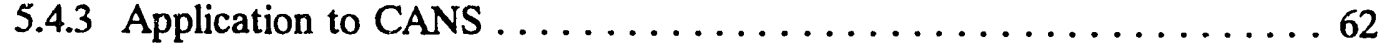

5.5 ALTERNATTVE REAL-TIME ACOUSTICAL

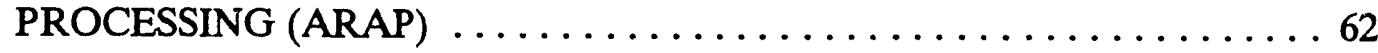

6. SUMMARY AND CONCLUSIONS $\ldots \ldots \ldots \ldots \ldots \ldots \ldots \ldots \ldots \ldots \ldots \ldots \ldots$

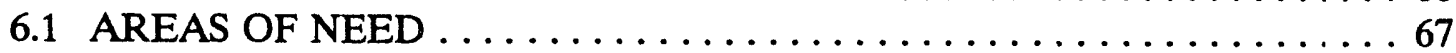

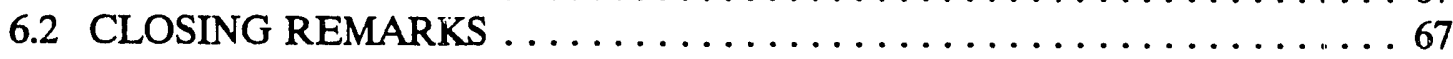




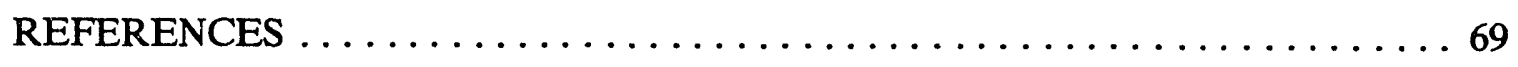

Appendix. THE SPECTRAL NEXUS: UNDERSTANDING THE

RELATIONSHIP BETWEEN RESPONSE FUNCTIONS AND

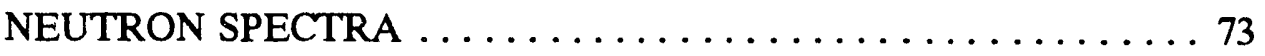




\section{FIGURES}

2.2..1 The TCC normalized data from monoenergetic irradiations and derived response functions, $\mathrm{R}(\mathrm{E})$, for the $\mathrm{BD}-100 \mathrm{R}$ and BDS-1500

2.4.1 Step function: average sensitivity in neutron response per unit fluence

3.4.1 The relative accuracy of the CPND to measure neutron dose equivalent $\left(\mathrm{H}_{\mathrm{EI}}\right.$ and $\left.\mathrm{H}_{\mathrm{T}}\right)$ for ORNL in situ spectra at TRU

3.4.2 The relative accuracy of the CPND to measure neutron dose equivalent $\left(\mathrm{H}_{\mathrm{El}}\right.$ and $\left.\mathrm{H}_{\mathrm{T}}\right)$ of $\mathrm{RADCAL}$ source spectra

3.4.3 Comparison of reference (BMS) and CPND measured spectra for

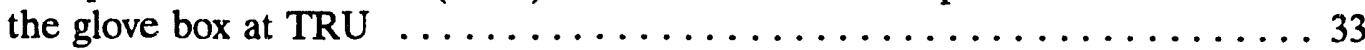

3.4.4 Comparison of reference (BMS) and CPND measured spectra for

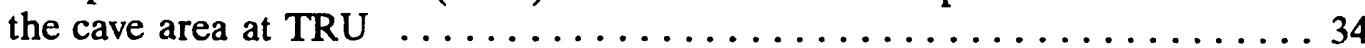

3.4.5 Comparison of reference (BMS) and CPND measured spectra for the control room at TRU . . . . . . . . . . . . . . . . . . 35

3.4.6 Comparison of reference (BMS) and CPND measured spectra for the waste transfer area at TRU

3.4.7 Comparison of reference (BMS) and CPND measured spectra for the analytical lab at TRU

3.4.8 Comparison of reference (BMS) and CPND measured spectra for

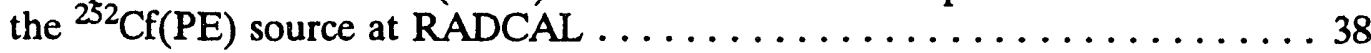

3.4.9 Comparison of reference and CPND measured spectra for the ${ }^{238} \mathrm{PuBe}$ source at RADCAL . . . . . . . . . . . . . . . . . . 39

3.4.10 Comparison of reference and CPND measured spectra for the ${ }^{252} \mathrm{Cf}\left(\mathrm{D}_{2} \mathrm{O}\right)$ source at $\mathrm{RADCAL}$

3.4.11 Comparison of reference and CPND measured spectra for the mixture of two RADCAL sources: ${ }^{252} \mathrm{Cf}\left(\mathrm{D}_{2} \mathrm{O}\right)$ and ${ }^{238} \mathrm{PuBe}$ [MIX(2)]

3.4.12 Comparison of reference and CPND measured spectra for the mixture of RADCAL sources: ${ }^{252} \mathrm{Cf}\left(\mathrm{D}_{2} \mathrm{O}\right),{ }^{252} \mathrm{Cf}(\mathrm{PE})$, and ${ }^{238} \mathrm{PuBe}[\mathrm{MIX}(3)]$ 


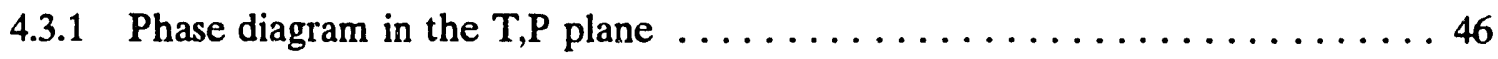

4.4.1 The life-cycle of a bubble $\ldots \ldots \ldots \ldots \ldots \ldots \ldots \ldots \ldots \ldots \ldots$

4.4.2 Correlative record of BD response and cumulative dose for a normal $\mathrm{BD}$ and one which contains bubbles that have

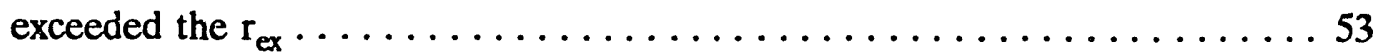

4.4.3 PAG tension loss as a function of bubble growth $\ldots \ldots \ldots \ldots \ldots \ldots$

5.1.1 Experimental neutron extremity dosimeter (BUDEX) $\ldots \ldots \ldots \ldots \ldots$

5.3.1 A photograph of the do-it-yourself bubble reader $\ldots \ldots \ldots \ldots \ldots \ldots$

5.3.2 An image captured with the di-it-yourself bubble reader:

(a) full image and (b) magnified image $\ldots \ldots \ldots \ldots \ldots \ldots \ldots \ldots$

5.4.1 Diagram of the modified TLD component of CANS $\ldots \ldots \ldots \ldots \ldots$

5.5.1 Real-time spectrometry: (A) "pop" detected by a microphone; (B) counted by simple circuitry and displayed; (C) multiple detector signals come to a signal processing board in a laptop computer where they are recorded, processed, and spectral results displayed graphically $\ldots \ldots \ldots \ldots \ldots \ldots \ldots \ldots \ldots \ldots \ldots \ldots \ldots \ldots \ldots$

5.5.2 Real-time temperature corrected neutron dosimeter using a BD-100R and miniature ARAP . . . . . . . . . . . . . . 64

A1 The BD-100R R(E) and ${ }^{241} \mathrm{AmBe}$ and ${ }^{252} \mathrm{Cf}$ (unmod) spectra normalized to $0.01 \mathrm{mSv}$ 


\section{TABLES}

2.3.1 Fluence distribution for TLD-600 sensitivity irradiations using ${ }^{252} \mathrm{Cf}_{\mathrm{D} 2 \mathrm{O}}$ with and without the $\mathrm{Cd}$ shell $\ldots \ldots \ldots \ldots \ldots \ldots \ldots \ldots$

2.3.2 TLD-600 response to neutrons in ${ }^{137} \mathrm{Cs} \mathrm{mR}$ equivalent $\ldots \ldots \ldots \ldots \ldots 15$

2.3.3 TLD-600 sensitivities to neutrons $\ldots \ldots \ldots \ldots \ldots \ldots \ldots \ldots \ldots \ldots \ldots \ldots \ldots \ldots \ldots$

2.4.1 Original CPND EIs, sensitivities, and $\bar{h}_{\alpha(B)} \quad \ldots \ldots \ldots \ldots \ldots \ldots$

2.4.2 Modified CPND EIs, sensitivities, and $\bar{h}_{(E)} \ldots \ldots \ldots \ldots \ldots \ldots \ldots$

3.2.1 The original measured dose equivalent $\left(\mathrm{H}_{\mathrm{EI}}\right.$ and $\left.\mathrm{H}_{\mathrm{T}}\right)$ and calculated $\mathrm{P}_{\mathrm{i}}$ results from the radioisotopic source measurements

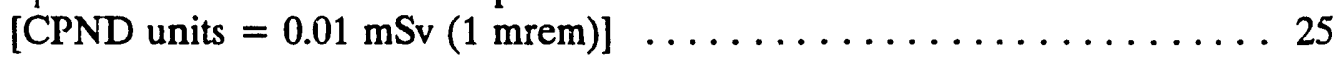

3.2.2 The original measured dose equivalent $\left(\mathrm{H}_{\mathrm{EI}}\right.$ and $\left.\mathrm{H}_{\mathrm{T}}\right)$ and calculated $P_{i}$ results from the in situ measurements at TRU

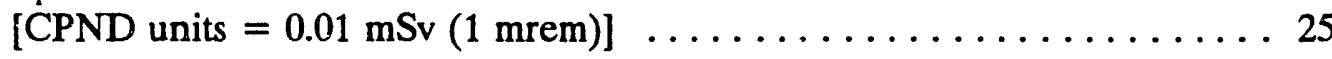

3.2.3 The individual bias and standard deviation of the original CPND for the radioisotopic measurements $\ldots \ldots \ldots 25$

3.2.4 The individual bias and standard deviation of the original CPND for the in situ measurements $\ldots \ldots \ldots \ldots \ldots \ldots \ldots \ldots \ldots$

3.2.5 The EI bias, standard deviation, and $\mathrm{L}$ value of the original CPND for the radioisotopic and in situ categories

3.3.1 Comparison of original and modified reference values for radioisotopic neutron $\mathrm{H}_{\mathrm{EI}}$ and $\mathrm{H}_{\mathrm{T}}$ results $\ldots \ldots \ldots \ldots \ldots \ldots \ldots \ldots \ldots$

3.3.2 Comparison of original and modified reference values for neutron $\mathrm{H}_{\mathrm{EI}}$ and $\mathrm{H}_{\mathrm{T}}$ in situ measurements $\ldots \ldots \ldots \ldots \ldots \ldots \ldots \ldots$

3.4.1 The modified CPND measured dose equivalent $\left(\mathrm{H}_{\mathrm{El}}\right.$ and $\left.\mathrm{H}_{\mathrm{T}}\right)$ and the calculated $P_{i}$ results for the radioisotopic measurements

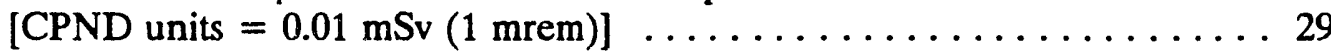

3.4.2 The modified CPND measured dose equivalent $\left(\mathrm{H}_{\mathrm{EI}}\right.$ and $\left.\mathrm{H}_{\mathrm{T}}\right)$ and the calculated $P_{i}$ for the in situ measurements at TRU [CPND units $=0.01 \mathrm{mSv}(1 \mathrm{mrem})]$ 
3.4.3 The individual bias and standard deviation of the modified

CPND for the radioisotopic measurements . . . . . . . . . . 32

3.4.4 The individual bias and standard deviation of the modified CPND for the in situ measurements

3.4.5 The overall bias, standard deviation, and $\mathrm{L}$ value of the modified

CPND for the radioisotopic and in situ categories

3.5.1 Comparison of the original and the modified overall performance indicators

4.4.1 Theoretical response of two bubble detectors before and after acquiring three bubbles exceeding $r_{c x}$

A.1 Calculated values of $\bar{E}(\phi), \bar{E}(H), \bar{h}$ and BD-100R response for several radioisotopic neutron sources 


\section{NOMENCLATURE}

\section{English Symbols}

$\begin{array}{ll}\text { ARAP } & \text { alternative real-time acoustical processing } \\ \text { BD } & \text { bubble detector } \\ \text { CPND } & \text { combination personnel neutron dosimeter } \\ \text { EI } & \text { energy interval } \\ \text { H } & \text { dose equivalent } \\ \mathrm{h}_{4} & \text { fluence-to-dose equivalent conversion factor } \\ \text { PAG } & \text { polyacrylamide gel } \\ \text { R(E) } & \text { response function } \\ \text { TLD } & \text { thermoluminescent dosimeter }\end{array}$

\section{Subscripts}

b bubble

c critical

cx critical expansion

fx critical formation

$t$ thermal

m medium

s slow

f fast

EI energy interval

$T$ total

\section{Greek symbols}
$\phi$ fluence
$\Phi$ flux
o surface tension
$\theta$ scattering angle of the neutron in the center-of-mass system
$\theta$ scattering angle of the recoil nucleus in the lab coordinate system 


\section{ACKNOWLEDGMENTS}

To T. A. Rhea: Thanks for the encouragement, instruction, and provisional opportunities early on in my career. To C. S. Sims: Thank you for the patience, encouragement, and guidance both technical and spiritual. To Dr. L. F. Miller and Dr. P. Groer: I appreciate your comments, instruction, and patience. To Lt. Comdr. Steve Doremus of the U. S. Navy's Naval Dosimetry Center, Dr. Gordon Riel of the Naval Surface Warfare Center, Dr. Martin Nelson and Dr. Mark Harper of the U. S. Naval Academy, Dr. W. H. Casson of Oak Ridge National Laboratory, Dr. H Ing of Bubble Technology Industries, Dr. R. E. Apfel of Apfel Enterprises, Dr. J. C. Liu of the Stanford Linear Accelerator Center, and Dr. R. B. Schwartz of the National Institute of Standard and Technology: Thank you for your encouragement, guidance, and stimulating technical discussions. I eagerly anticipate future professional interaction with you all. To my family and friends: Thank you! To David my true friend and brother: Thanks for the encouragement and the council!

The author would also like to thank Dr. Joel Rabovsky, Dr. Tom Bell, Dr. Judith Faulke, and the Department of Energy's Office of Health for their encouragement and financial support of bubble detector research. 
Providing accurate neutron dosimetry for a variety of neutron energy spectra is a formidable task for any dosimetry system. Unless something is known about the neutron spectrum prior to processing the dosimeter, the calculated dose may vary greatly from that actually encountered; that is until now. The entrance of bubble detector technology into the field of neutron dosimetry has eliminated the necessity of having an a priori knowledge of the neutron energy spectra. Recently, a new approach in measuring personnel neutron dose equivalent was developed at Oak Ridge National Laboratory. By using bubble detectors in combination with current thermoluminescent dosimeters (TLDs) as a Combination Personnel Neutron Dosimeter (CPND), not only is it possible to provide accurate dose equivalent results, but a simple four-interval neutron energy spectrum is obtained as well. The components of the CPND are a Harshaw albedo TLD (two TLD-600/700 pairs one covered by cadmium, the other by ABS plastic) and two bubble detectors with theoretical energy thresholds of $100 \mathrm{keV}$ and $1500 \mathrm{keV}$ (BD-100R and BDS-1500 from Bubble Technology Industries, Canada).

The original CPND methodology has been modified with the goal of improving the spectrometric capabilities and the resulting dosimetric accuracy. The foci of the modification were

1. refinement of the BD-100R and BDS-1500 response functions,

2. reevaluation of the TLD- 600 thermal neutron sensitivity,

3. redefinition of the energy intervals for which the neutron spectrum is described, and

4. introduction of a matrix algorithm for neutron spectrum deconvolution and dosimetric determination.

The effectiveness of the modifications was assessed by reevaluating the original raw data from a series of radioisotopic source and in situ measurements and comparing them with the original CPND results.

The results of the modified CPND temonstrate significant improvements in the spectrometric and dosimetric accuracy, relative to the original CPND characterization. This is evidenced by an overall increase in dosimetric accuracy of $2 \%$ for the in situ and $28 \%$ for the radioisotopic measurements. Individually, the modified version outperformed the original in eight of the ten measurements, while of the remaining two, one was the same and for the other the original results were better by $2 \%$. The final neutron dose equivalent results were within $11 \%$ of the reference values for the five in situ spectra and within $2 \%$ of the reference values for the radioisotopic source spectra.

Presented are

1. a synoptic history surrounding emergence of bubble detector technology,

2. a brief overview of the current theory on mechanisms of interaction,

3. the data and analysis process involved in refining the response functions,

4. performance evaluation of the original CPND and a reevaluation of the same data under the modified method as presented in this work, 
5. the procedure used to determine the reference values of component fluence and dose equivalent for field assessments,

6. analysis of the after-modification results,

7. a critique of some currently held assumptions, offering some alternative explanations, and 8. my personal thoughts concerning potential applications and directions for future research. Also provided in an appendix is a technical note detailing the organic nexus between the response characteristics of a neutron dosimeter, the fluence-to-dose equivalent factor, and the neutron spectrum being mieasured, which includes several radioisotopic snurce sensitivities and calibration factors calculated for the BD-100R and TLD-600. 


\section{INTRODUCTION}

A proposed increase in neutron quality factor and reduction of the annual dose equivalent limits for radiation workers; harbingers ind sed! Amidst the already numerous difficulties associated with performing neutron dosimetry these magnify the need to increase the accuracy and precision of our methods.

\subsection{NECESSITY OF ACCURATE NEUTRON DOSIMETRY}

We are at a critical juncture in Department of Energy (DOE) history. With the recent growth of activities aimed at ensuring the adherence of facilities utilizing nuclear grade material to the stringent guidelines required by the Occupational Safety and Health Administration (OSHA), Environmental Protection Agency (EPA), Nuclear Regulatory Cominission (NRC) and DOE, the current prospect of increasing the neutron quality factor, DOE's ongoing investigation into the plausibility of decreasing the annual dose equivalent limits, and emphasis on maintaining personnel exposures as low as reasonably achievable (ALARA), never has there existed a greater necessity to "monitor to the max." These prevailing winds of change necessitate a major reform of dosimetry as we know it. We will be required to run harder than before to stay in the same place.

Until recently, organizations would have been hard pressed to find an affordable neutron monitoring system capable of surmounting the inherent difficulties associated with routine neutron dosimetry in multiple spectral environments, not to mention these rigid demands lurking on the horizon. The exigency of the situation necessitates a serious look at the current status of neutron dosimetry.

\subsection{INHERENT DIFFICULTIES ASSOCIATED WITH NEUTRON DOSIMETRY}

Performing good personnel neutron dosimetry, with the current technology, requires

1. an in-depth understanding of the energy response characteristics of the dosimeter utilized,

2. fluence-to-dose equivalent conversion methodologies,

3. a cognizance of the calibration procedure and sources used,

4. an a priori knowledge of the neutron spectrum in the areas monitored, and

5. the calibration factors required to correct for variations in the field including differences between field and calibration spectra.

The perfect routine neutron dosimeter would provide an accurate assessment of the dose equivalent received by the individual being monitored without the application of correction factors.

To my knowledge, all current personnel neutron dosimetry systems are dependent upon some knowledge of the neutron energy spectra prior to assessment of the neutron dose equivalent. Whether it be from Bonner multi-sphere (BMS) measurements or 9-to-3 inch ratios, unless something is known about the neutron spectrum prior to processing the 
dosimeter, the calculated neutron dose equivalent $\left(\mathrm{H}_{\mathrm{n}}\right)$ could vary greatly from that actually encountered. That is until now!

The recent introduction of bubble detector technology has made navigable waters previously uncharted in the history of neutron dosimetry. It is now possible to provide an accurate measurement of neutron working environments without an $a$ priori knowledge of the neutron spectrum. This is attainable through the use of the Combination Personnel Neutron Dosimeter (CPND). The CPND measures neutron fluence (a real quantity) and reports it by virtue of a simple four-interval spectrum. This fluence measurement is the basis for determining the neutron dose equivalent.

\subsection{REPORT STRUCTURE}

The dissertation of Liu stated that "... the CPND was designed to be superior to present neutron dosimeters in that it will have crude neutron spectrometric capability..." (Liu 1989). After an in-depth and critical analysis of the work surrounding development and evaluation of the CPND, it was believed that (with some refinement) the demonstrated performance of the CPND to measure neutron dose equivalent for a variety of neutron spectra (both radioisotopic and in situ) could be made even better.

The remaining parts of Sect. 1 address the foundational work upon which bubble detector technology was erected. This includes the current status of the technology, a thumbnail sketch of the currently held beliefs on the mechanisms involved in bubble formation, and an introductory description of the CPND.

Section 2 describes the features of the CPND that were modified and the reasoning behind them. These include

1. refinement of the BD-100R and BDS-1500 response functions,

2. reevaluation of the thermal neutron sensitivity of TLD-600 (because the use of albedo TLD is prolific and information is available in abundant measure, little supporting information is provided),

3. redefinition of the energy intervals (EI) used to describe the spectra,

4. development of a spectrum deconvolution matrix algorithm, and

5. the final neutron dose equivalent determination.

The effectiveness of these modifications in enhancing the spectrometric capabilities and in improving the overall neutron dose equivalent accuracy was assessed by comparing the original raw data processed according to the modified methodology to the original results and to reference dosimetry. A condensed version of the original results (as well as a presentation and analysis of the results after modification) are described in Sect. 3. The redefinition of the energy intervals (EI) required that reference dosimeiry be redetermined to correspond with the newly defined EIs. The method and redefined reference dosimetry are included in this section. 
A more theoretical direction is taken in Sect. 4 where some currently held beliefs surrounding the bubble detector are addressed. A critique and some alternative explanations about

1. useable lifetime,

2. observed response variations,

3. temperature affects,

4. bubble growth,

5. bubble memory,

6. incompressible bubbles, and

7. theory of operation are provided.

Section 5 takes a look at some suggested research and potential applications of bubble detector technology for

1. extremity dosimetry,

2. accident level dosimetry,

3. a do-it-yourself bubble reader for research applications,

4. a Combination Area Neutron Spectrometer (CANS), and

5. a different approach to bubble detection, which is currently under development in the Dosimetry Application Research Group (DOSAR), Alternative Real-time Acoustical Processing (ARAP).

A summary statement and closing remarks are presented in Sect. 6.

Additional knowledge gained from this research is described in the Appendix: "The Spectral Nexus: Understanding the Relationship Between Response Functions and Neutron Spectra." This addresses

1. some of the pitfalls associated with the common prartice of describing a neutron spectrum by the average energy,

2. the expected variation in response of the BD-100R and TLD-600 for several radioisotopic source spectra (based on a folding of the response functions into a reference spectrum for each source),

3. the derived source specific sensitivities, and

4. a correction methodology.

Let us now take a brief look at the emergence of spectral investigation and the coming-of-age of the bubble detector.

\subsection{ADVENT OF SPECTRAL INFORMATION: THRESHOLD DETECTORS}

G. S. Hurst recognized in 1956 that knowledge of the neutron spectrum is essential for accurate tissue dose determination (Hurst et al. 1956). He introduced a method for measuring the spectrum of fast neutrons utilizing a series of activation foils. By creatively combining activations foils of differing energy thresholds and changing the shielding configurations (five detectors total), he was able to deconvolute a crude five-interval neutron spectrum. This device became appropriately known as the threshold detection unit or TDU. 


\subsection{BUBBLE CHAMBER}

Glasser discovered in 1952 that some liquids become radiosensitive while in a superheated or metastable state (Glasser 1952). A superheated or metastable state could be obtained by lowering the pressure of a chamber containing a liquid below the vapor pressure of that liquid. Tracks of bubbles are created in the bubble chamber by the incident radiation. Equilibrium is reestablished within the chamber by applying pressure sufficient enough to recompress the gas, transferring it back to the liquid phase. Lowering the applied pressure superheats the liquid, rendering it once again sensitive and ready for detection. The difficulties associated with sustaining a liquid in a superheated state are that the "live time" rarely exceeds a few minutes and the bubble chamber detects single events (the tracks of a single ion). These difficulties have impeded the use of the bubble chamber for neutron dosimetry or spectroscopy. The theory explaining bubble formation has become know as Seitz's thermal spike model, i.e., the vaporization of a superheated liquid by ionizing or secondary charged particles (Seitz 1958).

\subsection{BUBBLE DETECTOR (BD) OR SUPERHEATED DROP DETECTOR (SDD)}

With his investigation of "superheated droplets rising in a heated 'host' liquid," Apfel continued the study of radiation-induced acoustic cavitation begun by Liberman, Finch, Hahn, Peacock, West, and Howlet. Apfel discovered that the superheated state of liquid could be sustained for longer periods by isolating the liquid into droplets (Apfel 1979).

Recently, two hybrid neutron detectors that capitalize on the suspension of a superheated liquid (SHL) in a host medium have emerged. One is the superheated drop detector (SDD) of Apfel Enterprises (AE) (SDD is a trademark of Apfel Enterprises, Inc., 25 Science Park, New Haven, CT 06511), and the other is the Bubble-damage Detector (BD) of Ing's Bubble Technology Industries (BTI). Each utilizes its own unique design and detection philosophy. Both isolate individual droplets of SHL by dispersing them throughout a holding medium. This medium acts to isolate the droplets and to increase the tensile strength properties of the liquid. The result is a detector composed of many tiny bubble chambers. This isolation removes the necessity of recompression after detection of a single event, maintains the droplets in a superheated state nearly indefinitely (when compared to the bubble chamber), and facilitates the detection of multiple events integrated over time. Although both designs employ differing methodologies for isolating the SHL droplets and for quantifying the bubbles after formation, in principle, their genesis is traceable to Glasser's bubble chamber, Seitz's thermal spike model, and cavitation theory.

\subsubsection{BTI and Post-Event Detection}

The BTI detector is built upon a passive a posteriori concept. The SHL droplets are suspended in a transparent elastic polyacrylamide gel (PAG). Once a droplet is vaporized the PAG entombs or immobilizes the bubble at the site of formation, enabling it to be counted after growing to a visible size. 
The sensitivity of the BD may be controlled by changing the density or number of droplets per unit volume in the detector. Detectors with differing neutron energy thresholds have been made possible by manipulating the composition of the SHL and by altering the medium composition. A typical SHL droplet (prior to vaporization) is approximately $25 \mu \mathrm{m}$ in diameter. Immediately after vaporization a bubble is approximately 1 to $2 \mathrm{~mm}$ and may be seen by the unaided eye (Liu 1989). A new generation of bubble detectors with droplet sizes that are significantly smaller than the standard detector, has been manufactured by BTI. These $\mu$-bubble detectors require magnification or a 24 -h growing period before they can be easily read.

A semiautomatic reader capable of reading both the standard and $\mu$-droplet devices is available from BTI. The second generation reader will store the count information along with the detector number (entered by the operator). It will also report the dose equivalent when using the BD-100R (a nearly dose equivalent detector).

\subsubsection{Apfel and Active Detection}

An ad hoc approach to bubble detection is taken by AE. Because the microscopic drops of SHL are suspended in a viscous gel, neutron interactions may be detected by measuring (1) the gas volume evolving from the formed bubbles or (2) the number of acoustical sound waves or "pops" emitted during bubble formation. The first method is used with the Neutrometer. The Neutrometer resembles a piece of thin glass tubing filled with SHL mixture. A disc floats on the surface of the SHL mixture. As bubbles are formed, the evolved gas displaces the SHL mixture and the disc rises in the tube. The dose equivalent may be determined by correlating the position of the disc and the graduated scale on the side of the device. In the second method, a transducer or microphone is placed in proximity of a vial containing the SHL mixture. A small microprocessor records the number of acoustical "pops" and translates this information into neutron dose equivalent. The microprocessor can also correct for depletion of the SHL and temperature dependence and apply a correction factor to account for differences between the field and the calibration spectra. Detailed information on the theory and design of both these devices is available in the open literature (Roy, Apfel, and Lo 1987; Ing and Birnboim 1984).

\subsection{THEORY OF INTERACTION AND BUBBLE FORMATION}

In order to understand the complex transformation process from incident neutron to bubble, a knowledge of several different areas of science is required. The physical process encompasses the domains of

1. nuclear physics (ion production via neutron-nucleus interaction),

2. atomic physics (ionic interaction with matter), an $\hat{i}$

3. fluids and thermodynamics (bubble formation via vaporization) (Roy, Apfel, and Lo 1987).

Is it any wonder that no model currently exists which comprehensively predicts bubble formation? 
The following is a condensed summary of the major components constituting the currently accepted explanation for bubble formation, cavitation theory.

\subsubsection{Ion Production}

The first stage in the process is ion production by a nonionizing neutron. The primary mechanism responsible for this initial phase is the interaction of the incident neutron with the nucleus of an atom by means of a simple billiard-ball type elastic scatter.

The conservation of energy and momentum in the center-of-mass system (COM) defines the relationship between the energy of a recoil nucleus $\left[E_{R}\right.$ in the laboratory coordinate system (LCS)] and the kinetic energy of the incoming neutron ( $E_{n}$ in LCS) and the scatter angle of the recoil neutron $\theta$ (COM),

$$
E_{R}=\frac{2 A}{(1+A)^{2}}(1-\cos \theta) E_{n}
$$

where

$\mathrm{A}=$ mass of target nucleus divided by neutron mass.

The following association is made between the scattering angle of the recoil neutron $\theta$, in the COM, and the scattering angle of the recoil nucleus $\theta$, in the LCS:

$$
\cos \theta=\sqrt{\frac{1-\cos \theta}{2}} .
$$

Solving for $\cos \Theta$ and substituting it into Eq. (1.7.1), Eq. (1.7.2) simplifies to relate the energy of the recoil nucleus in terms of its own recoil angle,

$$
E_{R}=\frac{4 A}{(1+A)^{2}}\left(\cos ^{2} \theta\right) E_{n}
$$

From this we see that a distribution of $E_{R}$ from zero, for a slightly grazing encounter $(\theta=$ $\left.90^{\circ}\right)$, to a maximum, in the event of a head-on collision of $\left(\theta=0^{\circ}\right)$, will occur when all recoil angles are possible.By defining $\sigma(\theta)$ as the differential scattering cross section of the neutron in the COM and $\sigma_{\mathrm{s}}$ as the total scatter cross section integrated over all angles, the probability of a recoil ion of energy $E_{R}\left(P\left(E_{R}\right)\right.$ ) can be calculated by, 


$$
P\left(E_{n}\right)=\frac{(1+A)^{2}}{A} \times \frac{\sigma(\theta)}{\sigma_{s}} \times \frac{\pi}{E_{n}},
$$

(Knoll 1979). Eq. (1.7.4) shows that the expected distribution of the energy continuum of the recoil ion will mimic that of the $\sigma(\theta)$. The shape of the $\sigma(\theta)$ will favor forward scattering for most nuclei.

\subsubsection{Energy Transfer}

After the energy is transferred to a recoil nucleus, the charged nucleus deposits its energy by interaction with electrons and other nuclei via ionization and excitation.

\subsubsection{Bubble Formation}

According to Seitz's thermal spike model, ionization and excitation along the charged particle track induces heat which causes the SHL to vaporize or nucleate (Seitz 1958). Apfel offers an explanation for this nucleation or bubble formation known as cavitation or nucleation theory that incorporates Seitz's "thermal spike" model. (Apfel 1979; Apfel 1987).

According to Roy (Roy, Apfel, and Lo 1987), once a bubble of radius $\mathrm{r}$ is formed, it will continue to exist in a stable state as long as the pressure within the bubble remains equal to the pressure exerted on the bubble from without. This was described by him as the effective surface pressure,

$$
P_{e s}=\frac{2 \gamma(T)}{r}
$$

This equation may be rewritten in terms of the pressure differences $\Delta \mathbf{P}$ within and without the bubble,

$$
\Delta P=P_{v}(T)-P_{0}=\frac{2 \gamma(T)}{r_{c}},
$$

where $P_{v}(T)$ is the vapor pressure within the droplet at temperature $T$, and $\gamma(T)$ is the surface tension of the liquid at temperature T. Solving Eq. (1.7.6) for $r_{c}$ we obtain,

$$
r_{c}=\frac{2 \gamma(T)}{\Delta P}
$$

This equation indicates that if a bubble grows to a size where its radius is as large as or exceeds $r_{c}$, the bubble becomes thermodynamically unstable and it will continue to grow by 
consuming or boiling the entire SHL droplet. Thus $r_{c}$ is defined as the critical radius. According to Seitz, the minimum energy required to form a bubble of $r_{c}$ is provided by charged recoil particles from neutron interactions (Seitz 1958). Restated, the critical radius is the point at which the growing bubble becomes thermodynamically unstable, and it overcomes the surface tension of the liquid, the effective atmospheric pressure, and the surface tension of the holding medium. At this point it boils violently and emits an acoustical shockwave or acoustic pressure pulse (Roy, Apfel, and Lo 1987). This bubble will continue to grow until equilibrium is reestablished between the vapor pressure within the newly formed bubble, $P_{v}(T)$, and the external pressure, $P_{0}$.

The energy required to form a spherical bubble of radius $r$ is described by the free energy equations for surface free energy, vaporization and expansion (Roy, Apfel, and Lo 1987).

\subsection{COMBINATION PERSONNEL NEUTRON DOSIMETER (CPND)}

In 1989, C. J. Liu, led by information gathered from a review of current methods for neutron dosimetry, developed the Combination Personnel Neutron Dosimeter (CPND) at Oak Ridge National Laboratory (ORNL). The concept of the CPND is very similar to that employed in the TDU, i.e., the use of multiple detectors with differing thresholds to provide a simple neutron spectrum. The difference between the TDU and the CPND is that the CPND uses bubble detectors and albedo thermoluminescent dosimeters (TLD) instead of activation foils. The BD-100R and BDS-1500, which possess theoretical thresholds of 100 and $1500 \mathrm{keV}$, and the Harshaw albedo TLD used by Martin Marietta Energy Systems (MMES) are the elements of the CPND. The goal of the CPND is to provide an accurate measure of neutron dose equivalent by measuring the neutron spectrum contributing the dose equivalent. This becomes increasingly desirable considering the current recommended change of the neutron quality factor. Since fluence is a real quantity, if the spectrum is known, the neutron dose equivalent can be determined by applying the appropriate fluenceto-dose equivalent conversion factors $\left(h_{\phi} s\right)$. 


\section{IMPROVEMENT AND MODIFICATION OF THE CPND}

The "proof is in the pudding" so to speak, and the CPND has demonstrated its efficiency by providing an accurate measure of both dose equivalent and neutron spectrum for ten neutron fields, five radioisotopic, and five in situ environments at ORNL. Yet, even these good results can be improved by making a few modifications. A description of these modifications is provided.

\subsection{INTRODUCTION AND DESCRIPTION OF AREAS TO BE ADDRESSED}

Since the completion of Liu's dissertation, BD research has continued at ORNL as a joint venture with the Naval Surface Warfare Center (NSWC), Naval Research Laboratory (NRL), United States Naval Academy (USNA), and National Institute of Standards and Technology (NIST) with financial support from DOE. The additional information obtained from this collaboration was instrumental in achieving the desired modifications.

The modifications consisted of

1. refining the energy response characteristics of the BD-100R and BDS-1500,

2. a reevaluation of the accepted thermal neutron sensitivity of the TLD-600 elements of the CPND,

3. redefining the energy intervals, and

4. development of a matrix based spectrum deconvolution algorithm.

\section{REFINEMENT OF THE BD-100R AND BDS-1500 R(E)S}

The failure to establish an efficient method of collecting and maintaining data at the inception of a project often impedes future development and direction. Prior to this work, data collected from the evaluation and testing of bubble dosimeters had been retained by the individuals performing the various tests. Though the need for an individual to collect and manage the data was recognized early in the project, for various reasons no one was given the responsibility. The decision was made at the January 1990 Bubble Dosimeter Working Group Meeting that the DOSAR group would head up this task. In May of the same year action began on compiling the data and standardizing a method for data entry and retrieval.

DOSAR developed a data base in which the entire contents of the BD research coalition was amassed. This amalgamation of data constituted the largest single quantity of information on $\mathrm{BD}$ research to date.

\subsubsection{Monoenergetic Irradiations}

Included in this data were the results from a series of monoenergetic irradiations performed at the National Physical Laboratory (NPL) in England and a similar series of 
irradiations conducted at Pacific Northwest Laboratory (PNL) and the NIST reactor in the United States. Monoenergetic neutrons were obtained via scatter reactions at the Van de Graaff accelerators of NPL and PNL and three filtered reactor beams at NIST. The accelerator scatter-beams generated neutrons of $0.1,0.25,0.565,1.2,2.6,3.2,5.0$, and 14.8 $\mathrm{MeV}$, and the three reactor beams were at 2, 24, and $144 \mathrm{keV}$. Liu conducted the irradiations at PNL (Liu 1989), ard Schwartz conducted them at NPL (Schwartz and Hunt 1990).

Because (1) the detectors in both studies were not identical in sensitivity, (2) a constant temperature was not maintained for all the irradiations, and (3) different data recording methods were used, manipulation of the data was necessary. This was performed to establish a correlation between the two individual studies arid to produce a reference point for further analysis.

\subsubsection{Normalizing the Data}

The BDs varied in sensitivity from 0.75 to 3.5 bubbles per $0.01 \mathrm{mSv}$ (bu/mrem); therefore, the tube correction coefficient (TCC), defined as the reciprocal of the manufacturers sensitivity as found on the detector, was introduced as a means of normalizing the data. This approach mimics the element correct coefficient method employed for TLDs, i.e.,

$$
R_{t}=T C C * R_{0} \text {, }
$$

where

$\mathrm{R}_{\mathrm{t}}=$ response normalized to $1 \mathrm{bu} / 0.01 \mathrm{mSv}\left(\mathrm{mrem}^{-1}\right)$,

TCC = tube correction coefficient, $1 /$ (sensitivity on detector, i.e., $0.01 \mathrm{mSv} / \mathrm{bu}$ ),

$R_{0}=$ initial raw response of the detector (number of bu).

Thus, the result of each detector was normalized to reflect the anticipated response of a $1 \mathrm{bu}$ per $0.01 \mathrm{mSv}$ detector by multiplying the raw data by its respective TCC.

\subsection{Temperature Correction}

Because variations in ambient temperature are known to effect detector response (Ing and Birnboim 1984) and because a constant temperature was not maintained for all irradiations, initial temperature corrections were assumed based on the proportional relationship between temperature, volume, and pressure (i.e., PV $=\mathrm{kT}$ ). According to Eqs. (1.7.1) and (1.7.2), the related effect on the superheatedness of the SHL and therefore the $r_{c}$ is given by

$$
R_{c}=\left(T_{d} d T_{e}\right)^{\star} R_{t},
$$

where 
$\mathbf{R}_{\mathrm{c}}=$ response after temperature correction,

$T_{\mathrm{o}}=20^{\circ} \mathrm{C}$,

$\mathrm{T}_{\mathrm{e}}=$ temperature in ${ }^{\circ} \mathrm{C}$ at time of exposure,

$\mathbf{R}_{\mathbf{t}}=$ initial response normalized to 1 bu per $0.01 \mathrm{mSv}$.

The $R(E) s$ for the $B D-100 R$ and BDS-1500 were derived from curve fits to these normalized data.

Because the detector sensitivities provided by BTI, in bubbles per mSv, were based on calibration to the ${ }^{239} \mathrm{PuBe}$ source at Chalk River (Ing 1991), these derived $\mathrm{R}(\mathrm{E}) \mathrm{s}$ were normalized to yield a response of $1 \mathrm{bu}$ per $0.01 \mathrm{mSv}$ when exposed to a ${ }^{239} \mathrm{PuBe}$ spectrum. In essence, this $R(E)$ is taken to be the true representation of a 1 bu per $0.01 \mathrm{mSv}, 20^{\circ} \mathrm{C}$, ${ }^{239} \mathrm{PuBe}$ calibrated BTI detector. The normalized data and the $\mathrm{R}(\mathrm{E}) \mathrm{s}$ are shown in Fig. 2.2.1.

\section{REEVALUATION OF THE TLD-600 THERMAL NEUTRON SENSITIVITY}

There are several factors which affect the response of a TLD-600 albedo-based dosimeter. Some of the pertinent considerations include

1. the distance from the detector to the phantom or body,

2. the number, thickness, and dopants in the crystal,

3. the configuration and thickness of the thermal neutron absorbing filters [typically, cadmium (Cd) or boron $\left.\left({ }^{10} \mathrm{E}\right)\right]$,

4. the heating methodology and profile employed to read the TLD, and

5. the encapsulation material (glass, teflon or bare chip), if applicable.

Some of the different heating methodologies are planchet, hot-finger, thermoelectric, laser, and hot-gas. Several stages of the heating profile may be altered; pre-heating conditions, heating ramp rate (in degrees per unit time), the maximum temperature, and the holding and the anneal times are a few.

Consequentially, before inferences may be made from one type of configuration or heating profile to another, these differences should be carefully weighed and appropriate assumptions must be drawn.

It is my opinion that Liu made some incorrect assumptions in the previous determination of the thermal neutron sensitivity of the Cd-covered TLD-600 chip. These assumptions affect the appropriateness and accuracy of the measurements derived by this component of the CPND and consequently the performance of the CPND itself.

Liu derived the sensitivities of the TLD-600 elements of the CPND from the methodology espoused by Alsmiller (Alsmiller and Barish 1974). As I interpret it, in order for Liu to have come to his conclusions regarding the thermal neutron sensitivities of the TLD-600 elements, the following assumptions must have been held, either consciously or unconsciously. Note: not all of these poincs are necessarily disjoint from one other. As I interpret them the assumptions are 
ORNL-DWG 93-5904

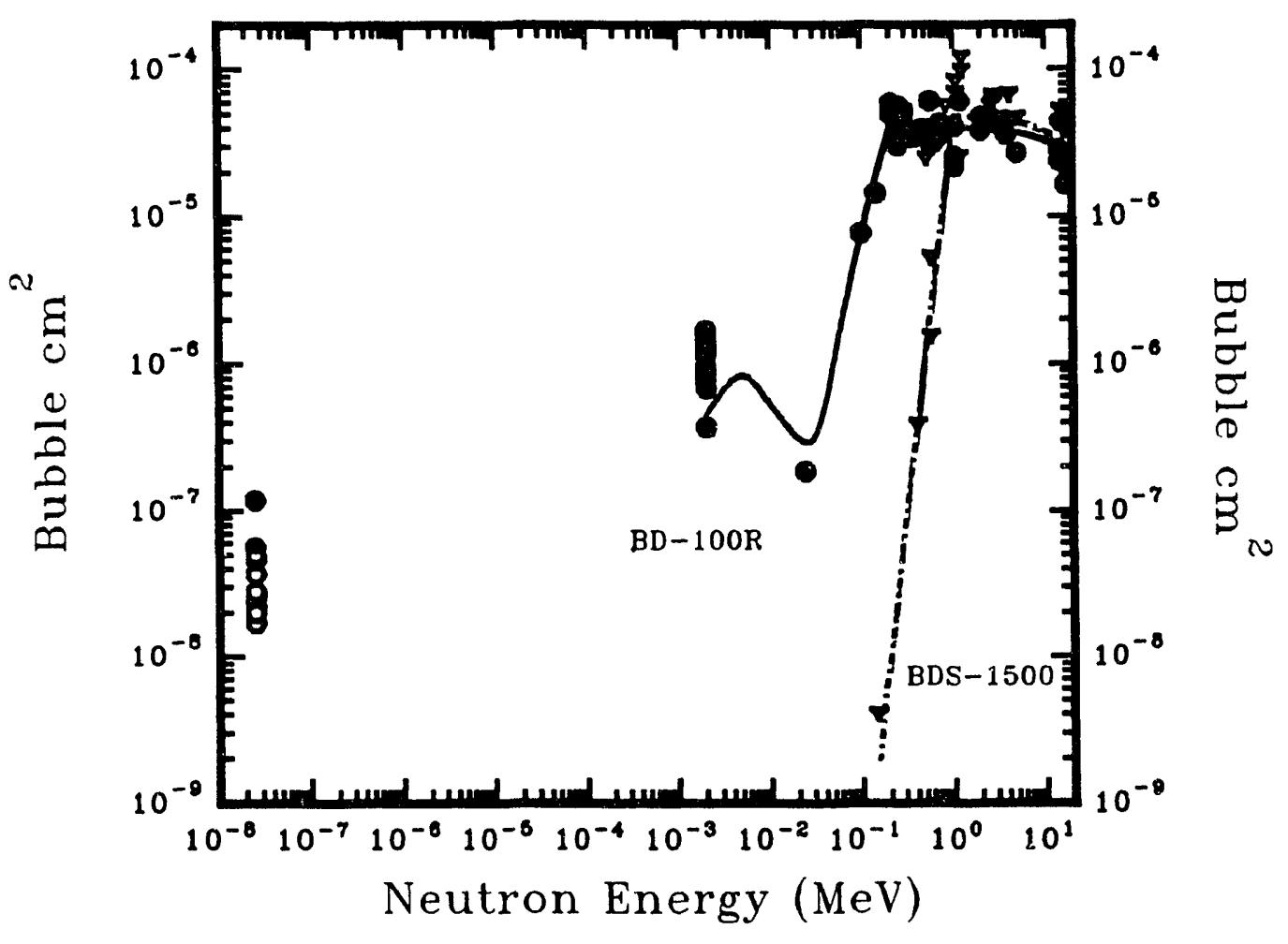

Fig. 2.21. The TCC normalized data from monoenergetic irradiations and derived response functions, $R(E)$, for the BD-100R and BDS-1500. 
1. "the Cd-covered TLD-600 detects only albedo thermal neutrons" (Liu 1989),

2. the thermal-albedo of incident neutrons above $0.414 \mathrm{eV}$ is negligible,

3. the response of the Cd-covered TLD-600 is due to the fraction of incident thermal neutrons that are reflected, which according to Fig. 2 of Alsmiller is $80 \%$,

4. applying a ratio of the relative response at known energies to the relative response at thermal energies, derived from Fig. 3 of Alsmiller, to the data obtained from monoenergetic neutron irradiations, is adequate for determining the thermal neutron sensitivity of the Cd-covered TLD-600, and

5. that dividing the derived thermal neutron sensitivity of the Cd-covered TLD-600 by "the albedo factor of 0.8 for thermal neutrons" is adequate for determining the thermal neutron sensitivity of the plastic covered TLD-600 (Liu 1989).

In my opinion, the method employed by Liu to determine the thermal neutron sensitivity of the TLD component of the CPND is incorrect. The Alsmiller data referenced by Liu, were derived from a one-dimensional discrete ordinate code using a 30-cm-thick semiinfinite tissue slab, and not TLD-600. The data in Fig. 2 of Alsmiller and Barish describe the "albedo-neutron fluence integrated over the specified energy ranges verses incident neutron energy for monoenergetic neutrons" (Alsmiller and Barish 1974). Figure 3 depicts the "relationship between the thermal albedo-neutron fluence and the dose equivalent produced in the tissue slab" (Alsmiller and Barish 1974). Liu bases the sensitivity of the C-covered TLD-600 on the ratio of the relative thermal neutron sensitivity to that at higher energies derived from Fig. 3. In so doing, he failed to recognize the disparity between the fraction of incident thermal neutrons which strike the phantom in the Alsmiller and Barish model as compared to the Cd-covered TLD-600 of the CPND. The relative thermal neutron sensitivity in Fig. 3 assumes that $100 \%$ of the incident thermal neutrons strike the slab, and that $80 \%$ of them are reflected. Although this is true for the Alsmiller model, it is not true of the Cd-covered TLD-600 in the CPND. The Cd-cover "absorbs $99.5 \%$ of the incident thermal neutrons" (Liu 1989). This alone would suggest that obtaining thermal neutron sensitivities for the CPND's Cd-covered TLD-600, by applying ratios derived from Fig. 3, will be in error. And, although the TLD-600 sensitivity to incident neutrons above $0.414 \mathrm{eV}$ is considerably lower than it is for thermal neutrons, according to Fig. 2 of Alsmiller, $45 \%$ of the incident neutrons from $0.414 \mathrm{eV}$ to $0.1 \mathrm{keV}$ are reflected as thermal neutrons. Liu states that the Cd-covered TLD-600 detects only albedo thermal neutrons. Thus, his determination of thermal neutron sensitivity of the Cd-cover TLD-600, using ratios derived from Fig. 3 of Alsmiller, indicates that he also failed to consider the portion of the Cd-covered TLD-600 response that is attributable to the incident neutrons above $0.414 \mathrm{eV}$, which are reflected at thermal energies. Consequently, the incident thermal neutron sensitivity he derived includes the sensitivity to incident neutrons of higher energies as well. These errors suggest that the true sensitivity of the Cd-covered TLD-600 to incident thermal neutrons is less than the $14.7 \times 10^{-5} \mathrm{mR} \mathrm{cm}^{2}$ stated by Liu.

Liu then proceeds to determine the thermal neutron sensitivity of the plastic covered TLD- 600 by dividing the Cd-covered sensitivity by the albedo factor of 0.8 obtained from Fig. 2 of Alsmiller. There are two errors associated with this procedure. First, as stated previously, application of the 0.8 albedo factor requires that $100 \%$ of the incident thermal neutrons strike the slab in order for $80 \%$ to be reflected, and this is not true for the Cd-covered TLD-600. Second, because the thermal neutron sensitivity of the Cd-covered 
TLD-600 was overestimated, the derived thermal sensitivity of the plastic-covered TLD-600 would also be an overestimate. Therefore, based on these statements, I conclude that the actual thermal neutron sensitivities of both TLD-600 elements are lower than those stated by Liu. These overestimates will promulgate errors in the CPND's spectrometric measurements. Consequently, the derivation of more accurate thermal neutron sensitivities should improve the spectrometric accuracy of the CPND.

A more desirable method for correctly ascertaining the thermal neutron sensitivity of the TLD-600 elements would be to conduct measurements in a calibrated thermal neutron beam. But since this was not possible, an alternative method was employed. A series of experiments was conducted exposing the TLDs on phantom and in air to ${ }^{252} \mathrm{Cf}\left(\mathrm{D}_{2} \mathrm{O}\right)$ with and without the $\mathrm{Cd}$ shell on the $\mathrm{D}_{2} \mathrm{O}$-filled sphere. The emission of the ${ }^{252} \mathrm{Cf}$ source at the time of irradiation was determined from the NIST certificate emission on 4/30/87 by adjusting tor decay using a half-life of 2.64 years using

$$
E_{t}=E_{0} \times e^{-\frac{0.693 \times t}{T_{1 / 2}}},
$$

where

$E_{t}=$ emission on date of interest,

$\mathrm{E}_{0}=$ emission on date $\mathrm{c}$. calibration,

$\mathrm{t}=$ time, in years, since calibration,

$\mathrm{T}_{\mathrm{i} / 2}=$ half-life of source, in years.

The fluence at $0.5 \mathrm{~m}$ (the voint of irradiation) was calculated for the irradiation with the Cd shell using

$$
\phi_{r}=\frac{E_{i} \times t}{4 \pi r^{2}}
$$

where

$\mathrm{E}_{\mathrm{i}}=$ source emission $\left(\mathrm{sec}^{-1}\right)$,

$\mathrm{t}=$ duration of irradiation $(\mathrm{sec})$,

$\mathrm{r}=$ distance from centerline of source $(\mathrm{cm})$.

Air and room scatter values were calculated using the methodology describeci in (Eisenhauer et al. 1985). The reduction in the total neutron fluence that occurs by adding the Cd shell is effected by the absorption of neutrons below the $\mathrm{Cd}$ cutoff of $0.414 \mathrm{eV}$, i.e., the absorption of thermal neutrons, and is calculated by (Eisenhauer 1984)

$$
\phi_{t}=0.115 \times \phi_{T},
$$

where

$\phi_{\mathrm{t}}=$ thermal fluence,

$\phi_{\mathrm{T}}=$ total fluence.

Thus, the difference in fluence between the irradiations with and without the Cd shell is assumed to be attributable solely to the thermal neutron fluence. The results are presented in Table 2.3.1. The total fluence, the fluence above $0.414 \mathrm{eV}$, and the thermal fluence (i.e., $<0.414 \mathrm{eV}$ ) are represented by $\phi_{\mathrm{T}}, \Phi_{\mathrm{Cd}}$, and $\phi_{\mathfrak{r}}$, respectively. 
Table 23.1. Fluence distribution for TLD-600 sensitivity irradiations using ${ }^{22} \mathrm{Cf}_{\mathrm{DzzO}}$ with and without the $\mathrm{Cd}$ shell

\begin{tabular}{lccc}
\hline & \multicolumn{3}{c}{ Fluence distribution at $0.5 \mathrm{~m}$ from the source } \\
\cline { 2 - 4 } $\begin{array}{c}\text { Source } \\
\text { Configuration }\end{array}$ & $\begin{array}{c}\phi_{\mathrm{T}} \\
(>0.025 \mathrm{eV})\end{array}$ & $\begin{array}{c}\phi_{\mathrm{Cd}} \\
(>0.414 \mathrm{eV})\end{array}$ & $(0.025-0.414 \mathrm{eV})$ \\
\hline${ }^{252} \mathrm{Cf}_{\mathrm{D} 2 \mathrm{O}(\mathrm{Cd})}{ }^{a}$ & & 24.94 & - \\
${ }^{252} \mathrm{Cf}_{\mathrm{D} 2 \mathrm{O}(\mathrm{BO} \mathrm{Cd})}{ }^{a}$ & 28.17 & 24.94 & 3.24 \\
\hline${ }^{a}$ Units $=10^{6} \mathrm{~cm}^{-2}$. & & &
\end{tabular}

The redetermination of the responses of the TLD-600 elements to thermal neutrons is built upon the following premises (assuming scatter to be negligible):

1. the in-air response when the $\mathrm{Cd}$-shell is on the sphere $\left(\mathrm{A}_{\mathrm{Cd}}\right)$ is attributable to incident epi-Cd neutrons, those above $0.414 \mathrm{eV}$;

2. the in-air response when the Cd-shell is removed from the sphere [defined as A, which is not the same $A$ of Eqs. (1.7.1), (1.7.3), and (1.7.4)] is attributable to incident thermal and epi-Cd neutrons (to $\phi_{\mathrm{i}}$ and $\phi_{C \mathrm{C}}$ );

3. the on-phantom response without the sphere's $\mathrm{Cd}$-shell $(\mathrm{Ph})$ is attributable to incident thermal $\left(\phi_{1}\right)$ and incident epi-Cd $\left(\phi_{C d}\right)$ neutrons, plus albedo thermal and albedo epi-Cd neutrons; and

4. the on-phantom response when the $\mathrm{Cd}$-shell is on the sphere $\left(\mathrm{Ph}_{\mathrm{Cd}}\right)$ is attributable to incident epi-Cd $\left(\phi_{C d}\right)$ and albedo epi-Cd neutrons.

The first two assumptions are applied to calculate the TLD-600 sensitivity to incident thermal neutrons. Subtracting the in-air response with the Cd-shell, $A_{C d}$, from the in-air response without the $\mathrm{Cd}$ shell, $\mathrm{A}$, and dividing by the thermal fluence, $\phi_{\mathfrak{r}}$, provides the sensitivity to incident thermal neutrons, i.e., $I_{t}=\left(A-A_{C_{d}}\right) / \phi_{r}$ The last two assumptions advocate determination of the total thermal neutron sensitivity by subtracting the on-phantom response with the $\mathrm{Cd}$-shell, $\mathrm{Ph}_{\mathrm{Cd}}$, from the on-phantom response without the $\mathrm{Cd}$ shell, $\mathrm{Ph}$, and dividing by the thermal fluence, i.e., $\mathrm{T}_{\mathrm{t}}=\left(\left(\mathrm{Ph}-\mathrm{Ph}_{\mathrm{Cd}}\right) / \phi_{\mathrm{t}}\right)$. This provides the sensitivity to both incident and albedo thermal neutrons. The sensitivity to albedo thermal neutrons is determined by subtracting the incident thermal neutrons sensitivity, $I_{t}$, from the total thermal neutron sensitivity, $T_{v}$ i.e., $A l b_{t}=T_{t}-I_{t}$. The experimentally determined TLD-600 responses, in ${ }^{137} \mathrm{Cs} \mathrm{mR}$ equivalent, are presented in Table 2.3 .2 , and the calculated sensitivities, in $\mathrm{mR} \mathrm{cm}^{2}$, are presented in Table 2.3.3.

Table 23.2 TLD-600 response to neutrons in ${ }^{137} \mathrm{Cs} \mathrm{mR}$ equivalent

\begin{tabular}{ccccc}
\hline & \multicolumn{2}{c}{${ }^{252} \mathrm{Cf}_{\mathrm{D} 2 \mathrm{O}}(\mathrm{Cd})$} & \multicolumn{2}{c}{${ }^{252} \mathrm{Cf}_{\mathrm{D} 2 \mathrm{O}}$ (no Cd $)$} \\
\cline { 2 - 5 } configuration & $\mathrm{A}_{\mathrm{Cd}}{ }^{a}$ & $\mathrm{Ph}_{\mathrm{Cd}}{ }^{b}$ & $\mathrm{~A}^{a}$ & $\mathrm{Ph}^{b}$ \\
\hline TLD-600 (Cd) & 192.04 & 1173.23 & 242.12 & 1417.76 \\
TLD-600 (Plastic) & 242.12 & 1965.96 & 592.63 & 1359.96 \\
\hline
\end{tabular}

\footnotetext{
${ }^{a} \gamma$ corrected in air response

${ }^{b} \gamma$ corrected on phantom response.

${ }^{c}{ }^{137} \mathrm{Cs} \mathrm{mR}$ equivalent.
} 
Table 23.3. TLD-600 sensitivities to neutrons

\begin{tabular}{lcccccc}
\hline & $\mathrm{I}_{\mathrm{t}}^{a}$ & $\mathrm{Alb}_{\mathrm{t}}^{b}$ & \multicolumn{1}{c}{$\mathrm{T}_{\mathrm{i}}^{c}$} & $\mathrm{I}_{\text {epi }}{ }^{d}$ & $\mathrm{~A}_{\text {epi }}{ }^{c}$ & $\mathrm{~T}_{\text {ep }}{ }^{f}$ \\
\hline TLD-600 (Cd) & 1.55 & 6.0 & 7.55 & 0.77 & 3.93 & 4.70 \\
TLD-600 (Plastic) $^{g}$ & 10.8 & 7.88 & 18.68 & .97 & 4.48 & 5.55 \\
\hline
\end{tabular}

${ }^{a} \gamma$ corrected response to incident thermal neutrons.

${ }^{b} \gamma$ corrected response to albedo thermal neutrons.

${ }^{c} \gamma$ corrected total response to thermal neutrons.

${ }^{d} \gamma$ corrected response to incident neutrons $>0.025 \mathrm{eV}$ (epi).

e $\gamma$ corrected albedo response to neutrons $>0.025 \mathrm{eV}$ (epi).

${ }^{f} \gamma$ corrected total response to incident neutrons $>0.025 \mathrm{eV}$ (epi).

${ }^{g}{ }^{137} \mathrm{Cs} \mathrm{mR}$ equivalent (Units $=10^{-5} \mathrm{mR}^{2}{ }^{2}$ ).

\section{REDEFINITION OF ENERGY INTERVALS (EIs)}

In principle the CPND operates much like the TDU. Four components (or detectors) with differing thresholds and response characteristics are utilized to determine the neutron spectral information. The rationale for subdividing energy range encountered in typical radiation protection environments (of $0.025 \mathrm{eV}$ to $15 \mathrm{MeV}$ ) into four segments or energy intervals (EIs) is described. Each of the CPND components is then described in terms of its average sensitivity in each EI multiplied by the fluence in that EI.

\subsubsection{Selection of EIs}

During the process of redefining the four EIs, the refined R(E)s of the CPND's TLD-600 elements and the refined $R(E) s$ of the BD-100R and BDS-1500 were considered. There were three primary factors involved in selecting the EIs: (1) the apparent natural break or drop in sensitivity of the BDS-1500 and BD-100R, (2) the Cd cutoff at $0.414 \mathrm{eV}$, and (3) the points that correspond to the change in the fluence-to-dose equivalent conversion factors as defined by the International Commission on Radiological Protection in Publication 21, i.e., ICRP $21 \mathrm{~h}$ (ICRP 1973). The objective was to define the EIs so as to best optimize these criteria. The new EIs (thermal, slow, medium, and fast) were redefined as follows:

$$
\begin{array}{ll}
\text { thermal } & =\leq 0.414 \mathrm{eV}, \\
\text { slow } & =0.414 \mathrm{eV}-0.1 \mathrm{MeV}, \\
\text { medium } & =0.1 \mathrm{MeV}-1 \mathrm{MeV}, \text { and } \\
\text { fast } & =1 \mathrm{MeV}-15 \mathrm{MeV} .
\end{array}
$$

For comparison, Liu's EIs are given:

$$
\begin{aligned}
& \text { thermal }=\leq 0.414 \mathrm{eV}, \\
& \text { slow }=0.414 \mathrm{eV}-0.15 \mathrm{MeV}, \\
& \text { medium }=0.15 \mathrm{MeV}-1.5 \mathrm{MeV}, \text { and } \\
& \text { fast }=1.5 \mathrm{MeV}-10 \mathrm{MeV} .
\end{aligned}
$$


For convenience, the fluence in each EI will be defined as the fast fluence $\left(\phi_{f}\right)$, medium fluence $\left(\phi_{\mathrm{m}}\right)$, slow fluence $\left(\phi_{\mathrm{s}}\right)$ and thermal fluence $\left(\phi_{V}\right)$, with the summation of these providing the total fluence $\left(\phi_{\mathrm{T}}\right)$ for the spectrum.

\subsubsection{EI Sensitivity of CPND Components}

The EI sensitivity $\left(\mathrm{S}_{\mathrm{EI}}\right)$ of each component is taken to be the average sensitivity, in response per unit neutron, of that component, for that EI. Thus, the $R(E)$ of each component may be both visualized as a step function (Fig. 2.4.1) and represented numerically by the equation

$$
R_{\tau}=\sum_{E I=\text { thermal }}^{\text {fast }}\left(S_{E I} \times \phi_{E J}\right)
$$

where

$R_{t}=$ total response of the component,

$\mathrm{S}_{\mathrm{EI}}=$ neutron sensitivity of the component for the EI,

$\phi_{\mathrm{EI}}=$ neutron fluence in the EI.

Thus, the total response of the plastic covered TLD-600 is seen to be its $S_{f}$ multiplied by $\phi_{\mathrm{f}}$, plus its $S_{\mathrm{m}}$ multiplied by $\phi_{\mathrm{m}}$, plus its $S_{\mathrm{s}}$ multiplied by $\phi_{\mathrm{s}}$, plus its $S_{\mathrm{t}}$ multiplied by $\phi_{\mathrm{r}}$ An analogous correspondence exists for the remaining three components. A comparison of Liu's EIs and sensitivities and the new EIs and sensitivities for each component is provided in Tables 2.4.1 and 2.4.2.

\section{MATRIX ALGORITHM AND SPECTRUM DECONVOLUTION}

Deconvolution of the spectral results is grounded upon the assumption that the fluence in each EI is uniformly distributed over the EI, i.e., the fluence in the medium EI (0.1 $1 \mathrm{MeV}$ ) is uniformly distributed between 0.1 and $1 \mathrm{Mev}$. This is assumed to be the case for each of the EIs: thermal, slow, medium, and fast.

A comparison between the original stripping method and the new matrix algorithm for spectrometric deconvolution is presented.

\subsubsection{Stripping Methodology}

The original (Liu) methodology utilized simple stripping or subtraction to determine the fluences in each EI. An alternative methodology utilizing a four-by-four matrix, or four simultaneous equations, was developed as part of the modification.

Liu determined the $\phi_{\mathrm{f}}$ from the BDS-1500 response, assuming the BDS-1500 responded only to neutrons above $1.5 \mathrm{MeV}$. The $\phi_{\mathrm{m}}$ was then determined by subtracting the BDS-1500 response from the $\mathrm{BD}-100 \mathrm{R}$ assuming a $\mathrm{BD}-100 \mathrm{R}$ threshold of $150 \mathrm{keV}$. 


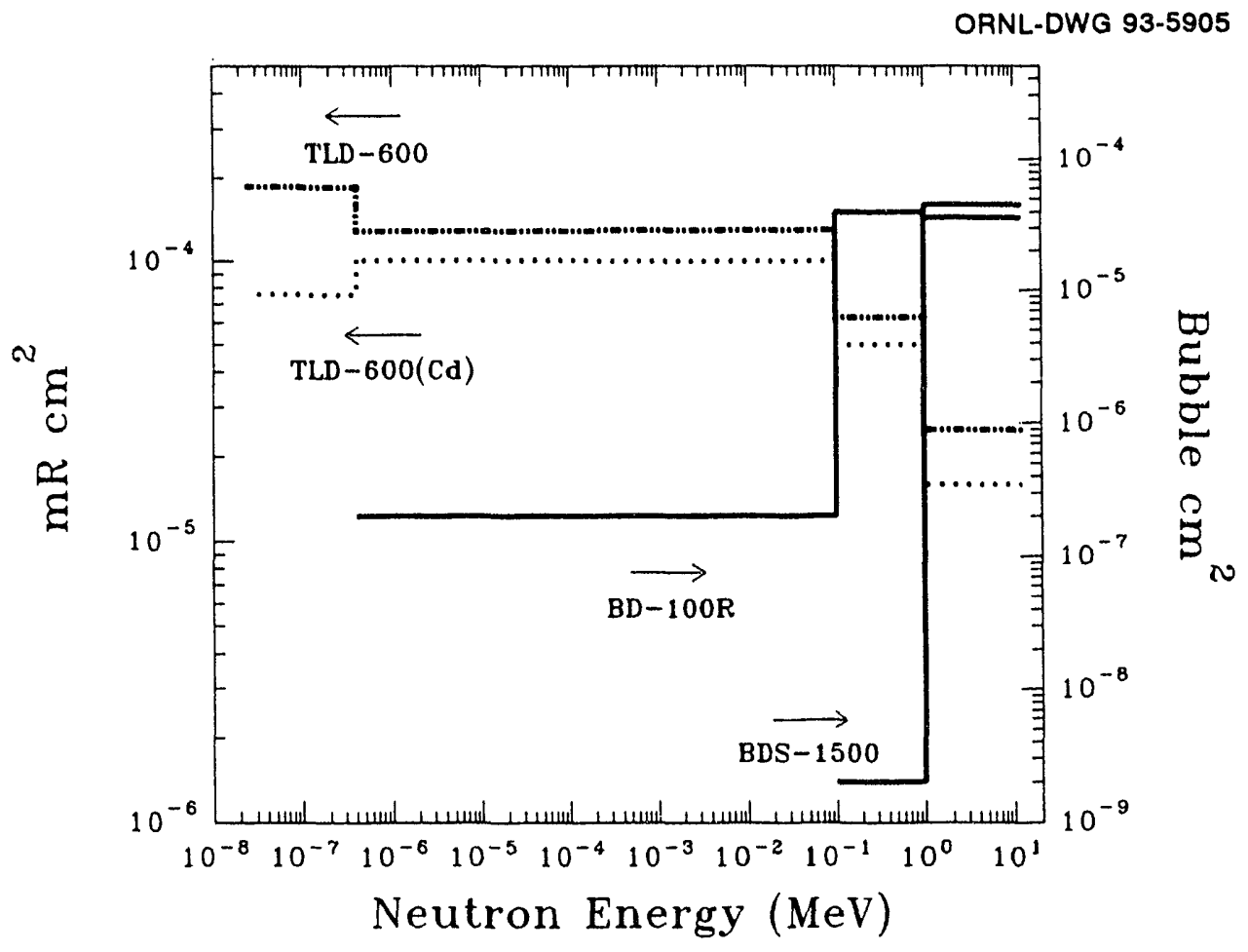

Fig. 24.1. Step function: average sensitivity in neutron response per unit fluence. 
Table 2.4.1. Original CPND EIs, sensitivities, and $\bar{h}_{\phi(E)}$

\begin{tabular}{lcccc}
\hline EIs & $\begin{array}{c}\text { Thermal } \\
0.025-0.414 \mathrm{eV}\end{array}$ & $\begin{array}{c}\text { Slow } \\
0.414 \mathrm{eV}-0.15 \mathrm{MeV}\end{array}$ & $\begin{array}{c}\text { Medium } \\
0.15-1.5 \mathrm{MeV}\end{array}$ & $\begin{array}{c}\text { Fast } \\
1.5-10 \mathrm{MeV}\end{array}$ \\
\hline Component & \multicolumn{5}{c}{ Sensitivities } \\
BDS-1500 & - & - & - & 5.0 \\
BD-100R & & - & 5.1 & 4.0 \\
Plastic-Cd $^{b}$ & - & - & - & - \\
Albedo $^{b}$ & 18.4 & 5.6 & 3.8 & 1.6 \\
\hline${\text { Average } \mathrm{h}_{t}}^{18.7}$ & $\mathrm{~h}_{\mathrm{t}}$ & $\mathrm{h}_{\mathrm{s}}$ & $\mathrm{h}_{\mathrm{m}}$ & $\mathrm{h}_{\mathrm{f}}$ \\
$\left(10^{-10} \mathrm{~Sv} \mathrm{~cm}^{2}\right)$ & 0.11 & 0.45 & 2.66 & 4.05 \\
\hline
\end{tabular}

${ }^{a}$ Units $=10^{-5} \mathrm{bu} \mathrm{cm}^{2}$.

${ }^{b}$ Units $=10^{-5} \mathrm{mR} \mathrm{cm}$.

Table 24.2. Modified CPND Els, sensitivities, and $\bar{h}_{\phi(E)}$

\begin{tabular}{lcccc}
\hline EIs & $\begin{array}{c}\text { Thermal } \\
0.025-0.414 \mathrm{eV}\end{array}$ & $\begin{array}{c}\text { Slow } \\
0.414 \mathrm{eV}-0.1 \mathrm{MeV}\end{array}$ & $\begin{array}{c}\text { Medium } \\
0.1-1 \mathrm{MeV}\end{array}$ & $\begin{array}{c}\text { Fast } \\
1-15 \mathrm{MeV}\end{array}$ \\
\hline Component & \multicolumn{5}{c}{ Sensitivities } \\
BDS-1500 & - & - & 0.0002 & 4.5 \\
BD-100R $^{a}$ & - & 0.02 & 4.0 & 3.6 \\
TLD-600(Cd) & 7.6 & 20 & 5.0 & 1.6 \\
TLD-600 & 18.7 & 13 & 6.3 & 2.5 \\
\hline Average $\mathrm{h}_{4}$ & $\mathrm{~h}_{\mathrm{t}}$ & $\mathrm{h}_{\mathrm{s}}$ & $\mathrm{h}_{\mathrm{m}}$ & $\mathrm{h}_{\mathrm{f}}$ \\
$\left(10^{-10} \mathrm{~Sv} \mathrm{~cm}^{2}\right)$ & 0.11 & 0.16 & 2.5 & 4.1 \\
\hline
\end{tabular}

${ }^{a}$ Units $=10^{-5} \mathrm{bu} \mathrm{cm}$.

${ }^{b}$ Units $=10^{-5} \mathrm{mR} \mathrm{cm}^{2}$. 
Because TLD-600 is sensitive to photons and neutrons, it is necessary to isolate the neutron portion of the TLD-600 response. To accomplish this, a TLD-700 element with identical $\mathrm{Cd}$ or plastic covering is paired with each TLD-600 element. Each of the elements is calibrated to ${ }^{137} \mathrm{Cs}$ photons. Subtracting the paired TLD-700 response from the TLD-600 response corrects for the response to photons from both the radiation field and from the photons produced by the $n-\gamma$ capture reaction of the Cd filter. Assuming that the TLD-700 response to neutrons is negligible and that the $\mathrm{Cd}$ cover absorbs the thermal neutrons on that element, it is presumed that the difference in response of the Cd-covered TLD-600 and the plastic-covered TLD-600 is simply attributable to the absorption of incident thermal neutrons by the $\mathrm{Cd}$ cover. Therefore, subtraction of the Cd-covered response from the plastic-covered response should provide a measure of the incident thermal fluence or $\phi_{1}$. Next, $\phi_{s}$ was calculated by subtracting the determined $\phi_{f}, \phi_{m}$ and $\phi_{1}$ from the plastic covered TLD-600 response.

In contrast, the seemingly absolute thresholds of $150 \mathrm{keV}$ and $1.5 \mathrm{MeV}$ for the BD-100R and BDS-1500, respectively, were neither absolute, i.e., the response below which was assumed to be negligible, nor representative of the actual threshold in the laboratory. Note that the $R(E) s$ of the BTI detectors were originally derived from the theoretical response calculated at $20^{\circ} \mathrm{C}$. A more in-depth look at temperature related effects will be discussed in Sect. 4.3. For now let it suffice to state that the empirical measurements of the response to monoenergetic neutrons indicted that actual thresholds of $100 \mathrm{keV}$ and $1 \mathrm{MeV}$ were more accurate and that both detectors respond below these thresholds. This cannot be ignored without adversely effecting the spectral results obtained by the CPND (Sects. 2.2 and 2.4). Because the CPND can be described by four equations (one for each component) with four unknowns (the $\phi_{\mathrm{Els}}$ ), it was felt that a method of deriving the spectral information by simultaneously solving these equations (thereby utilizing all the available information) would provide results that were more accurate. This was the reason for developing the matrix deconvolution algorithm.

\subsubsection{Definition of Matrix Equations}

The four equations relating the total response of each component to its $\mathrm{S}_{\mathrm{El}} \mathrm{S}$ (Table 2.4.2) and the unknown fluences [expressed by Eq. (2.4.1)] can be arranged in matrix form as follows:

$$
\left[\begin{array}{c}
R_{T L D-600} \\
R_{T D D-600(C D)} \\
R_{B D-100 R} \\
R_{B D S-1500}
\end{array}\right]=\left[\begin{array}{cccc}
18.7 \times 10^{-5} & 13 \times 10^{-5} & 6.3 \times 10^{-5} & 2.5 \times 10^{-5} \\
7.6 \times 10^{-5} & 20 \times 10^{-5} & 5 \times 10^{-5} & 1.6 \times 10^{-5} \\
0 & 2.0 \times 10^{-7} & 4.0 \times 10^{-5} & 3.6 \times 10^{-5} \\
0 & 0 & 2.0 \times 10^{-9} & 4.5 \times 10^{-5}
\end{array}\right]\left[\begin{array}{l}
\phi_{t} \\
\phi_{s} \\
\phi_{m} \\
\phi_{f}
\end{array}\right] .
$$




\subsection{Matrix Inversion}

Inverting the above four-by-four matrix in Eq. (2.5.1), produces a set of new equations describing the fluence in each $\mathrm{EI}\left(\phi_{\mathrm{El}}\right)$ in terms of the normalized responses of the CPND components. These can also be represented in matrix form as follows:

$$
\left[\begin{array}{l}
\phi_{t} \\
\phi_{s} \\
\phi_{m} \\
\phi_{f}
\end{array}\right]=\left[\begin{array}{cccc}
7624.38 & -4716.3 & -5546.13 & 2078.04 \\
-2763.92 & 6800.7 & -4147.82 & 2435.74 \\
13.82 & -34 & 25021.74 & -20012.98 \\
-0.0006 & 0.0015 & -1.11 & 22223.11
\end{array}\right]\left[\begin{array}{c}
R_{T L D-600} \\
R_{T L D-600(C A)} \\
R_{B D-100 R} \\
R_{B D S-1500}
\end{array}\right] .
$$

Once the responses of the CPND components have been normalized, [that is, after subtracting the gamma component from the TLD-600 response, normalizing the BD results by applying a TCC, Eq. (2.2.1), and making appropriate temperature corrections, Eq. (2.2.2)], the normalized responses are substituted into Eq. (2.5.2). The solution of this matrix produces the measured EI fluences of the spectrum.

\subsection{DOSE EQUIVALENT CONVERSION}

The next step is to convert the EI fluences to dose equivalent. The dose equivalent produced by neutrons in each $\mathrm{EI}\left(\mathrm{H}_{\mathrm{El}}\right)$ is calculated by multiplying the EI fluences, $\phi_{\mathrm{f}, \mathrm{m}, \mathrm{s}, \mathrm{v}}$ by their respective average $h_{\text {, }}$

$$
H_{E I}=\phi_{E I} \times \bar{h}_{\phi_{U}}
$$

The average $h_{\phi}(E I)$ is defined as the average value of the $h_{\phi}$ over the EI. The average is obtained from a $\ln$ - In interpolation of the ICRP $21 h_{\phi}$ values. The calculated average $h_{\phi}(E I) s$ are listed in Table 2.4.2. The total neutron dose equivalent, $H_{T}$, is derived from the summation of the $\mathrm{H}_{\mathrm{EI}} \mathrm{s}$ contributed by each $\mathrm{EI}$,

$$
H_{T}=\sum_{E I=t}^{f} H_{E D}=H_{\imath}+H_{s}+H_{m}+H_{f} .
$$

In light of the volatile environment surrounding neutron dosimetry (i.e., the proposed increase in the neutron quality factor, reduction of the annual dose equivalent limits, and the various dose equivalent reporting conventions employed) this simple spectrum affords a sure footing upon which to base the neutron dose equivalent. Because fluence is real and as such affords the luxury of applying various reporting conventions, as the situation dictates, a solid foundation is laid upon which to build a personnel neutron dosimetry system. We will now address the spectrometric and neutron dose equivalent performance of the modified CPND for the ten irradiation spectra. 


\section{PERFORMANCE EVALUATION AND ANALYSIS OF RESULTS}

The performance of the modified CPND was assessed by comparison of the spectrometric $\left(\phi_{E I}\right)$ and dose equivalent results $\left(\mathrm{H}_{\mathrm{EI}}\right.$ and $\left.\mathrm{H}_{\mathrm{T}}\right)$ to reestablished reference dosimetry (necessitated by the new EIs) and the original results. A description of (1) the field and source irradiations conditions, (2) the previous performance results of Liu, (3) the reassessment of the reference spectra and dosimetric values, and (4) performance reevaluation are provided.

\subsection{INTRODUCTION}

The performance of the CPND had previously been tested in five pure and mixed field radioisotopic neutron spectra and in five in situ neutron spectra at ORNL. The radioisotopic spectra were obtained from various combinations of ${ }^{238} \mathrm{PuBe}$, polyethylene (PE) moderated ${ }^{252} \mathrm{Cf}$, and $\mathrm{D}_{2} \mathrm{O}$ moderated ${ }^{252} \mathrm{Cf}$. The average neutron energies of these sources are $4 \mathrm{MeV}$, $0.65 \mathrm{MeV}$ (at $2 \mathrm{~m}$ ), and $0.55 \mathrm{MeV}$, respectively. The moderated spectra were obtained by placing the ${ }^{252} \mathrm{Cf}$ source in the center of a PE sphere and in the center of a $\mathrm{D}_{2} \mathrm{O}$-filled sphere; both spheres were $30-\mathrm{cm}$ in diameter. Five locations at ORNL's Transuranic Processing Plant (TRU) and the High Flux Isotope Reactor (HFIR), which were designed to provide quantities of transuranium and transcalifornium elements, were selected as sites for the in situ measurements.

During the in situ measurements a CPND was placed on the front and back of a $40 \times 40$ $\times 20-\mathrm{cm}$ polymethyl methacrylate (PMMA) phantom to approximate a $4 \pi$ measuring geometry. Whenever possible the direction of the radiation source was determined and the phantom was oriented with the front facing it. For the single-source and mixed-source irradiations, at least three GPNDs were placed on the front face of the phantom, and the results were averaged. A more in-depth description of the irradiation procedure is available in ORNL-6593, The Development, Characterization, and Performance Evaluation of a New Combination Type Personnel Dosimeter (Liu 1989).

\subsubsection{Radioisotopic Neutron Sources}

The radioisotopic irradiations were conducted using the neutron sources available at the Radiation Calibration Laboratory (RADCAL). The five spectra were ${ }^{252} \mathrm{Cf}(\mathrm{PE})$; ${ }^{238} \mathrm{PuBe}$; ${ }^{252} \mathrm{Cf}\left(\mathrm{D}_{2} \mathrm{O}\right)$; a combination of ${ }^{238} \mathrm{PuBe}$ and ${ }^{252} \mathrm{Cf}[\mathrm{MIX}(2)]$; and a combination of ${ }^{252} \mathrm{Cf}(\mathrm{PE})$, ${ }^{252} \mathrm{Cf}\left(\mathrm{D}_{2} \mathrm{O}\right)$, and ${ }^{238} \mathrm{PuBe}[\mathrm{MIX}(3)]$.

\subsubsection{Working Environments}

The CPND was subjected to real-world work environments for which neutrons were present. The sites selected were the cave area, glove box, waste transfer area, control room, and the analytical laboratory located at TRU and HFIR. 


\subsubsection{Reference Dosimetry}

The reference spectra for the in situ and the ${ }^{252} \mathrm{Cf}$ moderated by polyethylene irradiations were determined from the unfolding of Bonner multi-sphere spectrometer (BMS) measurements provided by Dr. Ferenc Hajnal of the Environmental Measurements Laboratory (EML), New York (Liu 1989). During the original measurements two or more 100-s measurements were taken with each of the twelve detectors in the BMS set. The position of the BMS set was adjacent to the CPND location for each spectra. The reference spectra for the other radioisotopic irradiations were taken from emission spectra available in the open literature [for ${ }^{238} \mathrm{PuBe}$ (Block et al. 1967) and for ${ }^{252} \mathrm{Cf}\left(\mathrm{D}_{2} \mathrm{O}\right)$ (IAEA 1985)]. The original reference values, $\mathrm{H}_{\mathrm{EJ}}$, for both the radioisotopic and the in situ irradiations are provided Sect. 3.3.

\subsection{PREVIOUS PERFORMANCE}

The previous CPND results (both dose equivalent and spectrometric for the in situ and the radioisotopic categories) are compared to the derived reference values of total neutron dose equivalent and spectrum accuracy. The individual and overall dose equivalent performance is evaluated according to the conventionally accepted methodology currently utilized by the DOE Laboratory Accreditation Program (DOELAP) as outlined in the Department of Energy Standard For The Performance Testing of Personnel Dosimetry Systems, DOE/EH-0027 (DOE 1986). The performance index,

$$
P_{i}=\frac{[(\text { measured })-(\text { reference })]}{(\text { reference })},
$$

was calculated for each individual measurement, and the bias,

$$
B=\frac{1}{n} \sum_{i=1}^{n} P_{i}
$$

standard deviation,

$$
S=\left[\frac{\sum_{i=1}^{n}\left(P_{i}-B\right)^{2}}{n-1}\right]^{1 / 2},
$$

and tolerance level (L),

$$
|B|+S \leq L,
$$


were calculated for each category to access the relative accuracy of the results. It should be noted that the DOELAP includes an error term (E) to account for the potential error in the reference dosimetry of the irradiation laboratory, i.e., $|B|+S-E \leq L$. For our purposes, $E$ can be neglected. The $P_{i}$ provides an indication of the accuracy for individual measurements. The standard deviation, in our analysis, may be considered as an indicator of the precision of the measurements within the respective irradiation category, either radioisotopic or in situ. The bias may be viewed as an indication of the overall accuracy of the measurements within each category. The tolerance level takes into consideration the combination of overall accuracy and precision within each category. The optimum detector would have zeros for all four values, $P_{i}, S, B$, and $L$. As stated in DOE/EH-0027, a value of $\mathrm{L}=0.30$ is considered as passing, and therefore, acceptable.

\subsubsection{Dose Equivalent Performance Utilizing the Liu Method}

First, considering the $\mathrm{H}_{\mathrm{T}}$ performance of each irradiation within the two categories, as indicated by the $P_{i}$ values, the original results were all within $\pm 30 \%$ for the in situ category while only one lay outside of $\pm 30 \%$ for the radioisotopic category, i.e., $34 \%$ high for the ${ }^{252} \mathrm{Cf}\left(\mathrm{D}_{2} \mathrm{O}\right)$ measurement (Tables 3.2.1 and 3.2.2). Overall, when compared to the DOELAP acceptance criteria, i.e., $\mathrm{L} \leq 0.30$, the total neutron dose equivalent as measured by the original CPND was well within the acceptable range for the in situ category, with an $\mathrm{L}=$ 0.12 , yet, was just barely acceptable for the radioisotopic category, with an $L=0.30$ (note the bottom line of Tables 3.2.1. and 3.2.2). The results, as indicated by the bias values, indicate an average overresponse of $13 \%$ in radioisotopic spectra and an average underresponse of $8 \%$ for the in situ spectra. The standard deviations suggest that the original CPND more accurately measured the dose equivalent for the in situ spectra than it did for the radioisotopic spectra. The $B$ and $S$ values were calculated for each measurement in the two catagories. These results appear in Tables 3.2.3 and 3.2.4. Now let us turn to consider the spectrometric capabilities of the original method.

\subsubsection{Spectrometric Performance Utilizing the Liu Method}

The original spectrometric abilities of the CPND were good. Analysis of the spectrometric $\mathrm{B}, \mathrm{S}$, and $\mathrm{L}$ for each $\mathrm{EI}$ in the two categories is presented in Table 3.2.5. The original CPND tended to underestimate the $\phi_{m}$ and consequently underestimate $H_{m}$, while overestimating $\phi_{s}$ and $\phi_{l}$, consequently overestimating $H_{s}$ and $H_{f}$ as evidenced by the values of B in Table 3.2.5. Thus, in some cases the "goodness" of the measured $\mathrm{H}_{\mathrm{T}}$ could be conceived as a fortuitous combination of errors (note Tables 3.2.1 and 3.2.2).

From a cursory examination, one would conclude that the CPND measured the reference neutron spectrum with reasonable accuracy. The poorest performance was found when measuring spectra with large fluence components between $100 \mathrm{keV}$ and $2 \mathrm{MeV}$ and large therma: components. The consistent underestimation of $H_{s}$ and $H_{f}$ and the overestimation of $\mathrm{H}_{\mathrm{m}}$ is felt to be attributable to the thresholds assumed for the BD-100R and BDS-1500. The overestimation of the $\phi_{1}$ for the ${ }^{252} \mathrm{Cf}\left(\mathrm{D}_{2} \mathrm{O}\right)$ and ${ }^{238} \mathrm{PuBe}$ and the overestimation of $\mathrm{H}_{s}$ by greater than a factor of two for four of the ten spectra is believed to stem from two other weakness. These are (1) the thermal neutron sensitivity assumed for the TLD-600 elements and (2) accepting the subtraction of TLD-600(Cd) from TLD-600(plastic) as an 
accurate measure of $\phi_{\mathrm{r}}$. Let us now turn to consider the reassessment of the reference dosimetry and the results of the modified approach.

Table 3.2. The original measured dose equivalent $\left(H_{\mathrm{Eg}}\right.$ and $\left.\mathrm{H}_{T}\right)$ and calculated $P_{i}$ results from the radioisotopic source measurements [CPND units $=0.01 \mathrm{mSv}(1 \mathrm{mrem})$ ]

\begin{tabular}{|c|c|c|c|c|c|c|c|c|c|c|}
\hline & \multicolumn{2}{|c|}{${ }^{252} \mathrm{Cf}(\mathrm{PE})$} & \multicolumn{2}{|c|}{${ }^{238} \mathrm{PuBe}$} & \multicolumn{2}{|c|}{${ }^{252} \mathrm{Cf}(\mathrm{D}, \mathrm{O})$} & \multicolumn{2}{|c|}{$\operatorname{MIX}(2)$} & \multicolumn{2}{|c|}{$\operatorname{MIX}(3)$} \\
\hline & CPND & $P_{i}$ & CPND & $P_{i}$ & CPND & $P_{i}$ & CPND & $P_{i}$ & CPND & $P_{i}$ \\
\hline $\mathrm{H}_{\mathrm{s}}$ & 3.15 & -0.28 & 4.69 & - & 3.07 & - & 0.93 & - & 2.55 & 0.15 \\
\hline $\mathrm{H}_{s}$ & 5.55 & 0.68 & 0.00 & - & 138.40 & 2.79 & 22.93 & 3.53 & 30.26 & 3.14 \\
\hline $\mathrm{H}_{\mathrm{m}}$ & 26.40 & -0.13 & 6.58 & -0.39 & 32.93 & -0.49 & 10.67 & -0.20 & 64.43 & -0.29 \\
\hline $\mathrm{H}_{t}$ & 41.10 & .0 .15 & 59.78 & 0.13 & 154.67 & 0.07 & 40.00 & -0.05 & 402.05 & 0.10 \\
\hline $\mathrm{H}_{\mathrm{T}}$ & 76.20 & -0.12 & 71.05 & 0.12 & 329.07 & 0.34 & 74.53 & 0.23 & 499.29 & 0.07 \\
\hline
\end{tabular}

Table 3.2.2. The original measured dose equivalent $\left(H_{E}\right.$ and $\left.H_{T}\right)$ and calculated $P_{i}$ results from the in situ measurements at TRU [CPND units $=0.01 \mathrm{mSv}(1 \mathrm{mrem})$ ]

\begin{tabular}{|c|c|c|c|c|c|c|c|c|c|c|}
\hline & \multicolumn{2}{|c|}{ GLOVE } & \multicolumn{2}{|c|}{ CAVE } & \multicolumn{2}{|c|}{ CNTRL } & \multicolumn{2}{|c|}{ WASTE } & \multicolumn{2}{|c|}{$L A B$} \\
\hline & CPND & $P_{i}$ & CPND & $P_{i}$ & CPND & $P_{i}$ & CPND & $P_{i}$ & CPND & $P_{i}$ \\
\hline $\mathrm{H}_{\mathrm{t}}$ & 17.38 & -0.30 & 10.39 & -0.12 & 0.03 & -0.92 & 4.56 & 0.05 & 3.57 & 0.72 \\
\hline $\mathrm{H}_{s}$ & 126.79 & 1.47 & 27.89 & 0.66 & 0.25 & -0.77 & 60.85 & 1.64 & 72.54 & 2.39 \\
\hline $\mathrm{H}_{\mathrm{m}}$ & 169.69 & -0.52 & 54.69 & -0.29 & 3.21 & -0.23 & 164.77 & -0.18 & 131.70 & -0.40 \\
\hline $\mathrm{H}_{\mathrm{f}}$ & 367.07 & 0.04 & 59.79 & -0.07 & 4.95 & 0.45 & 174.12 & -0.15 & 254.49 & 0.11 \\
\hline $\mathrm{H}_{\mathrm{t}}$ & 680.93 & -0.13 & 152.76 & -0.10 & 8.44 & -0.07 & 404.30 & -0.07 & 462.30 & -0.02 \\
\hline
\end{tabular}

Table 3.2.3. The individual bias and standard deviation of the original CPND for the radioisotopic measurements

\begin{tabular}{lrrrrr}
\hline & ${ }^{252} \mathrm{Cf}(\mathrm{PE})$ & ${ }^{238} \mathrm{PuBe}$ & ${ }^{252} \mathrm{Cf}\left(\mathrm{D}_{2} 0\right)$ & $\mathrm{MIX}(2)$ & $\operatorname{MIX}(3)$ \\
\hline $\mathrm{B}$ & 0.03 & 1.11 & 1.36 & 1.05 & 0.78 \\
$\mathrm{~S}$ & 0.44 & 2.39 & 1.83 & 1.73 & 1.59 \\
\hline
\end{tabular}


Table 3.24. The individual bias and standard deviation of the original CPND for the in situ measurements

\begin{tabular}{lccccc}
\hline & GLOVE & CAVE & CNTRL & WASTE & LAB \\
\hline B & 0.17 & 0.05 & -0.37 & 0.34 & 0.70 \\
S & 0.89 & 0.42 & 0.62 & 0.87 & 1.21 \\
\hline
\end{tabular}

Table 3.25. The EI bias, standand deviation, and $\mathrm{L}$ value of the original CPND for the radioisotopic and in situ categories

\begin{tabular}{lcccccc}
\hline & \multicolumn{3}{c}{ Radioisotopic } & & & \multicolumn{2}{c}{ In situ } \\
\cline { 3 - 6 } & $\mathrm{B}$ & $\mathrm{S}$ & $|\mathrm{B}|+\mathrm{S}$ & $\mathrm{B}$ & $\mathrm{S}$ & $|\mathrm{B}|+\mathrm{S}$ \\
\hline $\mathrm{H}_{\mathrm{t}}$ & 1.71 & 2.10 & 3.82 & -0.11 & 0.59 & 0.70 \\
$\mathrm{H}_{\mathrm{s}}$ & 2.03 & 1.58 & 3.61 & 1.08 & 1.20 & 2.28 \\
$\mathrm{H}_{\mathrm{m}}$ & -0.30 & 0.14 & 0.44 & -0.32 & 0.14 & 0.46 \\
$\mathrm{H}_{\mathrm{f}}$ & 0.02 & 0.12 & 0.14 & 0.08 & 0.23 & 0.31 \\
\hdashline $\mathrm{H}_{\mathrm{T}}$ & 0.13 & 0.17 & 0.30 & -0.08 & 0.04 & 0.12 \\
\hline
\end{tabular}

\subsection{REASSESSMENT OF REFERENCE SPECTRA AND DOSIMETRIC VALUES}

Because new EIs were defined for the CPND, it was necessary to recalculate the reference values for the $\phi_{E I}$ and $\mathrm{H}_{\mathrm{EI}}$ for each of the test spectra. The original 26-energy group BMS data provided by EML and the reference spectra published in the open literature were used as the starting point. These spectral data were entered into a spreadsheet. Computations based on $\ln$-In interpolation were performed to determine the relative abundance of the neutrons and the spectra were broken down into $20 \mathrm{keV}$ intervals from $0.025 \mathrm{eV}$ to $15 \mathrm{MeV}$ for each spectra using

$$
\begin{aligned}
\ln \left(\phi_{E_{i}}\right)= & \ln \left(\phi_{E_{i}}\right)+ \\
& {\left[\left(\frac{\ln \left(E_{u}\right)-\ln \left(E_{i}\right)}{\ln \left(E_{i}\right)-\ln \left(E_{l}\right)}\right) \times\left(\left(\ln \left(\phi_{E_{i}}\right)-\ln \left(\phi_{E_{\alpha}}\right)\right)\right],\right.}
\end{aligned}
$$

and,

$$
\phi_{E_{1}}=e^{\ln \left(\phi_{E_{l}}\right)},
$$

where,

$$
\begin{aligned}
& E_{i, u, \text { and } l}=\text { the energy of interest and the upper and lower energies, } \\
& \Phi_{E_{b, \text { and }}}=\text { the fluence at the energies just stated. }
\end{aligned}
$$


The fluence in each EI was taken to be the sum of the $20-\mathrm{keV}$ fluences within the EI. The dose equivalent for the $20-\mathrm{keV}$ intervals $\left(\mathrm{H}_{20 \mathrm{keV}}\right)$ was calculated by multiplying each $\phi_{20 \mathrm{keV}}$ by the average $h$, for that $20-\mathrm{keV}$ interval determined by a $\ln$-ln interpolation of ICRP 21 $h_{\phi}$. The $H_{E I}$ was taken to be the summation of the $\mathrm{H}_{20 \text { kev }}$ within the EI, and the total $\mathrm{H}_{T}$ was taken to be the summation of all $\mathrm{H}_{20 \mathrm{keV}}$ from $0.025 \mathrm{eV}$ to $15 \mathrm{MeV}$. The observed difference in reference values between this work and the original stem from the different EIs. Liu's $\phi_{\mathrm{m}}$ included the neutrons between 1 and $1.5 \mathrm{MeV}$, while these neutrons were included in the $\phi_{\mathrm{f}}$ according to the modified EIs. Consequently, the reference $\mathrm{H}_{\mathrm{f}}$ for the modified EIs would typically be greater than that of the original. It is believed that this

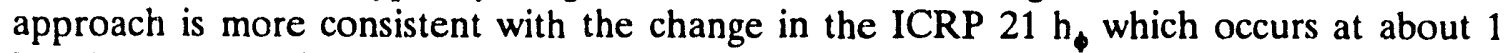
$\mathrm{MeV}$. Details of the "New" and Liu reference values of $\mathrm{H}_{\mathrm{El}}$ and $\mathrm{H}_{\mathrm{T}}$ for both the radioisotopic and the in situ irradiations are provided in Tables 3.3.1. and 3.3.2.

Table 3.3.1. Comparison of original and modified reference values for radioisotopic neutron $\mathrm{H}_{\mathrm{E}}$ and $\mathrm{H}_{\mathrm{T}}$ results

\begin{tabular}{|c|c|c|c|c|c|c|c|c|c|c|}
\hline & \multicolumn{2}{|c|}{${ }^{252} \mathrm{Cf}(\mathrm{PE})^{a}$} & \multicolumn{2}{|c|}{${ }^{228} \mathrm{PuBe}^{a}$} & \multicolumn{2}{|c|}{${ }^{252} \mathrm{Cf}\left(\mathrm{D}_{2} \mathrm{O}\right)^{a}$} & \multicolumn{2}{|c|}{$\operatorname{MIX}(2)^{a}$} & \multicolumn{2}{|c|}{$\operatorname{MIX}(3)^{a}$} \\
\hline & NEW & LIU & NEW & LIU & NEW & LIU & NEW & LIU & NEW & LIU \\
\hline $\mathrm{H}_{\mathrm{r}}$ & 56.70 & 48.45 & 55.21 & 52.67 & 147.68 & 145.20 & 48.99 & 42.10 & 432.97 & 365.84 \\
\hline $\mathrm{H}_{\mathrm{m}}$ & 19.06 & 30.30 & 7.62 & 10.80 & 63.99 & 64.40 & 13.49 & 13.33 & 85.76 & 90.78 \\
\hline $\mathrm{H}_{\mathrm{s}}$ & 3.40 & 3.30 & 0 & 0 & 34.66 & 36.53 & 5.62 & 5.06 & 21.69 & 7.37 \\
\hline $\mathrm{H}_{\mathrm{L}}$ & 4.29 & 4.35 & 0 & 0 & 0 & 0 & 0 & 0 & 2.15 & 2.21 \\
\hline $\mathrm{H}_{\mathrm{T}}$ & 83.47 & 86.40 & 62.83 & 63.46 & 246.13 & 246.13 & 60.49 & 68.1 & 542.57 & 466.14 \\
\hline
\end{tabular}

${ }^{a}$ Units $=0.01 \mathrm{mSv}(\mathrm{mrem})$

Table 3.3.2. Comparison of original and modified reference values for neutron $\mathrm{H}_{\mathrm{z}}$ and $\mathrm{H}_{\mathrm{T}}$ in situ measurements

\begin{tabular}{cccccccccccc}
\hline & \multicolumn{2}{c}{ GLOVE $^{a}$} & \multicolumn{2}{c}{ CAVE $^{a}$} & \multicolumn{2}{c}{ CNTRL $^{a}$} & \multicolumn{2}{c}{ WASTE $^{a}$} & \multicolumn{2}{c}{ LAB $^{a}$} \\
& NEW & LIU & NEW & LIU & NEW & LIU & NEW & LIU & NEW & LIU \\
\hline $\mathrm{H}_{\mathrm{f}}$ & 450.62 & 352.95 & 79.7 & 64.35 & 6.52 & 3.42 & 250.23 & 205.11 & 278.71 & 228.62 \\
$\mathrm{H}_{\mathrm{m}}$ & 246.14 & 352.95 & 56.76 & 76.57 & 3.16 & 4.18 & 137.74 & 200.55 & 148.67 & 220.60 \\
$\mathrm{H}_{\mathrm{s}}$ & 38.87 & 51.31 & 12.89 & 16.77 & 0.86 & 1.11 & 17.44 & 23.02 & 14.12 & 21.41 \\
$\mathrm{H}_{\mathrm{l}}$ & 23.97 & 24.71 & 11.57 & 11.85 & 0.33 & 0.36 & 4.21 & 4.33 & 2.13 & 2.08 \\
\hdashline $\mathrm{H}_{\mathrm{T}}$ & 759.6 & 781.92 & 160.92 & 169.54 & 11.66 & 9.07 & 409.62 & 433.01 & 443.64 & 472.71 \\
\hline
\end{tabular}

${ }^{a}$ Units $=0.01 \mathrm{mSv}(\mathrm{mrem})$ 


\subsection{PERFORMANCE REEVALUATION}

The $\phi_{E \mathrm{E}}, \mathrm{H}_{\mathrm{EI}}$, and $\mathrm{H}_{\mathrm{T}}$ results from the radioisotopic and in situ irradiations were compared to reference values and the CPND performance prior to modifications. The performance index values of $P_{i}, B, S$, and $L$ were as calculated for the modified results as described in Sect. 3.2. The modifications brought about improvements in the accuracy of the spectrometric and the total neutron dose equivalent results.

\subsubsection{Dose Equivalent Performance}

The dosimetric performance of the CPND is displayed in Tables 3.4.1 and 3.4.2. The ratio of the measured to new reference values are graphically depicted in Figs. 3.4.1 and 3.4.2. T, S, M, and $F$ correspond to $H_{v}, H_{s}, H_{m}$, and $H_{f}$. The $H_{T} L$ value 0.02 and 0.10 for the radioisotopic and in situ categories, respectively, were well below the 0.30 limit of DOELAP. The $\mathrm{P}_{\mathrm{i}}$ values of the individual $\mathrm{H}_{\mathrm{T}}$ reveal that the worst performance for the radioisotopic measurements was 0.02 while the worst for the in situ measurements was -0.11 . The $B$ values indicate an average overresponse of $1 \%$ in radioisotopic spectra and an average underresponse of $3 \%$ for the in situ spectra. The standard deviations suggest that the original CPND more accurately measured the dose equivalent for the in situ spectra than it did for the radioisotopic spectra, but only by $6 \%$. Both were within $7 \%$. The B and S values were calculated for each of the measurements in the two catagories. These results appear in Tables 3.4.3 and 3.4.4. Now let us turn to consider the spectrometric capabilities of the original method.

\subsubsection{Spectronnetric Performance}

The spectrometric results of the modified CPND for both the radioisotopic and in situ spectra are presented in Figs. 3.4.3 through 3.4.12, respectively. The reference values represented were derived from BMS measurements for the in situ and ${ }^{252} \mathrm{Cf}(\mathrm{PE})$ values and from the published literature for the source spectra as described in Sect. 3.3. With the exception of ${ }^{252} \mathrm{Cf}(\mathrm{PE})$, all other reference spectra for the radioisotopic irradiations are for the emission spectra only and, therefore, do not include the scatter component, which would have been measured by the CPND. The overall $\mathrm{B}, \mathrm{S}$, and $\mathrm{L}$ values were calculated for the $\mathrm{H}_{\mathrm{EI}} \mathrm{S}$ and $\mathrm{H}_{\mathrm{T}} \mathrm{s}$ in each catagory. These appear in Table 3.4.5.

\subsection{ANALYSIS OF RESULTS}

The modified CPND outperformed the original in overall dose equivalent results across the board (Table 3.5.1). It demonstrated improved accuracy and precision as evidenced by the improved $B$ and $S$ values. The modified CPND displayed improved $\mathrm{H}_{n}$ accuracy for eight of the ten spectra. For the other two, the original performance was better by $2 \%$ in the analytical laboratory and the same for the control room. Overall a net improvement in $\mathrm{H}_{\mathrm{T}}$ of $28 \%$ was achieved for the radioisotopic category and only $2 \%$ for the in situ category. 
Table 3.4.1. The modified CPND measured dose equivalent $\left(H_{E}\right.$ and $\left.H_{T}\right)$ and the calculated $P_{i}$ results for 'he radioisotopic measurements [CPND units $=0.01 \mathrm{mSv}(1 \mathrm{mrem})$ ]

\begin{tabular}{|c|c|c|c|c|c|c|c|c|c|c|}
\hline & \multicolumn{2}{|c|}{${ }^{252} \mathrm{Cf}(\mathrm{PE})$} & \multicolumn{2}{|c|}{${ }^{238} \mathrm{PuBe}$} & \multicolumn{2}{|c|}{${ }^{252} \mathrm{Cr}\left(\mathrm{D}_{2} \mathrm{O}\right)$} & \multicolumn{2}{|c|}{$\operatorname{MIX}(2)$} & \multicolumn{2}{|c|}{$\operatorname{MIX}(3)$} \\
\hline & CPND & $P_{i}$ & CPND & $P_{i}$ & CPND & $P_{i}$ & CPND & $\mathrm{P}_{\mathrm{i}}$ & CPND & $P_{i}$ \\
\hline $\mathrm{H}_{\mathrm{t}}$ & 4.56 & 0.06 & 0.09 & - & 0.00 & - & 0.29 & - & 2.14 & 0.00 \\
\hline $\mathrm{H}_{s}$ & 2.40 & -0.29 & 0.19 & - & 35.66 & 0.03 & 6.82 & 0.21 & 8.85 & -0.59 \\
\hline $\mathrm{H}_{\mathrm{m}}$ & 31.77 & 0.67 & 6.76 & -0.11 & 37.15 & -0.42 & 11.79 & -0.13 & 77.37 & -0.10 \\
\hline $\mathrm{H}_{\mathrm{f}}$ & 46.30 & -0.18 & 56.47 & 0.02 & 174.42 & 0.18 & 50.68 & 0.03 & 453.31 & 0.05 \\
\hline $\mathrm{H}_{\mathrm{T}}$ & 85.03 & 0.02 & 63.51 & 0.01 & 247.23 & 0.00 & 69.58 & 0.02 & 541.67 & 0.00 \\
\hline
\end{tabular}

Table 3.4.2 The modified CPND measured dose equivalent $\left(H_{\mathrm{ft}}\right.$ and $\left.\mathrm{H}_{\mathrm{T}}\right)$ and the calculated $\mathrm{P}_{\mathrm{i}}$ for the in situ measurements at TRU [CPND units $=0.01 \mathrm{mSv}(1 \mathrm{mrem})$ ]

\begin{tabular}{|c|c|c|c|c|c|c|c|c|c|c|}
\hline & \multicolumn{2}{|c|}{ GLOVE } & \multicolumn{2}{|c|}{ CAVE } & \multicolumn{2}{|c|}{ CNTRL } & \multicolumn{2}{|c|}{ WASTE } & \multicolumn{2}{|c|}{$\mathrm{LAB}$} \\
\hline & CPND & $P_{i}$ & CPND & $P_{i}$ & CPND & $P_{i}$ & CPND & $P_{i}$ & CPND & $P_{i}$ \\
\hline $\mathrm{H}_{\mathrm{t}}$ & 20.34 & -0.15 & 15.11 & 0.31 & 0.33 & -0.06 & 3.16 & -0.25 & 1.25 & -0.41 \\
\hline $\mathrm{H}_{\mathrm{s}}$ & 37.32 & -0.04 & 10.57 & -0.18 & 0.71 & -0.17 & 16.02 & -0.08 & 19.25 & 0.36 \\
\hline $\mathrm{H}_{\mathrm{m}}$ & 202.98 & -0.18 & 65.46 & 0.15 & 4.53 & -0.43 & 184.64 & 0.34 & 143.25 & -0.04 \\
\hline $\mathrm{H}_{\mathrm{f}}$ & 413.67 & -0.8 & 67.30 & -0.16 & 6.09 & -0.07 & 182.63 & -0.27 & 260.67 & -0.06 \\
\hline $\mathrm{H}_{\mathrm{t}}$ & 674.31 & -0.11 & 158.44 & -0.02 & 11.66 & 0.07 & 386.45 & -0.06 & 424.42 & -0.04 \\
\hline
\end{tabular}




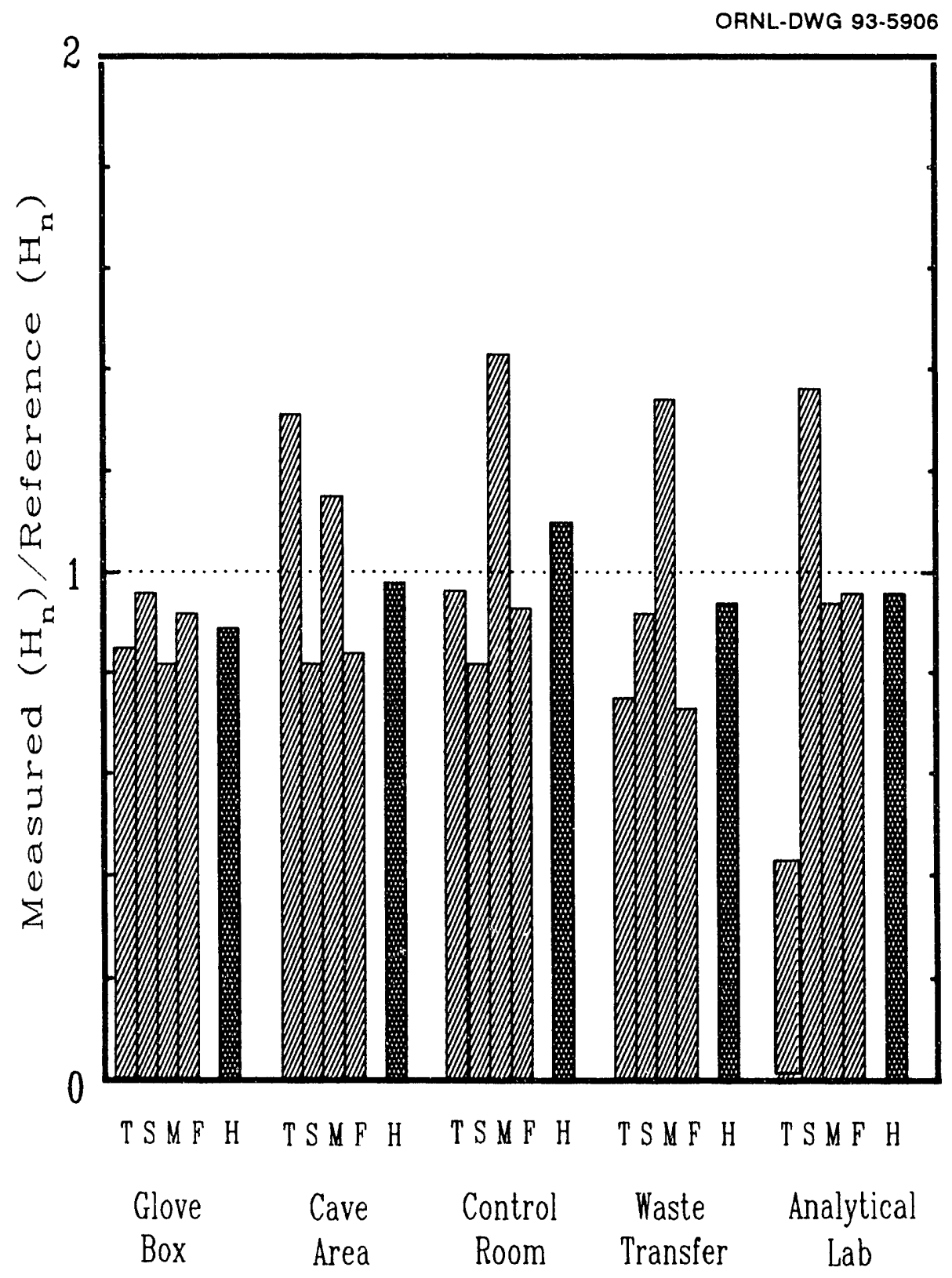

Fig. 3.4.1. The relative accuracy of the CPND to measure neutron dose equivalent $\left(\mathrm{H}_{\mathrm{Ea}}\right.$ and $\left.\mathrm{H}_{\mathrm{T}}\right)$ for $\mathrm{ORNL}$ in situ spectra at TRU. 


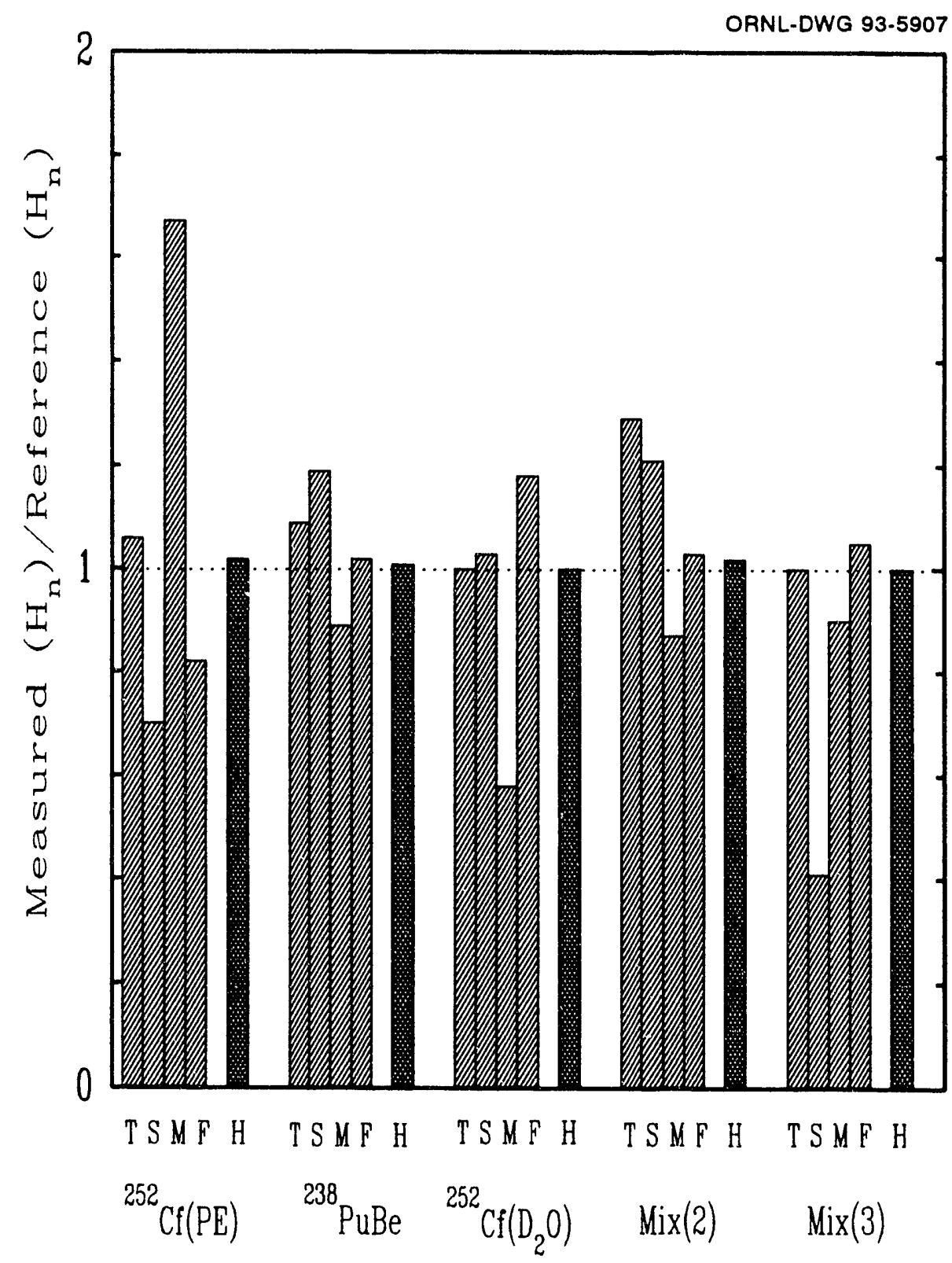

Fig. 3.4.2 The relative accuracy of the CPND to measure neutron dose equivalent $\left(H_{E}\right.$ and $\left.H_{T}\right)$ of RADCAL source spectra. 
Table 3.4.3. The individual bias and standard deviation of the modified CPND for the radioisotopic measurements

\begin{tabular}{rrrrrr}
\hline & ${ }^{252} \mathrm{Cf}(\mathrm{PE})$ & ${ }^{28} \mathrm{PuBe}$ & ${ }^{252} \mathrm{Cf}\left(\mathrm{D}_{2} 0\right)$ & $\mathrm{MIX}(2)$ & \multicolumn{1}{c}{$\mathrm{MIX}(3)$} \\
\hline $\mathrm{B}$ & 0.06 & 0.05 & -0.05 & 0.10 & -0.16 \\
$\mathrm{~S}$ & 0.42 & 0.13 & 0.26 & 0.19 & 0.29 \\
\hline
\end{tabular}

Table 3.4.4. The individual bias and standard deviation of the modified CPND for the in situ measurements

\begin{tabular}{rrrrrr}
\hline & GLOVE & CAVE & CNTRL & WASTE & \multicolumn{1}{c}{ LAB } \\
\hline B & -0.11 & 0.03 & 0.03 & -0.06 & -0.04 \\
S & 0.06 & 0.24 & 0.27 & 0.28 & 0.32 \\
\hline
\end{tabular}

These results reveal that enhanced spectral resolution was obtained, which produced an overall improvement in the dosimetric accuracy. The $L$ value calculated for each EI reveals an improvement in spectrometric performance for all EIs in both categories except for the fast in the radioisotopic category whe re the original performance was better by $1 \%$. We, therefore, conclude that the modified CPND demonstrated spectrometric and dose equivalent superiority over the original.

We will now take up a more philosophical venue as we survey some current assumptions about bubble detectors (such as useable lifetime, reproducibility, temperature affects and compensation methods, and theory of operation) and, in turn, offer some alternative explanations. We will also offer an explanation of bubble growth, bubble memory, and incompressible bubbles. 


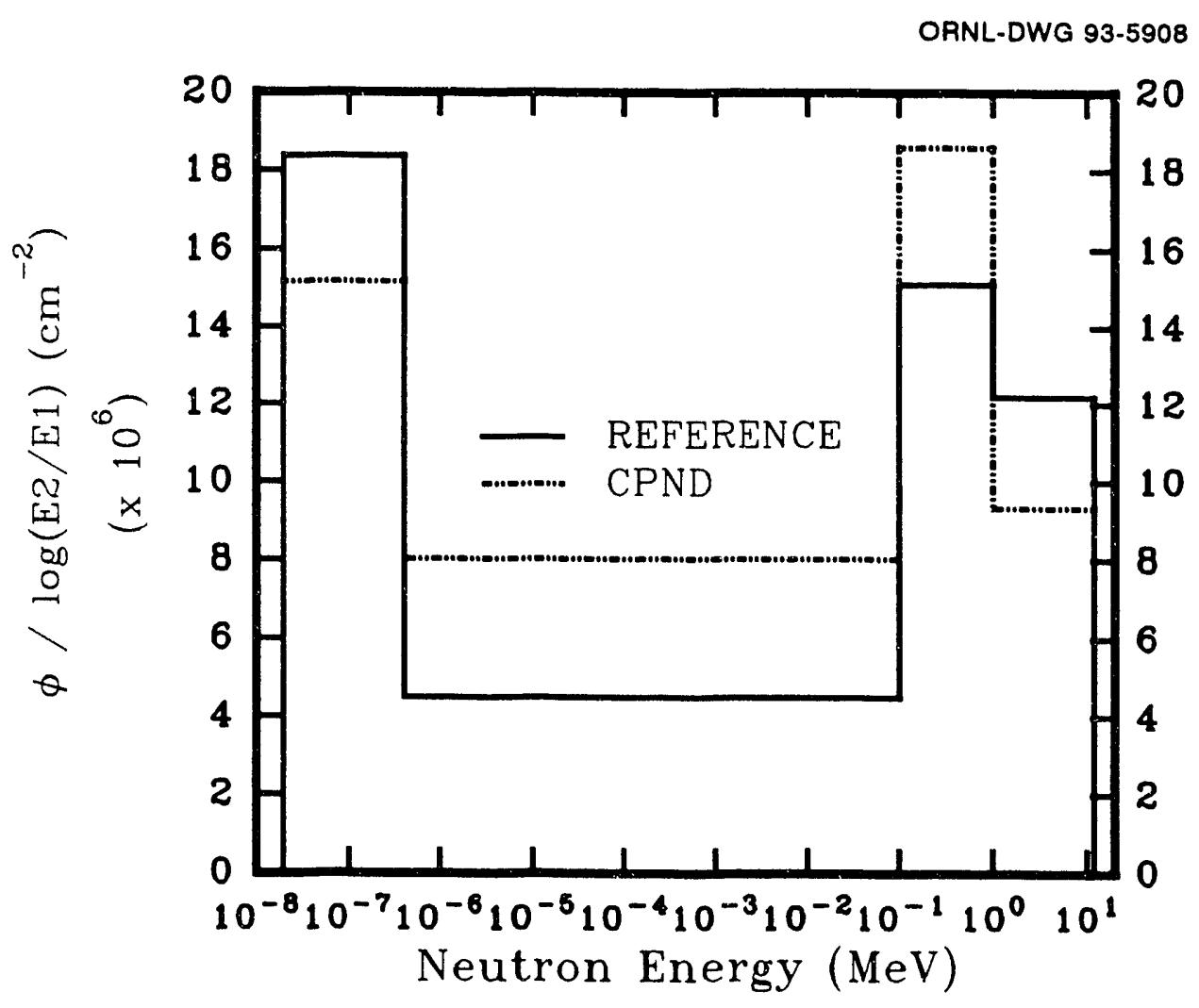

Fig. 3.4.3. Comparison of reference (BMS) and CPND measured spectra for the glove box at TRU. 


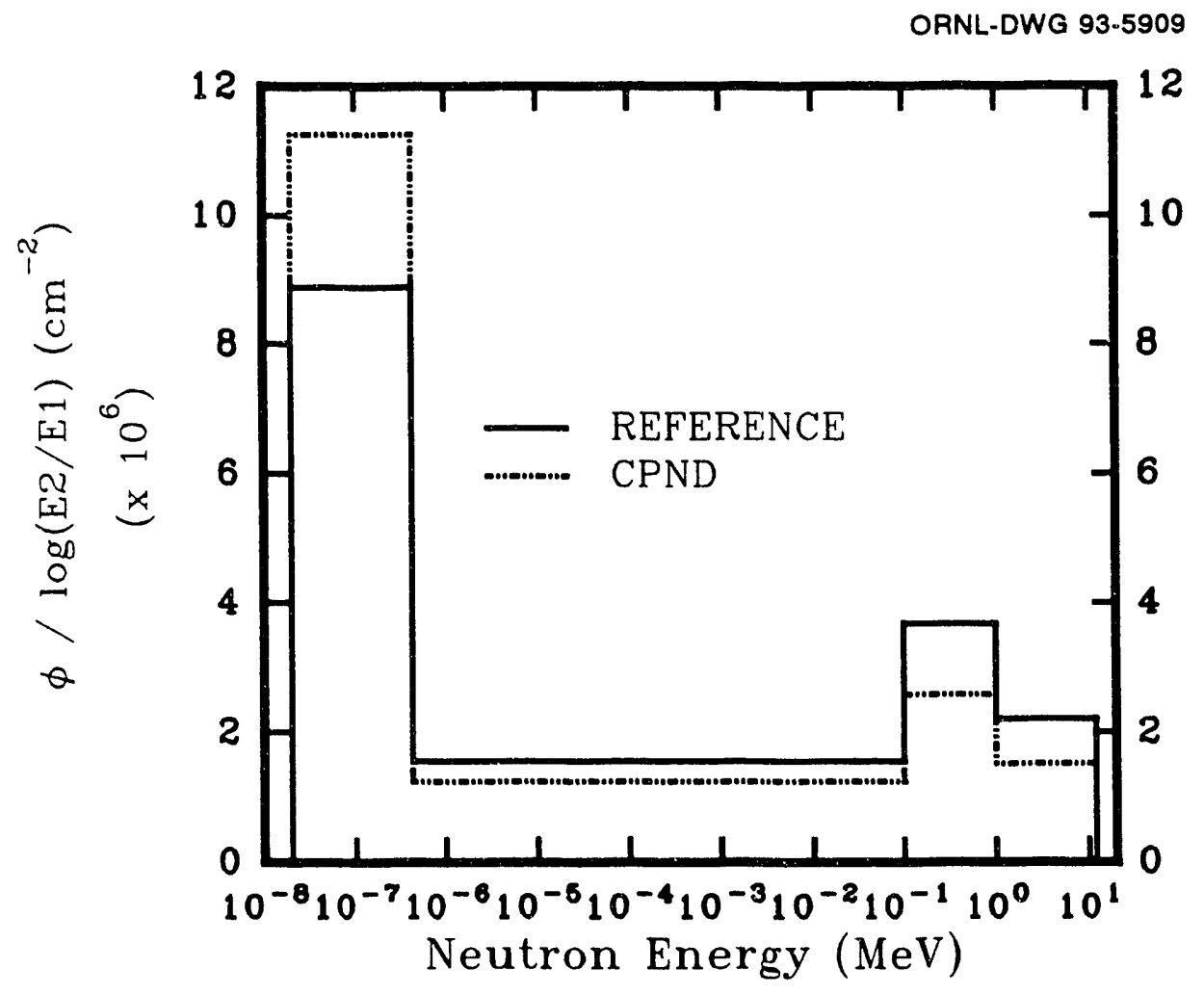

Fig. 3.4.4. Comparison of reference (BMS) and CPND measured spectra for the cave area at TRU. 


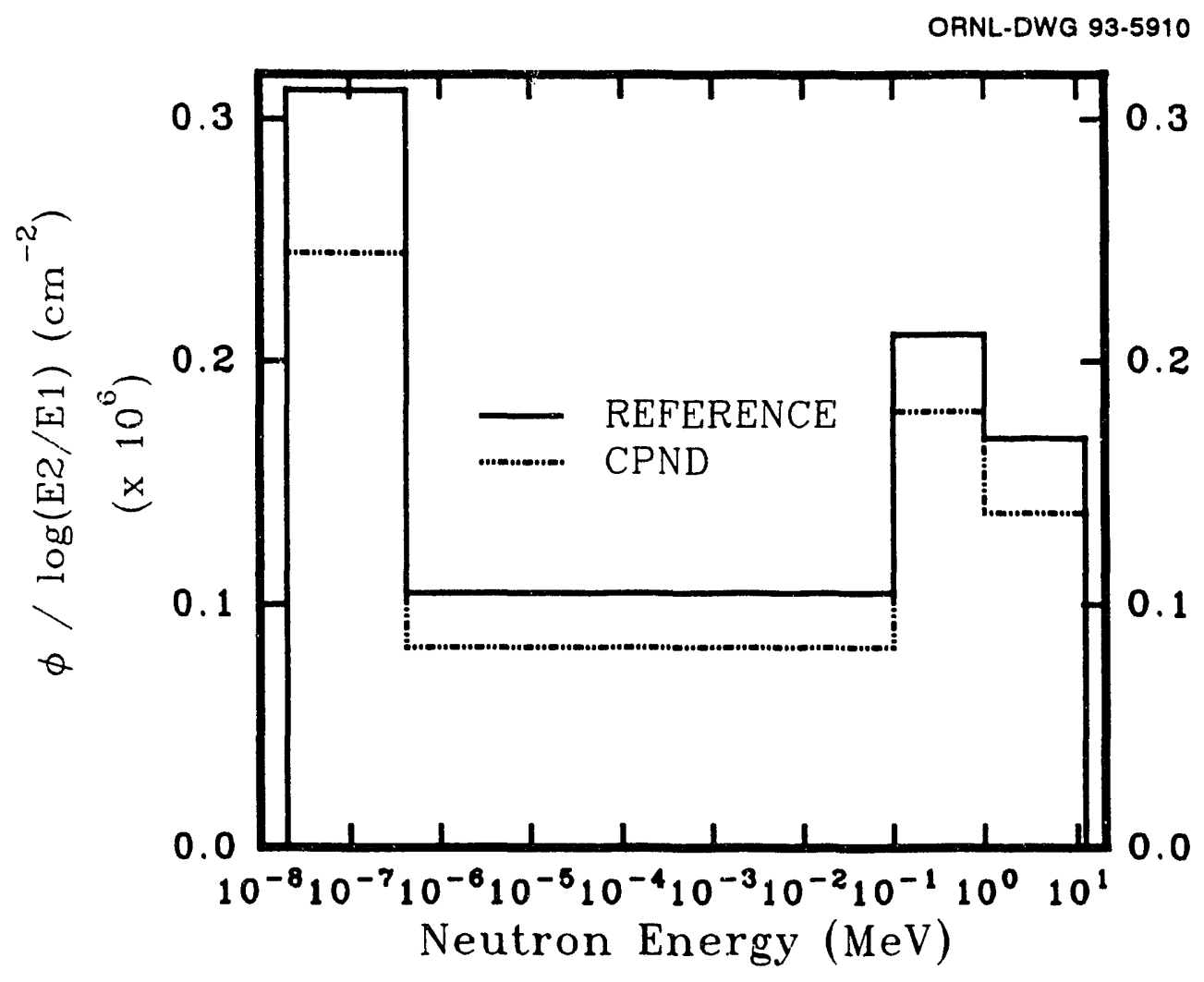

Fig. 3.4.5. Comparison of reference (BMS) and CPND measured spectra for the control room at TRU. 
ORNL-DWG 93-5911

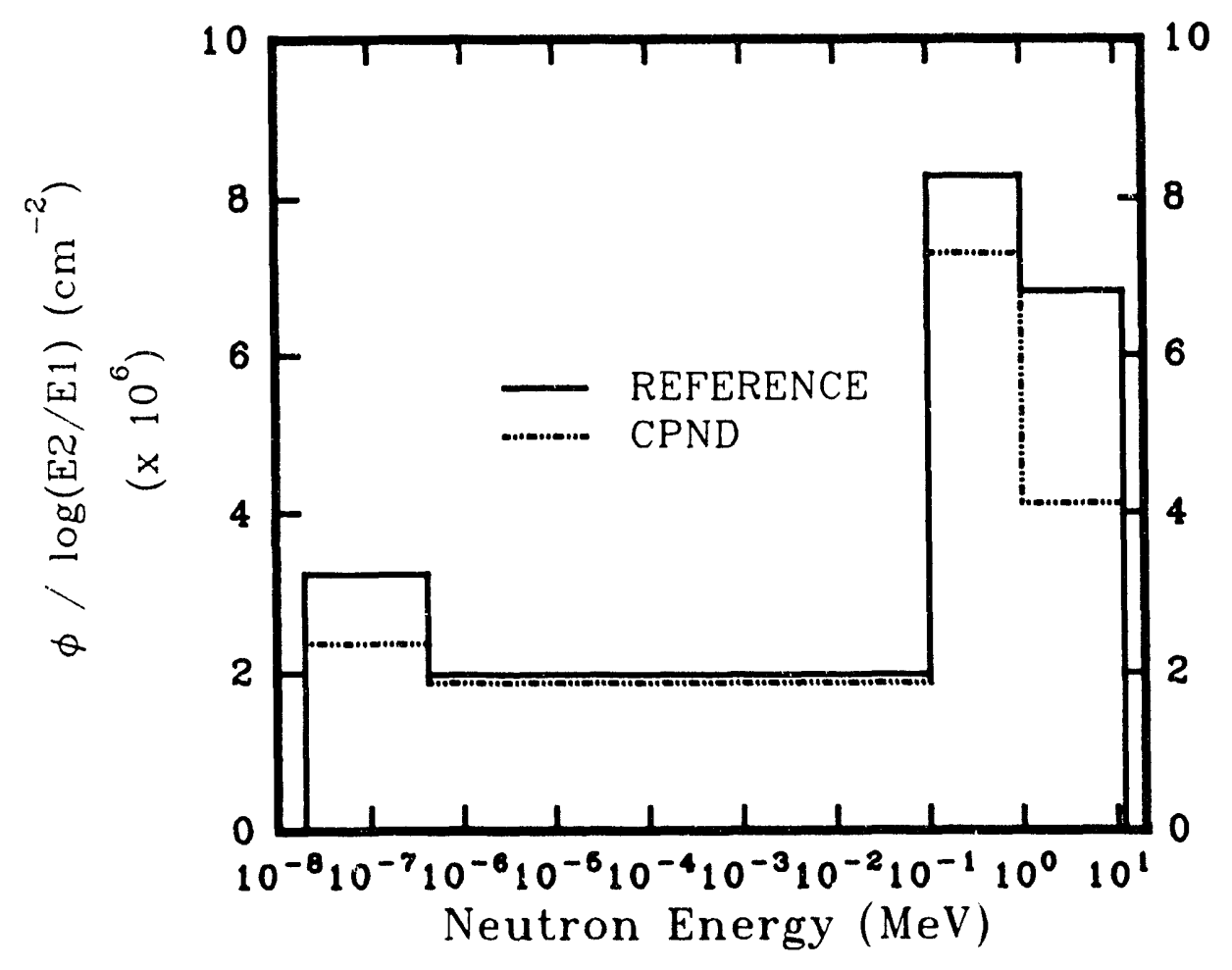

Fig. 3.4.6. Comparison of reference (BMS) and CPND measured spectra for the waste transfer area at TRU. 


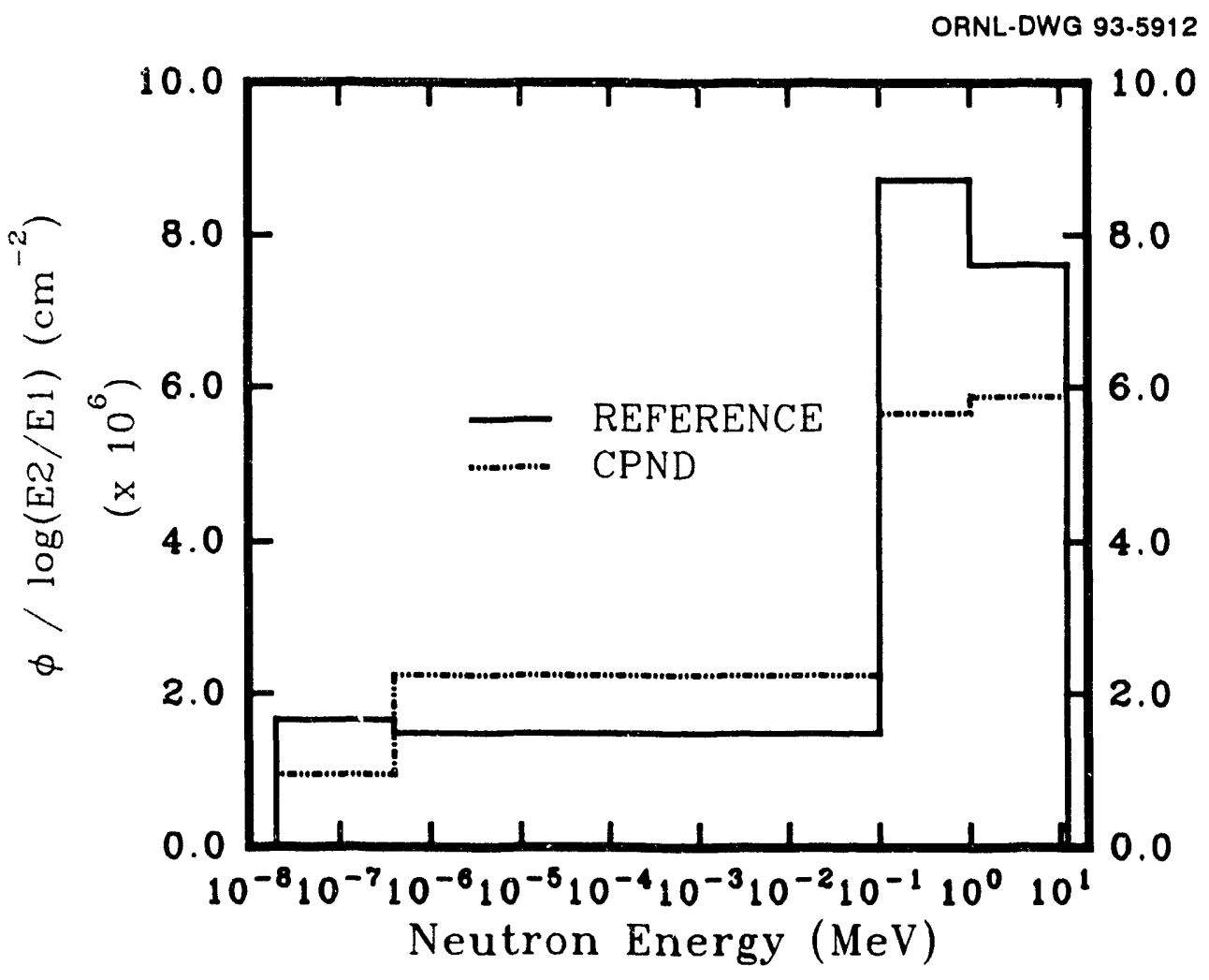

Fig. 3.4.7. Comparison of reference (BMS) and CPND measured spectra for the analytical lab at TRU. 
ORNL-DWG 93.5913

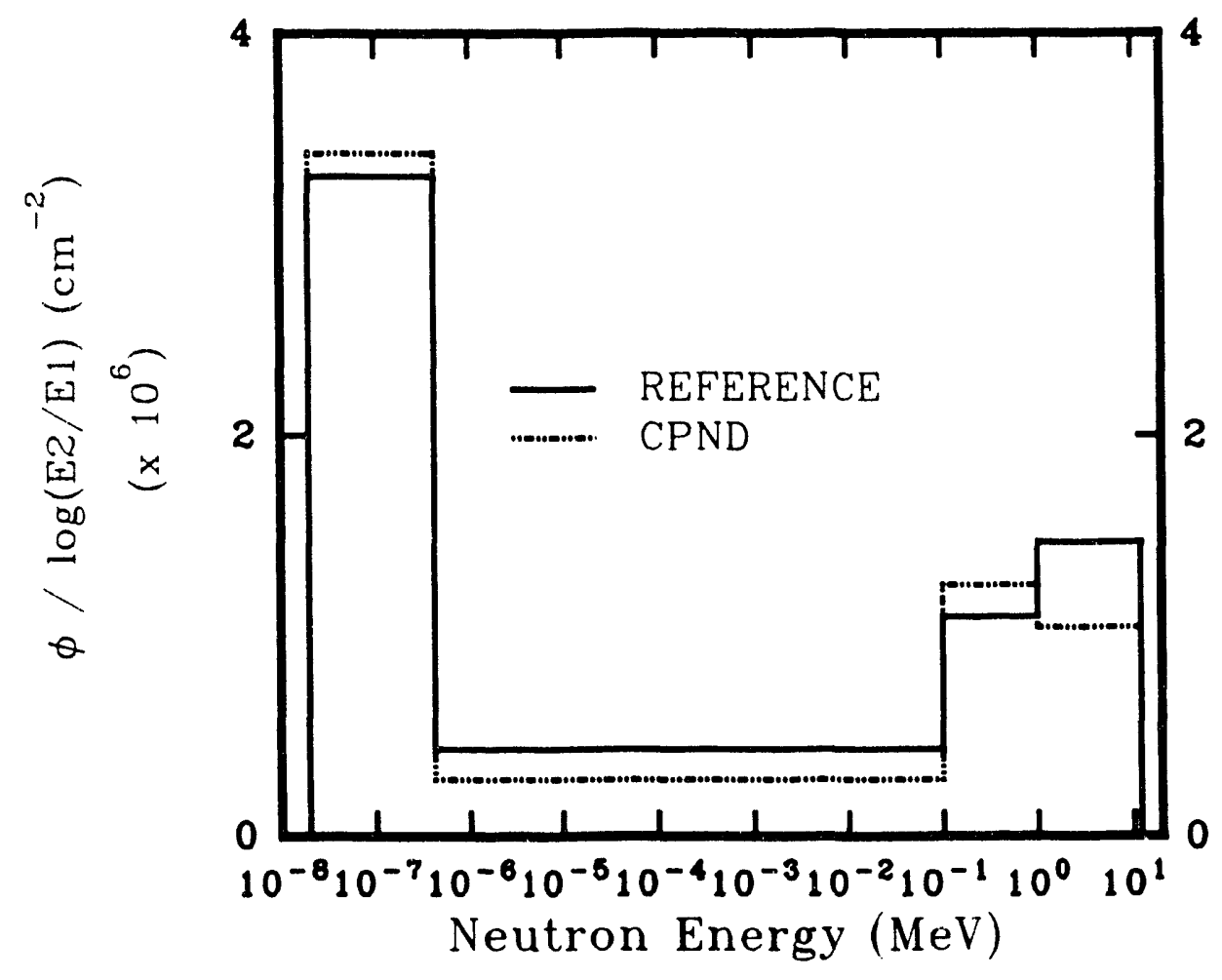

Fig. 3.4.8. Comparison of reference (BMS) and CPND measured spectra for the ${ }^{252} \mathrm{Cf}(\mathrm{PE})$ source at RADCAL. 


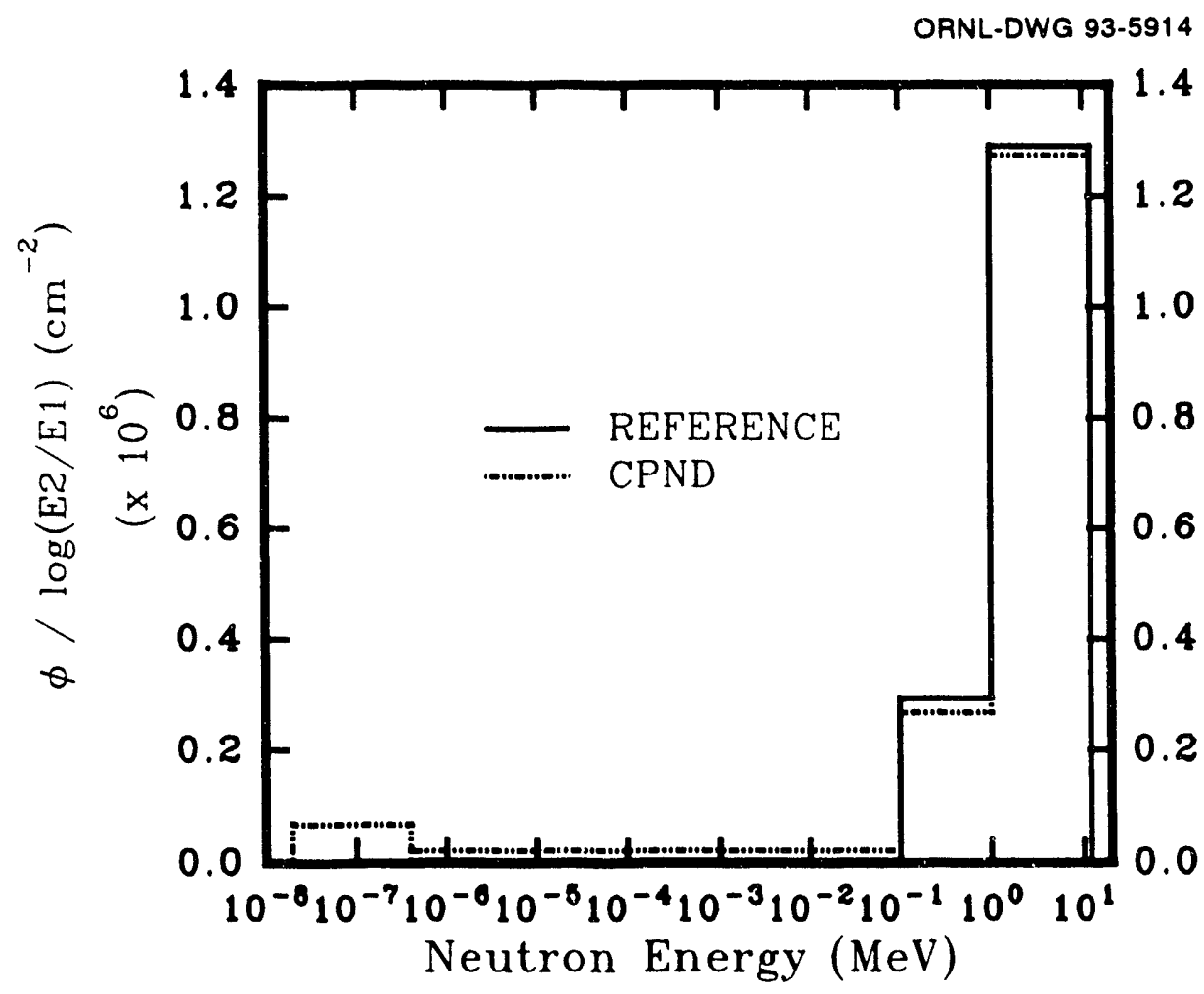

Fig. 3.4.9. Comparison of reference and CPND measured spectra for the ${ }^{23} \mathrm{PuBe}$ source at RADCAI. 


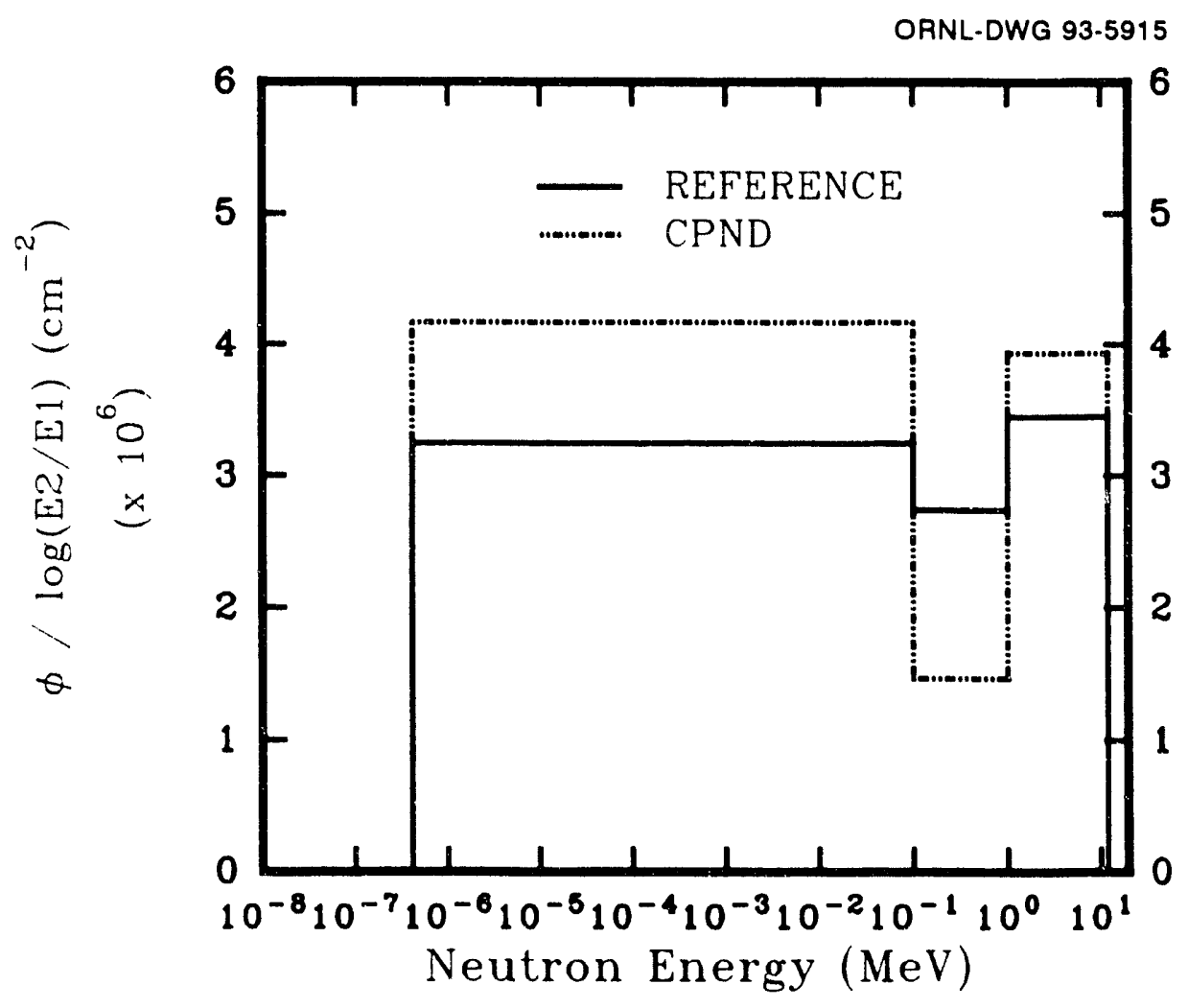

Fig. 3.4.10. Comparison of reference and CPND measured spectra for the ${ }^{252} \mathrm{Cf}\left(\mathrm{D}_{2} \mathrm{O}\right)$ source at RADCAL. 
ORNL-DWG 93.5916

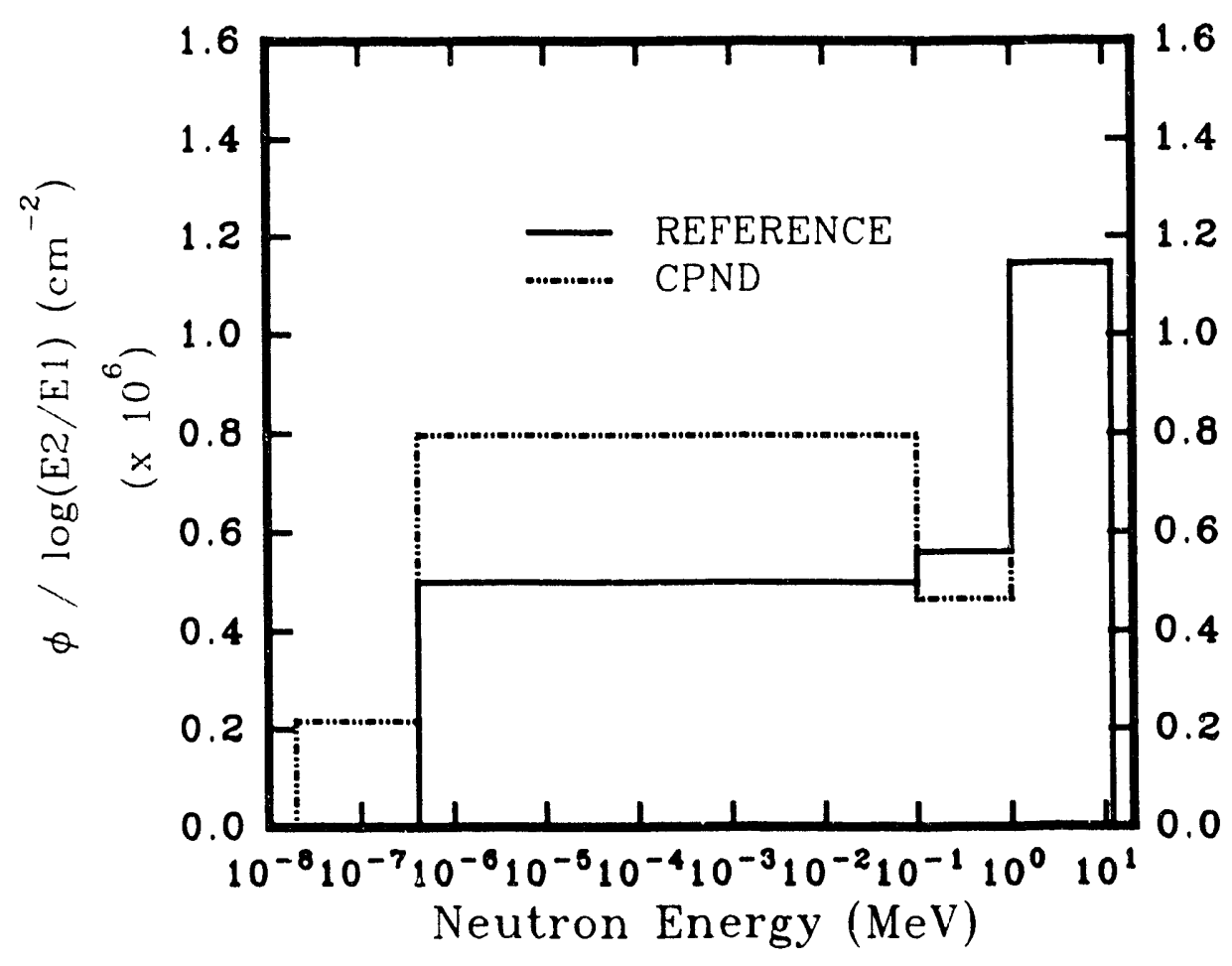

Fig. 3.4.11. Comparison of reference and CPND measured spectra for a mixture of two RADCAL sources: ${ }^{252} \mathrm{Cf}\left(\mathrm{D}_{2} \mathrm{O}\right)$ and ${ }^{238}$ PuBe [MIX(2)]. 


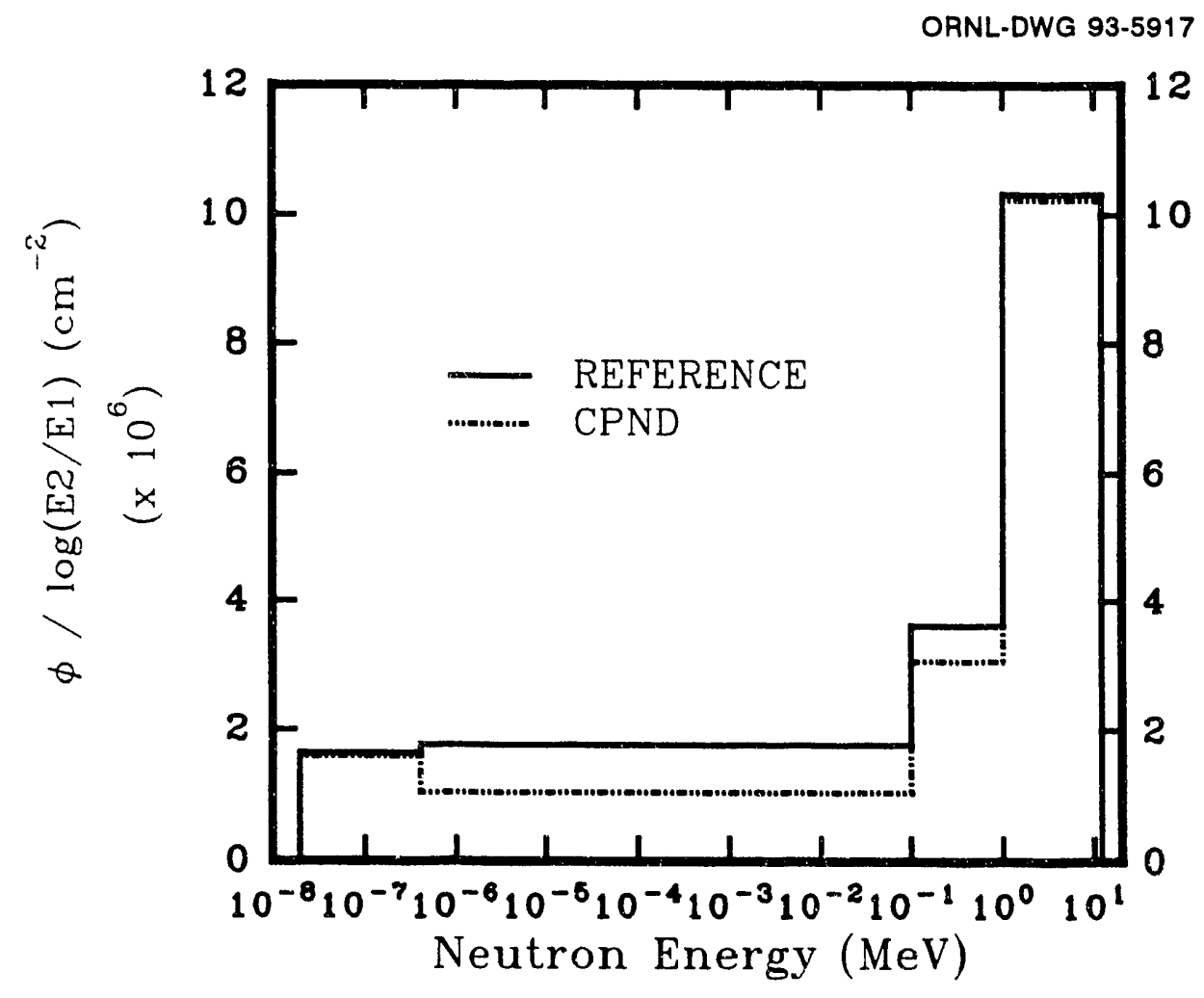

Fig. 3.4.12 Comparison of reference and CPND measured spectra for mixture of RADCAL sources: ${ }^{252} \mathrm{Cf}\left(\mathrm{D}_{2} \mathrm{O}\right),{ }^{252} \mathrm{Cf}(\mathrm{PE})$, and ${ }^{238} \mathrm{PuBe}[\mathrm{MTX}(3)]$. 
Table 3.4.5. The overall bias, standard deviation, and $L$ value of the modified CPND for the radioisotopic and in situ categories

\begin{tabular}{llllllll}
\hline & \multicolumn{3}{c}{ Radioisotopic } & & \multicolumn{3}{c}{ In situ } \\
\cline { 2 - 3 } \cline { 5 - 7 } & $\mathrm{B}$ & $\mathrm{S}$ & $\mathrm{L}$ & $\mathrm{B}$ & $\mathrm{S}$ & $\mathrm{L}$ \\
\hline $\mathrm{H}_{\mathrm{t}}$ & 0.09 & 0.12 & 0.21 & -0.11 & 0.27 & 0.38 \\
$\mathrm{H}_{\mathrm{s}}$ & -0.09 & 0.35 & 0.44 & -0.02 & 0.22 & 0.25 \\
$\mathrm{H}_{\mathrm{m}}$ & -0.02 & 0.40 & 0.42 & 1.14 & 0.25 & 0.40 \\
$\mathrm{H}_{\mathrm{f}}$ & 0.02 & 0.13 & 0.15 & -0.13 & 0.09 & 0.22 \\
\hline $\mathrm{H}_{\mathrm{T}}$ & 0.01 & 0.01 & 0.02 & -0.03 & 0.07 & 0.10 \\
\hline
\end{tabular}

Table 3.5.1. Comparison of the original and the modified overall performance indicators

\begin{tabular}{lccccccc}
\hline & \multicolumn{3}{c}{ Radioisotopic } & & \multicolumn{3}{c}{ In situ } \\
\cline { 2 - 6 } \cline { 5 - 7 } & $\mathrm{B}$ & $\mathrm{S}$ & $\mathrm{L}$ & $\mathrm{B}$ & $\mathrm{S}$ & $\mathrm{L}$ \\
\hline Original & 0.13 & 0.17 & 0.30 & 0.08 & 0.04 & 0.12 \\
Modified & 0.01 & 0.01 & 0.02 & -0.03 & 0.07 & 0.10 \\
\hline
\end{tabular}




\section{SOME CURRENT ASSUMPTIONS AND ALTERNATIVE EXPLANATIONS}

Investigative research and data analysis often unearth observations that are initially very curious and sometimes difficult, if not impossible, to explain by current paradigms. For the bubble detector, some of the more elusive items to explain have been

1. useable lifetime;

2. variations in the reproducible response of a detector observed by different investigators and sometimes even the same investigator;

3. temperature affects and compensation methods;

4. bubble formation, growth and memory;

5. incompressible bubbles; and

6. a theory accurately predicting bubble nucleation.

In reply, some theories are presented that attempt to explain some of these more "mysterious" phenomena and question some of the methodologies employed to either compensate, control, or explain them.

\subsection{USEABLE LIFETOME}

Studies have been conducted at the Naval Surface Warfare Center (NSWC) and ORNL with the goal of addressing the usable lifetime of the bubble detector. We will use this term loosely because of the complexity surrounding the issue. BTI claims a life span on the order of months before a noticeable decrease in sensitivity is encountered (Roy 1991). This life span presupposes a life style of moderation, i.e., recompression on a routine basis either daily or every other day. This is to minimize damage to the PAG caused by bubble growth (see Sect. 4.4). There seems to be a correlation between an appreciable decrease in sensitivity and the time from initial sensitization to recompression. This may be associated with diffusion of the SHL into the surrounding medium, which effectually reduces the number of potential nucleation sites, ergo, a reduction in sensitivity.

The preliminary results from the NSWC studies should be considered inconclusive because of the testing conditions. For the majority of the failing detectors, the time between initial sensitization and recompression exceeded the weekly cycle suggested by BTI: "a period of up to a week between recompression cycles is possible without noticeable sensitivity changes or incompressible bubbles" (Roy 1991). NSWC was hoping to find a means of extending the time between recompressions to accommodate an exchange cycle of at least a month. According to BTI it is possible to manufacture bubble detectors that will remain sensitive for this period of time, but there is a trade-off. The expense is loss of reusability due to accumulation of incompressible bubbles (Roy 1991).

\subsection{RESPONSE VARIATION}

Several of the bubble detector researchers have observed unexplainable variations in their resuits. These variations were characterized by larger than desired standard deviations and variances observed in repeated irradiations of a single detector and during testing of the 
same detector type. It is our belief that unless the bubbles in a detector are allowed to grow excessively (the effects of which will be addressed in Sect. 4.4.) the inherent reproducibility and stability of a bubble detector should be on the order of a few percent. It seems that the source of these variations may be attributable to the reader being used and the threshold selected for counting. The number of bubbles counted by the first generation readers is critically related to the threshold selected during image processing. The threshold determines how intense and large the light spot indicating a bubble must be before it is counted. The intensity and size of the light spot is also strongly dependent on the size of the bubble being imaged.

\subsection{TEMPERATURE EFFECTS AND COMPENSATION METHODS}

It is known that the response of a bubble detector, because of its composition, i.e., a SHL, is affected by temperature changes. So variations in ambient temperature create the potential problem of detector instability. This instability is exhibited as fluctuations in sensitivity that are proportional to the temperature variations; the greater the temperature variation, the poorer the confidence in the response of the detector. This is clearly not a problem if one is assured that the temperature in the working environment will remain constant or at least within a few degrees of the calibration temperature. But if the detector is to be used when temperature changes are expected or uncontrollable, achieving the highest level of accuracy requires some means of compensation. A plethora of compensation methods have been suggested. A select few are briefly described.

\subsubsection{How Temperature Affects Response}

Before we can consider the techniques of temperature compensation we must first understand how it is that a BD is affected by temperature. Keep in mind the effect of pressure and temperature on liquid-vapor phase change (Fig. 4.3.1).

Let us begin by stating that an increase in temperature brings about an increase in sensitivity in a two fold manner, by (1) lowering the threshold and (2) increasing the sensitivity above the threshold. This is attributable to the increase in the degree of superheat created by the increase in temperature. The more superheated the liquid, the smaller the $r_{c}$. Therefore, neutrons previously incapable of producing a thermodynamically unstable seed bubble (those just below the threshold energy) could now contribute to bubble formation. An equivalent fluence of neutrons above the initial "inhibition energy" or threshold, will produce a greater number of bubbles than they would have produced at a lower temperature. This phenomenon, if ignored, will transform the original detector into a variable "Jekyll and Hyde." This new beast possesses an $R(E)$ which differs from the original creature. This alteration of the $R(E)$ will also mean that the temperature effect is energy dependent. In other words, the increase in response as a function of temperature will vary from spectrum to spectrum. 


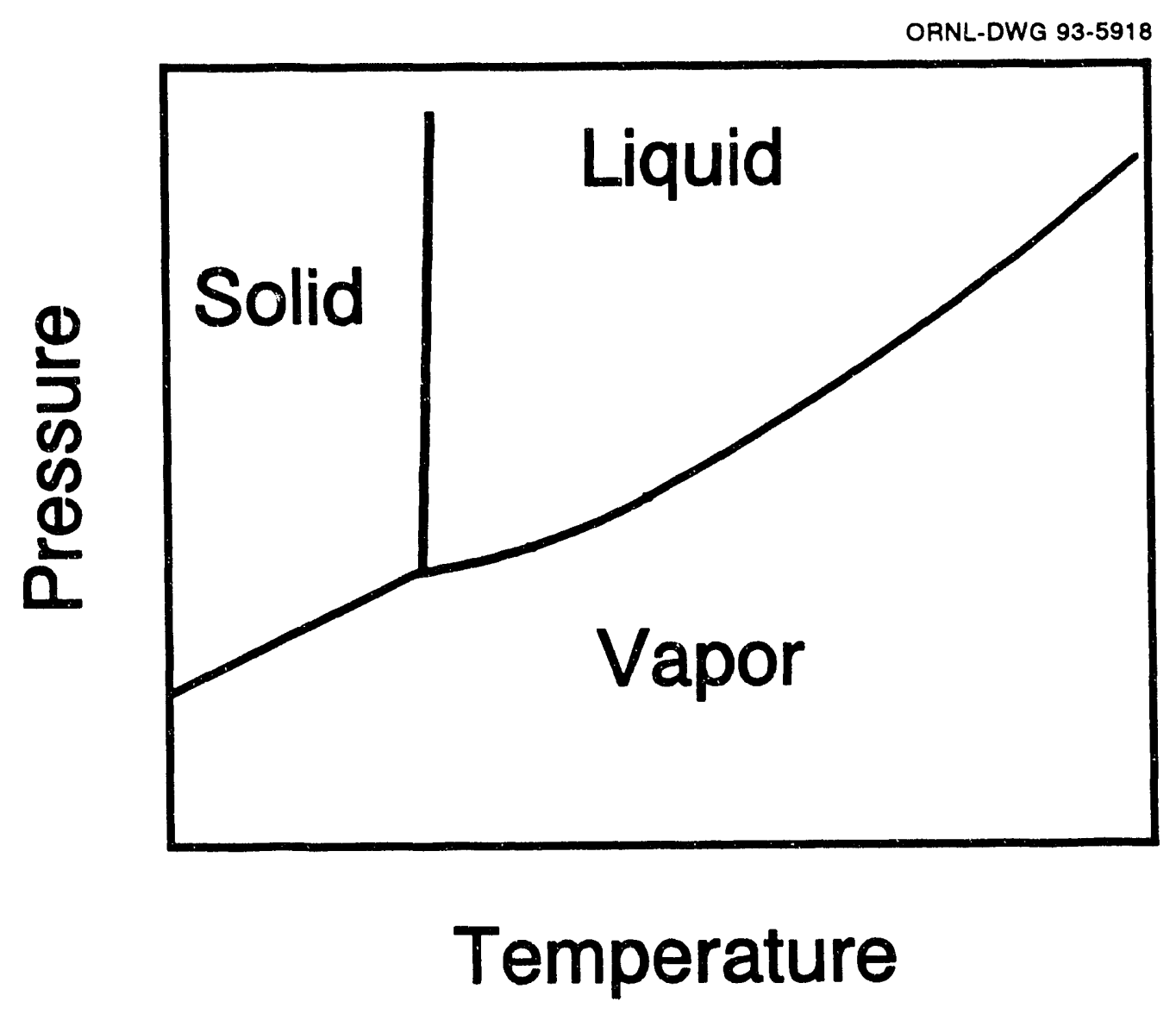

Fig. 4.3.1. Phase diagram in the T,P plane. 
An analogy may better illustrate the sensitivity changes brought about by a change in temperature. Consider the home run hitting abilities of a baseball team when playing at home (a function of the average distance the player can hit the ball and the distance to the fence). If we assume the pitcher to be a constant in this analogy, then the frequency of home runs for the team when playing away would be expected to increase when playing an opponent whose home field was smaller, i.e., a shorter distance to the fence. Those players who would just miss hitting it out at home would be more likely to hit one out on the smaller field, while the number of home runs hit by those players normally hitting it out at home would increase only slightly. This makes sense for bubble detectors if we consider the normal home run hitters in our analogy to be representative of the neutrons above the threshold, those with a high probability of producing a bubble at the calibration temperature; the occasional home run hitters as neutrons just below the threshold, while still capable of occasionally causing a bubble to form, the probability of doing so is much lower; and the distance to the fence as the $r_{c}$. Increasing the temperature has the same effect on bubble formation as does playing on a field with a shorter distance to the fence: the $r_{c}$ becomes smaller. Those neutrons only occasionally causing a bubble to form at the calibration temperature (or at home) do so more often (with a much higher probability) at a higher temperature (on a shorter field). A decrease in sensitivity would be expected if the temperature were decreased: analogous to playing on a field with a greater distance to the fence.

\subsubsection{Pressure Compensation}

Presently BTI is employing a means of compensation that attempts to compensate for both of the known culprits responsible for temperature-induced response variation. Maintaining a state of equilibrium between the internal vapor pressure of the SHL droplet and the external pressure, a combination of the PAG and atmospheric pressure, is the key to their compensation model. A reservoir of material that expands and contracts with changes in temperature is attached to the detector, and by utilization of an appropriate mechanical advantage, the pressure within the detector remains virtually constant as the temperature changes. The external pressure applied to the detector is proportional to the combined changes of increased vapor pressure and reduced surface tension experienced by the superheated droplet (Ing 1991). This method of pressure compensation is intended to maintain the SHL at a constant state of superheat, effectively "freezing" the $R(E)$ regardless of the ambient temperature.

\subsubsection{Environmental Control}

Another approach is to control the temperature environment in which the bubble detector is operated. This could be achieved via a small heat pump type device. The device would provide the cooling or heating required to maintain the device at a preset temperature. Currently BTI is working on a small box type device, containing a "heat-disk," to maintain the temperature near normal body temperature (Roy 1991).

\subsubsection{Computational Compensation}

An alternative to mechanical compensation or environmental control would be to maintain a parallel record of the cumulative response and temperature. This would allow correction of the results by application of derived temperature correction factors. This 
assumes either short intervals of time between readouts and cognizance of the temperature during bubble formation or a historical record correlating bubble formation and temperature. The frequent reading cycle is impractical for most applications, but a parallel real-time detection and temperature logging technique is currently under development at DOSAR.

The first step in the procedure will be to determine the $R(E)$ at a specified calibration temperature, i.e., $25^{\circ} \mathrm{C}$. The best possible method of determining the correlation of temperature and energy would be to maintain one variable constant while varying the other. A new investigation is being proposed to assess the temperature effect on response by performing a series of monoenergetic irradiations while precisely controlling the temperature of the detectors. In this manner the effect of temperature on the $R(E)$ will be determined, i.e., the change in sensitivity at a specific energy as a function of temperature, $\Delta R(E) d T$. This work promises to make significant inroads toward a better understanding of $\mathrm{BD}$ response characteristics.

Next, the $R(E)$ of each component is segmented into a number of defined EIs with the sensitivity for each $\mathrm{EI}[\mathrm{R}(\mathrm{EI})]$, taken to be the average sensitivity, in bu- $\mathrm{cm}^{2}$, in that region. The effective change in sensitivity per ${ }^{\circ} \mathrm{C}$ for each interval will be assessed from the data. Translated, instead of applying a single temperature correction for the change in sensitivity over the entire $R(E)$ (the equivalent of assuming the shape of the $R(E)$ is constant and only the amplitude or sensitivity changes, which we have seen is an incorrect assumption), we will correct for the temperature effects by reestablishing the shape of the $R(E)$ to reflect what the $R(E)$ would be at the irradiation temperature. Because the total response of a BD is a function of the $R(E)$ and the spectrum, and changes in temperature bring about changes in the $R(E)$, to correctly compensate for the temperature-induced changes in $R(E)$, a temperature correction factor will be necessary for each spectrum. Temperature corrections derived for one source will not necessarily be applicable to a different source unless the spectra are similar.

\subsubsection{Heat Induced Alteration}

One other approach may provide a viable option. Because an increase in temperature effectively increases the superheat of a $B D$ (shifting the $R(E)$ threshold downward in energy) and because we desire a detector whose $R(E)$ approximates $h_{\psi}$, heating a BD with a higher threshold could shift the threshold down to create a detector with a near dose equivalent response. For example, maintaining a BDS-2500 at a temperature predetermined to achieve the desired threshold shift would eliminate any variation in response associated with temperature fluctuations below the set-point temperature.

\subsection{BUBBLE FORMATION, GROWTH, AND MEMORY}

A normal bubble "life cycle" is characterized by the progression: droplet $\rightarrow$ formation $\rightarrow$ growth $\rightarrow$ recompression $\rightarrow$ droplet. Figure 4.4.1. depicts this life cycle. Cognizance of this progression may afford insight to our understanding of such phenomena as changes in sensitivity, bubble growth, bubble memory (the apparent reformation of the 
ORNL-DWG $93-5919$
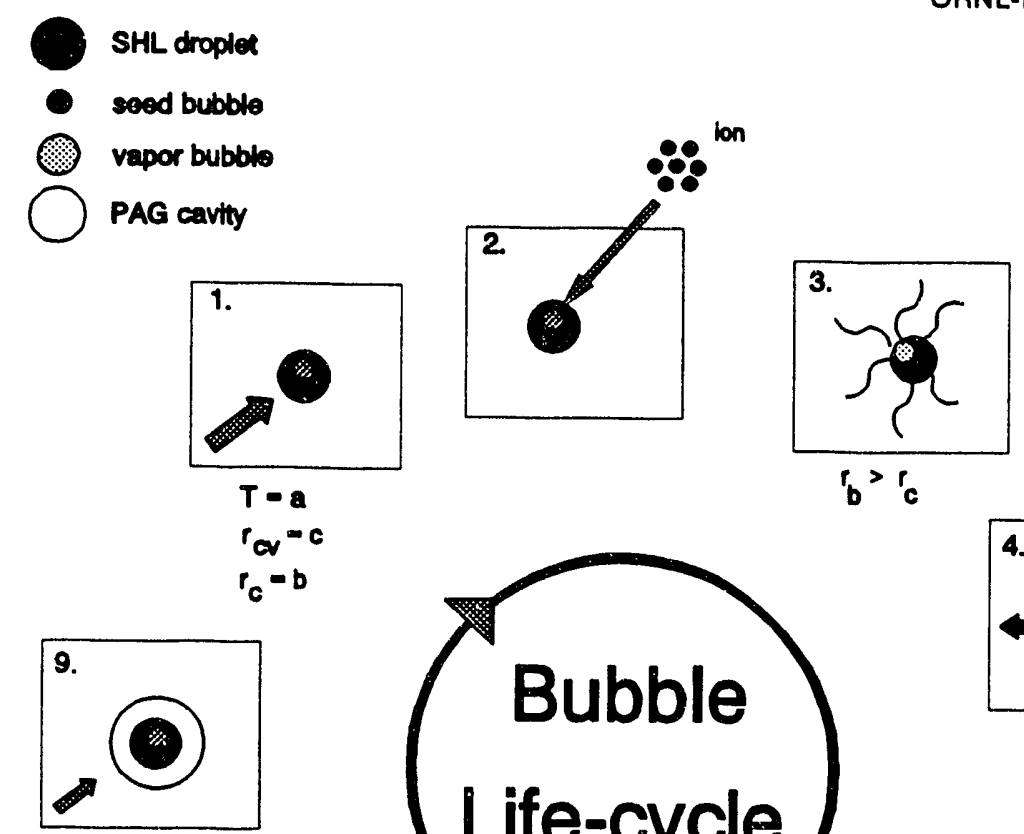

$T-a^{\prime}<a$

$\mathrm{CO}^{-}-\mathrm{c}^{\prime}>c$

$r_{c}=b^{\prime}<b$
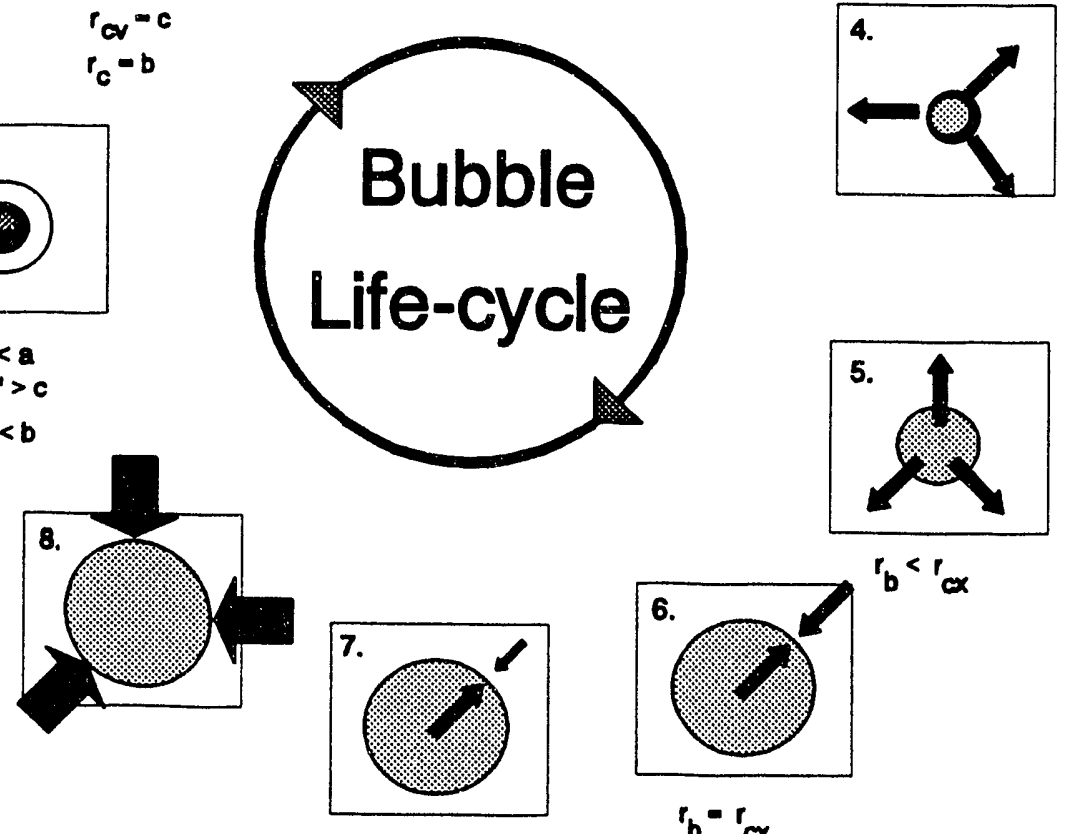

$r_{b}>r_{c x}-r_{f x}$

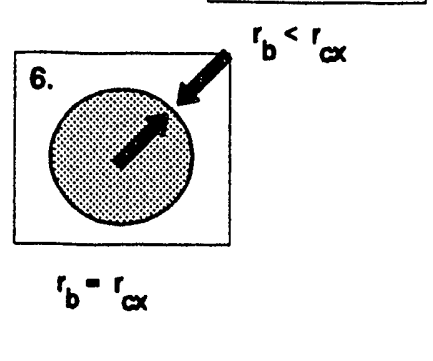

Fig. 4.4.1. The life-cycle of a bubble. 
same bubble time and time again), and incompressible bubbles. A narrative of this progression is presented, and some inferences and explanations for the observed phenomena are provided.

\subsubsection{Bubble Formation}

An in-depth description of the currently accepted theory explaining the metamorphosis from incident neutron to bubble is available in the literature (Apfel, Roy, and Lo 1987; Lo 1987). The most recent is offered in the Ph.D. dissertation of Dr. Mark Harper of the U. S. Naval Academy (Harper 1991). In Apfel's model, I assume, the surface tension of the holding medium is assumed to be equivalent to that of the SHL, i.e., similar to Glaser's bubble chamber where the entire volume is the SHL (the reason tracks are produced instead of a single bubble in the bubble chamber). Though this may be the case in the SDD, it is certainly not valid during all the stages of bubble formation for the BTI detector. $P_{o}$ for the BTI detector is the summation of the atmospheric pressure transferred through the medium, the surface tension of the noncompressible liquid, and the force exerted on it by the PAG or "firm...polymer" (Ing and Birnboim 1984). It is my belief that the PAG component of $\mathrm{P}_{0}\left(\mathrm{P}_{\mathrm{PAG}}\right)$ plays a greater or lesser role in the total $\mathrm{P}_{0}$ depending upon the present stage expansion or recompression phases. This change is effected by the elasticity and tensile properties of the PAG as it expands and contracts. Because the radius of the seed bubble is much smaller than the SHL droplet during the formation phase, the $\mathrm{P}_{\mathrm{PAG}}$ is negligible and the surface tension of the SHL is the dominate factor. The $P_{\mathrm{PAG}}$ becomes significant once the droplet is consumed and the bubble begins to grow and stretch the PAG.

\subsubsection{Bubble Growth}

At the risk of oversimplification, we will quickly describe the stages depicted in Fig. 4.4.1., and then offer an explanation of these by way of analogy. Frame 1 describes the condition of a virgin SHL droplet, where $P_{P A G}$ is determined by the PAG tension, $T=a$, and the PAG cavity, i.e., the void in the PAG which the droplet occupies (a result of polymerization) with a radius, $r_{c v}=c$. At this point $r_{c v}$ is equal to the droplet radius, $r_{d}$. When ions created by an impinging neutron deposit energy within a potential seed bubble, that bubble will begin to grow. Many interactions may occur which produce a seed bubble that does not expand beyond $r_{c}$. These bubbles collapse or recondense (frame 2). But once a seed bubble expands to $r_{c}$ it will violently boil consuming the entire droplet (frame 3 ). The bubble will continue to grow (frames 4 and 5) until an equilibrium pressure is reached between the internal vapor pressure and the external pressure now primarily from atmospheric pressure, $P_{2}$, and $P_{P A G}$. The bubble will continue to grow as the PAG stretches (frame 6). Growth of the bubble beyond a certain point will result in damage and consequent loss of tension in the PAG. The radius at which this begins to occur is defined as the critical expansion radius $r_{c x}$ At some point the bubble is recompressed by application of external pressure, typically hydrostatic (frame 8). After the recompression pressure is released, though the bubble is recondensed, the $r_{c v}$ and $r_{c}$ have been altered due to a loss of tension in the PAG caused by excessive expansion of the bubble. A bubble that is allowed to expanded beyond a $r_{c x}$ will eventually exceed a radius defined as the critical formation radius, $r_{f x}$ (frame 7 ). This bubble, although recompressed, will no longer remain recompressed once the applied pressure is removed. Let us now attempt to explain what is happening by way of analogy. 
The loss of tension in the PAG may be compared to what occurs when inflating a balloon. For the sake of comparison we will subdivide the inflation of the balloon into three stages. The primary stage is characterized by a small radius and slow expansion. At this stage a significant amount of pressure is required to inflate the balloon (frames 3 and 4). The secondary stage is characterized by a sudden expansion of the balloon, a constantly increasing radius, and a noticeable decrease in the pressure required to continue inflating (frames $5 \& 6$ ). The tertiary stage, is characterized by a large radius and slow expansion rate (frame 7). This is the point where you blow and blow and the balloon barely enlarges. This last stage is also the point just before the balloon ruptures. Deflating the balloon is analogous to recompression. The transition from the primary to the secondary stage is marked by a sudden increase in the expansion of the balloon and a marked decrease in the pressure required to maintain growth. Because the PAG is elastic, once an initial pressure equilibrium is established, any growth beyond this $r_{b}$ will constitute a loss in the elasticity of the PAG. It is at this point that the $r_{b}$ has exceed $r_{c x}$ Once the transition is made from the secondary to the tertiary stage, a significant loss in elasticity occurs. This is the point at which the $r_{f x}$ is exceeded.

\subsubsection{Bubble Memory}

Bubble memory is manifested as the reappearance or reformation of the same bubble or bubbles nearly every irradiation. At first glance such reappearance would seem particularly odd when one considers that among the thousands of droplets in a single detector, each possessing an equally likely probability for formation, and that these same bubble continue to reform with nearly $100 \%$ probability. Let us return to the balloon analogy in order to offer an explanation for bubble memory.

Consider inflating and deflating a single large balloon. Observe the tension of the balloon after it is deflated each time and notice that this tension is directly proportional to the pressure required to inflate the balloon each subsequent time. If the balloon is inflated only slightly for a repetitive number of times, the amount of pressure required to inflate it each successive time is nearly equal, and it is only slightly less, if less at all. Therefore we may conclude that the tension loss associated with expansion to this radius is practically inconsequential. This is analogous to a bubble that obtains initial pressure equilibrium. However, the larger the balloon is inflated, the easier it is to inflate the next time, and we deduce the greater the radius, the greater the tension loss. There exists a radius which, if exceeded, results in a substantial tension loss experienced by the balloon. This radius is defined as the critical expansion radius, $r_{c x}$

Now turning to the formation of bubbles. Prior to formation, the liquid droplet (i.e., the condensed vapor bubble) possess a finite radius, $r_{d}$, and the PAG immediately bounding the droplet can be conceived of as a cavity with radius $r_{c v}$ which, prior to formation, is equal to $r_{d}$. After the bubble expands beyond $r_{c x}$ it can be recompressed and condensed to a droplet with radius $r_{d}$, but the PAG in exceeding the $r_{c x}$ has lost a substantial fraction of its tension. Therefore, when the pressure used to recompress the detector is released, the PAG cavity will no longer maintain its original radius. Consequentially, the new radius of the PAG cavity will be greater than the original $r_{c r}$ This increase in the cavity radius is proportional to the tension loss due to expansion beyond $r_{c x}$ 
Because the $r_{c v}$ is increased, i.e., the volume of the cavity containing the droplet is larger, part of the droplet passes to the vapor state, which increases the vapor pressure in the cavity effectively increasing the degree of superheat of the droplet and decreasing the $r_{c}$. Therefore, less energy is required to induce formation. This will mean that the bubble will possess a greater probability of formation and thus form "sooner" in the dose history, i.e., dose as a function of time (which for all practical purposes should be a linear function). A healthy detector should exhibit a linear increase in the number of bubbles formed as the neutron dose equivalent increases. A detector containing bubbles that have exceeded $r_{c x}$ will manifest a sudden increase in sensitivity early in the dose history. Figure 4.4.2 depicts the correlation of bubbles and dose graphically for a normal or healthy bubble detector (one which has been recompressed before any bubbles exceeded $r_{c x}$ ) and a detector possessing a number of bubbles that have exceed $r_{c x}$. This implies that an overresponse will be more significant when measuring lower doses. For a theoretical example consider the responses of two BD-100Rs originally possessing sensitivities of $10 \mathrm{bu}$ per $0.01 \mathrm{mSv}$, and 1 bubble per $0.01 \mathrm{mSv}$, respectively, before and after they develop 3 bubbles exceeding $r_{c x}$ The results are presented in Table 4.4.1. This suggests that the bubble memory phenomena will have a greater impact on the accuracy when measuring low doses and when encountered in lower sensitivity detectors.

One possible method of reducing the memory problem, other than administratively controlling the size of the bubbles before recompression, would be to nucleate all bubble sites and allow them to grow to the desired size prior to application for measurement purposes. The success of this approach could be empirically verified by repeated irradiations of two sets of detectors, one having all of its droplets nucleated prior to the study and the other comprised of virgin detectors. The nucleation of all the sites for the first set is achievable by placing the detector in a hot water bath. The results from a preliminary study of this theory are currently inconclusive.

\subsubsection{Bubble Incompressibility}

In order to understand bubbles that appear to be incompressible, let us once again turn to the balloon analogy. Consider the condition of the deflated balloon once it is inflated to the brink of rupture, i.e., exceeding $r_{f x}$ Once this is done, very little pressure is necessary to inflate it to the same point again. Thus, most of the original tension, which affected the rate of expansion of the bubble, or the balloon in our analogy, is expiated. This can be seen by comparing our deflated balloon to either one that has never been inflated or to one that has not been inflated beyond the $r_{c r}$ The overinflated balloon will be limp in comparison and significantly larger than either of the other two.

The analog to this in the realm of bubble formation would be a bubble that has expanded to the brink of rupturing the polymer or beyond and is then recompressed. If the $r_{c v}$ after recompression is proportional to the tension loss from excessive expansion as observed in the balloon analogy, it can be inferred that the greater the $r_{b}$ the greater the degree of superheat of the successive droplet. Once the $r_{b}$ exceeds $r_{f x}$ the successive droplet will find itself in a PAG with a $r_{c v}$ so large that the superheat of the droplet is sufficient to spawn spontaneous formation of the bubble. The net effect of this immediate spontaneous formation will be an "as-if" appearance of an incompressible bubble. Figure 4.4.3 depicts the tension lost by the PAG as the $r_{b}$ increases. 


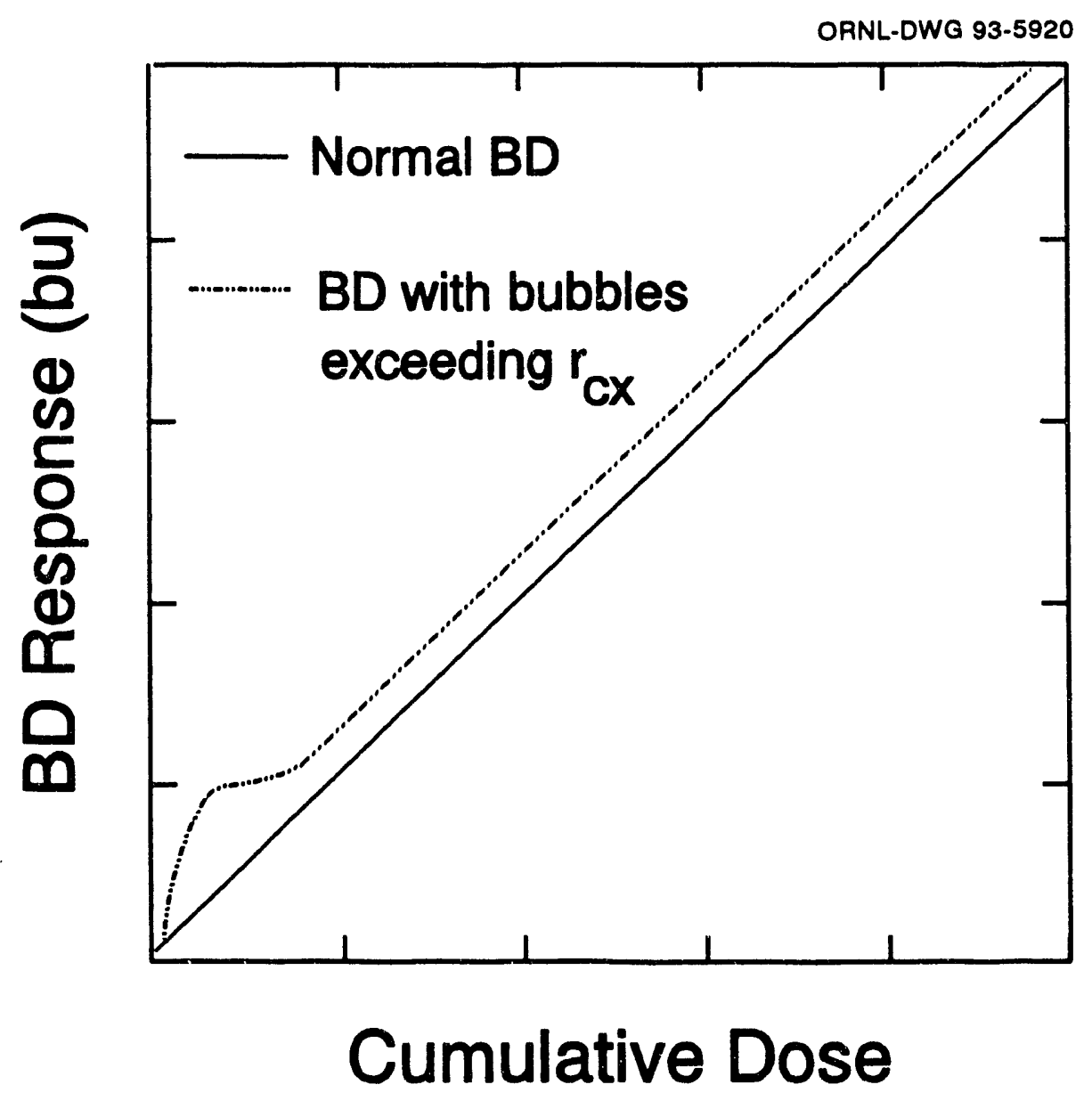

Fig. 4.4.2 Correlative record of BD response and cumulative dose for a normal BD and one which contains bubbles that have exceeded the $\mathbf{r}_{\boldsymbol{c}}$ 
Table 4.4.1. Theoretical response of two bubble detectors before and after acquiring three bubbles exceeding $r_{a}$

\begin{tabular}{ccccccc}
\hline \multirow{2}{*}{$\begin{array}{c}\text { Initial Sensitivity } \\
\text { (bu per 0.01 mSv) }\end{array}$} & \multicolumn{2}{c}{ Response to $0.01 \mathrm{mSv}$} & & \multicolumn{2}{c}{ Response to $0.1 \mathrm{mSv}$} \\
\cline { 2 - 3 } & Before & After & & Before & After \\
\hline 1 & 1 & 3 & & 10 & 13 \\
10 & 10 & 13 & & 100 & 103 \\
\hline
\end{tabular}

ORNL-DWG 93.5921

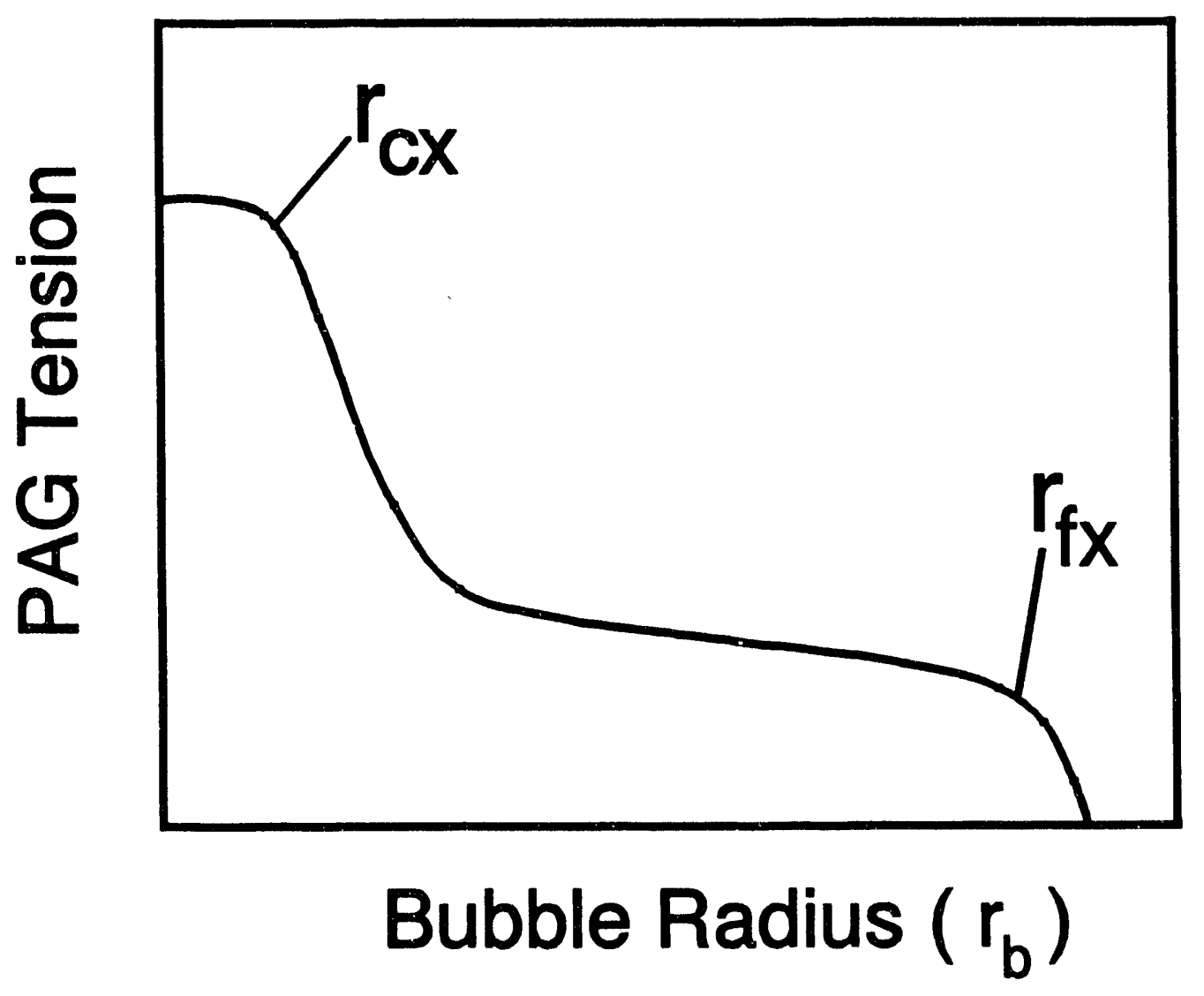

Fig. 4.4.3. PAG tension loss as a function of bubble growth. 


\section{FUTURE DIRECTIONS AND APPLICATIONS}

It is often important to try to see the "big picture," to occasionally stop and evaluate from whence we have come, where we find ourselves presently, and to what lofty heights we expect our dreams to one day take us. With a realistic eye to the past and present, several applications of this technology are discussed, two upon which initial work has begun.

\subsection{EXTREMTTY DOSIMETRY}

An experimental extremity dosimeter was assembled to assess the feasibility of applying bubble detector technology to measure neutron exposure to the extremities. Because the BD-100R possess a "nearly" dose equivalent response, it was the material of choice for this experimental model. A sketch of BUDEX (an experimental bubble dosimeter for extremities) appears in Fig. 5.1.1.

A clear plastic disc was affixed to a cross sectional portion of an old bubble detector that was filled with BD-100R material and covered with another plastic disc. The BUDEX was attached to a plastic rod to simulate a finger phantom and irradiated with ${ }^{238} \mathrm{PuBe}$ neutrons. Results indicate that this application holds great promise. BUDEX could provide a good approximation of the neutron dose equivalent delivered to the extremities regardless of neutron spectra or irradiation scen rio. This is a feat no TLD-based extremity dosimeter could hope of achieving.

\subsection{ACCIDENT LEVEL DOSIMETRYSPECTROMETR'Y}

Based upon a cursory review of the literature available on cavitation theory which attempts to explain the formation of bubbles, in my estimation, we need a more detailed investigation considering the complex effects of compound surface tension terms, polymer expansion/compression elasticity variables, a reevaluation of the critical radius in light of these, and a continuum of energy transfers from elastic scattering. The summation of energy transferred by multiple recoil nuclei that are insufficient to produce a bubble of $r_{c}$ should be considered. Granted, except for the fluxes typically encountered in standard personnel dosimetry, this factor would be negligible; yet, as accident scenario dose rates are approached, this factor might be used to our advantage.

Consider a recoil nucleus that deposits an insufficient amount of energy in a SHL droplet to produce a bubble (defined as a subcritical event producing a bubble of subcritical radius, $r_{s}$ ). If we assume an initial temperature of the droplet, $t_{0}$, the energy deposited in producing the subcritical seed bubble as localized heat, according to the "thermal spike" model, would increase the temperature of the droplet within the vicinity of the event to $t_{1}$. A time interval, $t_{c}$, would be required for this heat to dissipate, i.e., cool back to the initial $t_{0}$. Assuming that this account of the process is representative of what actually occurs for subcritical events, it is conceivable that a bubble could be formed as the result of a temperature increase produced by the summation of multiple subcritical events. Consequently, the effective sensitivity of a detector will be related, in some manner, to the 
ORNL-DWG 93-592?

a) top view

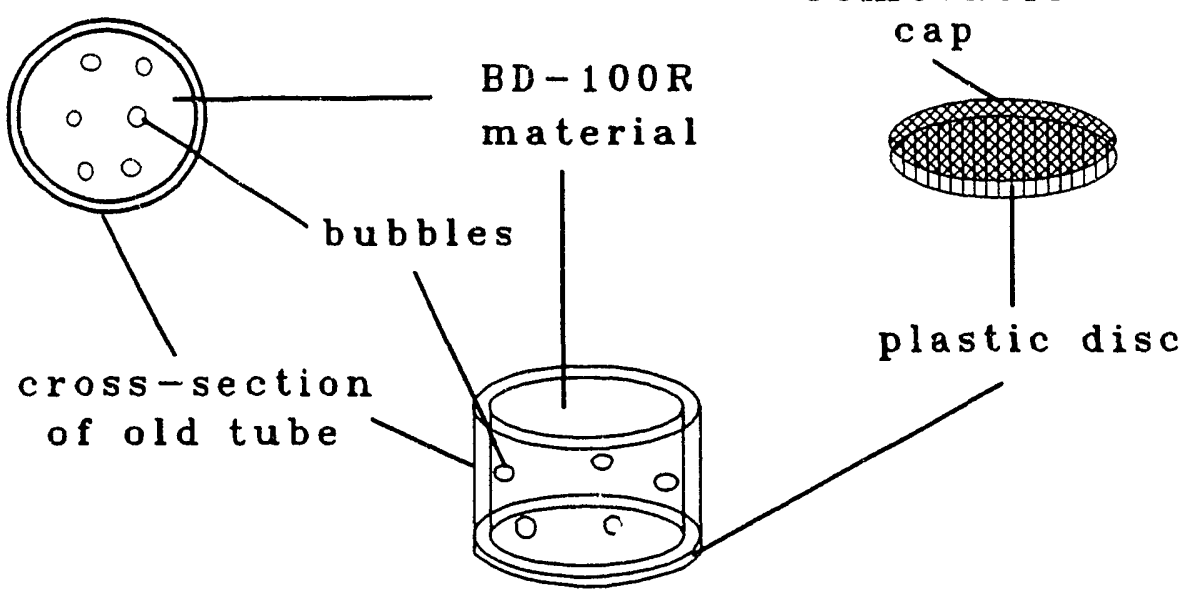

b) side view

Fig. 5.1.1. Experimental neutron extremity dosimeter (BUDEX). 
neutron flux impinging on it. The flux at which this phenomenon begins is defined as the critical flux, $\Phi_{c}$. If the relationship between $\Phi_{c}$ and the degree of superheat can be determined, this knowledge might possibly be applied to create an accident neutron spectrometer (ANTS) by maintaining sufficient pressure on a detector (critical pressure $p_{c}$ ) to render it insensitive to neutron flux below $\Phi_{c}$. The $p_{c}$ and $\Phi_{c}$ will probably vary for each type of detector with greater pressure being required by detectors possessing higher degrees of superheat and larger $\Phi_{\mathrm{c}}$. Once the $\Phi_{\mathrm{c}}$ is encountered, bubbles would form increasing the pressure in the detector. By employing a pressure relief valve the increase in pressure will be bled off, maintaining a constant $\mathrm{p}_{\mathrm{c}}$. By using the CPND in this type of application, spectral information may be obtainable in the event of a nuclear criticality. The realization of such a device would make more accurate dose and dose equivalent assessment of criticality accidents a reality.

\subsection{A "DO-IT-YOURSELF” BUBBLE READER}

The challenge that lies before us is developing an inexpensive, yet accurate and reproducible, means for counting bubbles. The superior accuracy and reproducibility that the detector itself possesses are often offset by the inherent problem of accurately and reproducibly counting the bubbles. The current generation reader available from BTI is capable of accurately reading approximately 350 bubbles in a single detector. This is under ideal conditions and assumes that $\mu$-droplet detectors are used and that they are read before the bubbles grow large enough to create an overlap problem. This reader can be yours for a mere $\$ 35,000$.

Typically, in the read process (1) the detector is placed in the reader and an image is displayed on a video monitor, at which time (2) image enhancement may be performed (3) followed by counting. The reader provides the number of bubbles it counted in the image. Because magnification is employed, the upper and lower halves of a detector are imaged and counted separately with the total resulting from the summation of the two counts. It would be nice if the images from which the counts were taken were permanently stored. This would afford an opportunity for manual verification of the numbers and provide a permanent dosimetric record, similar to a glow curve.

Due to budget constraints and the diversity and flexibility required for quality research, I embarked on a quest for a do-it-yourself research-grade bubble reader. The following attributes were desired:

1. storage of the image for future retrieval and analysis,

2. flexibility in image analysis, and

3. imaging whole bubbles and not just a bright spot of light reflected through the bubble (characterized by the first generation BTI reader).

By using an off-the-shelf image analysis software package from Jandel Scientific called JAVA, an available video camera, a PC-AT, and various lighting configurations, this goal was realized. A photo of the reader and an example of an image acquired with it are shown in Figs. 5.3.1 and 5.3.2, respectively. This was achieved for less than $\$ 5,000$. 


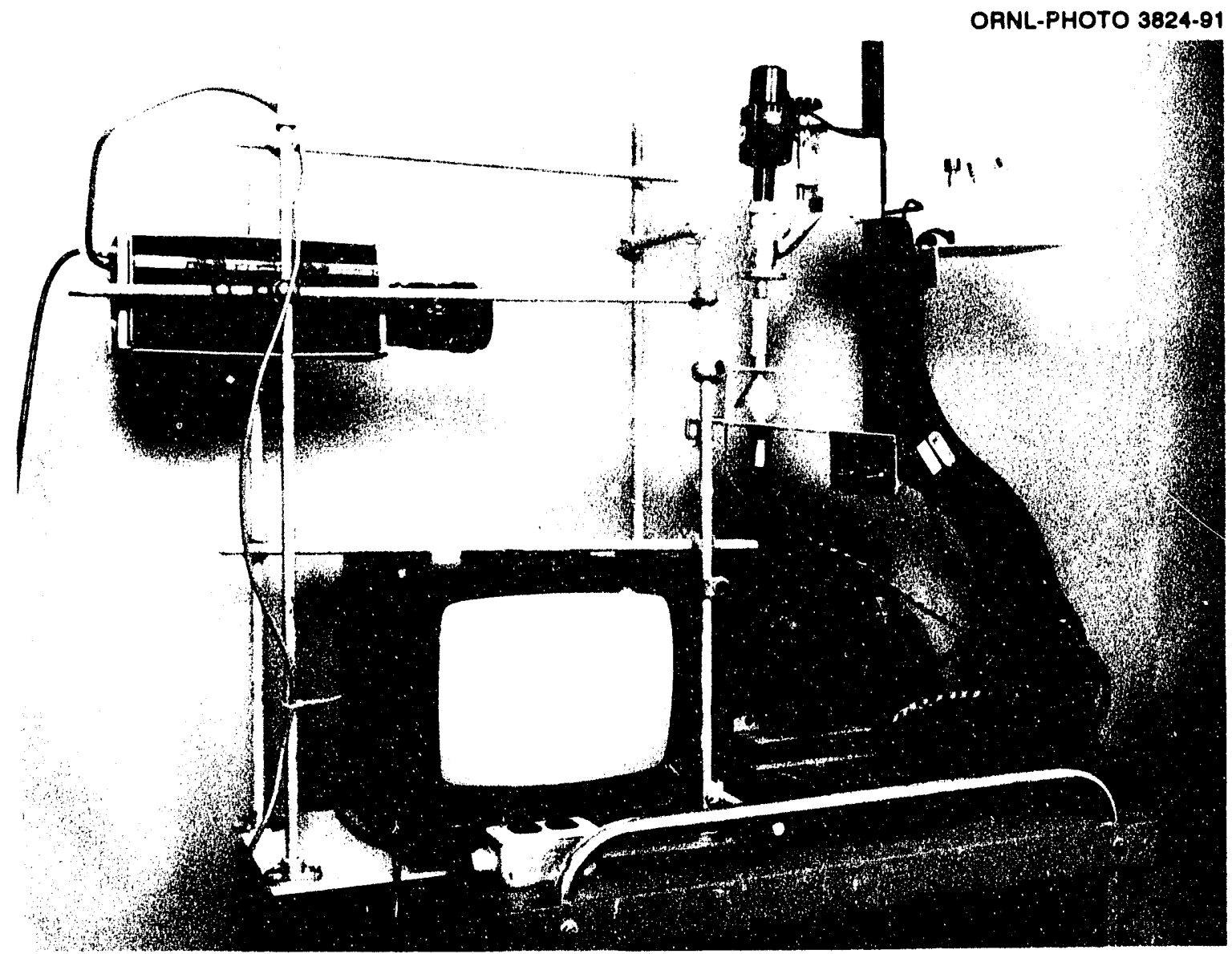

Fig. 5.3.1. A photograph of the do-it-yourself bubble reader. 
OANL-PHOTO 950-93

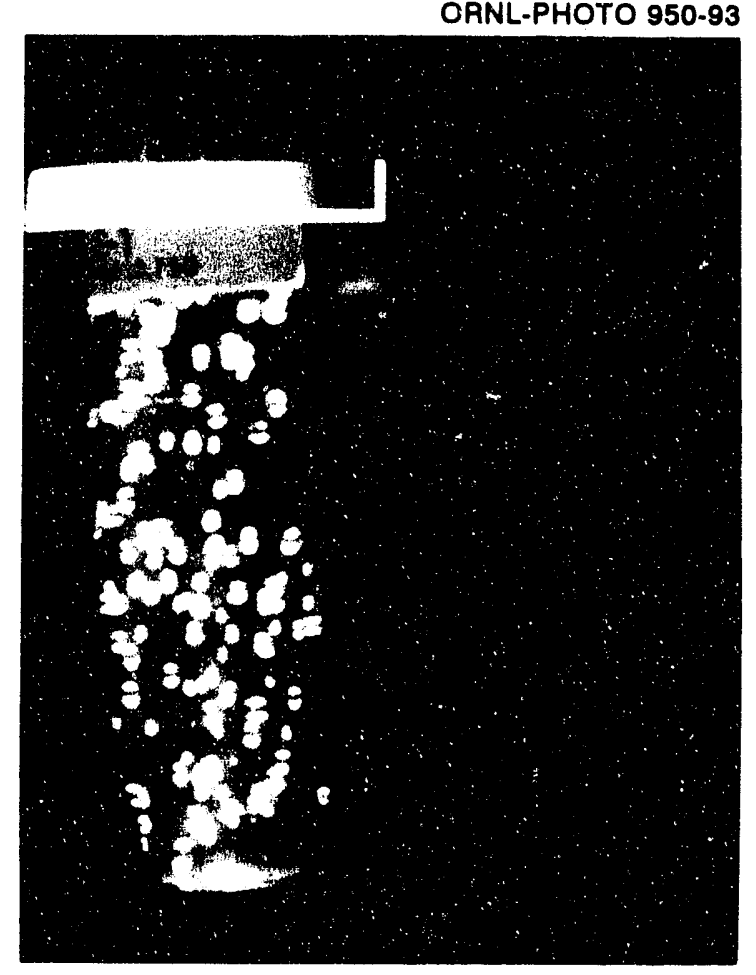

(a)

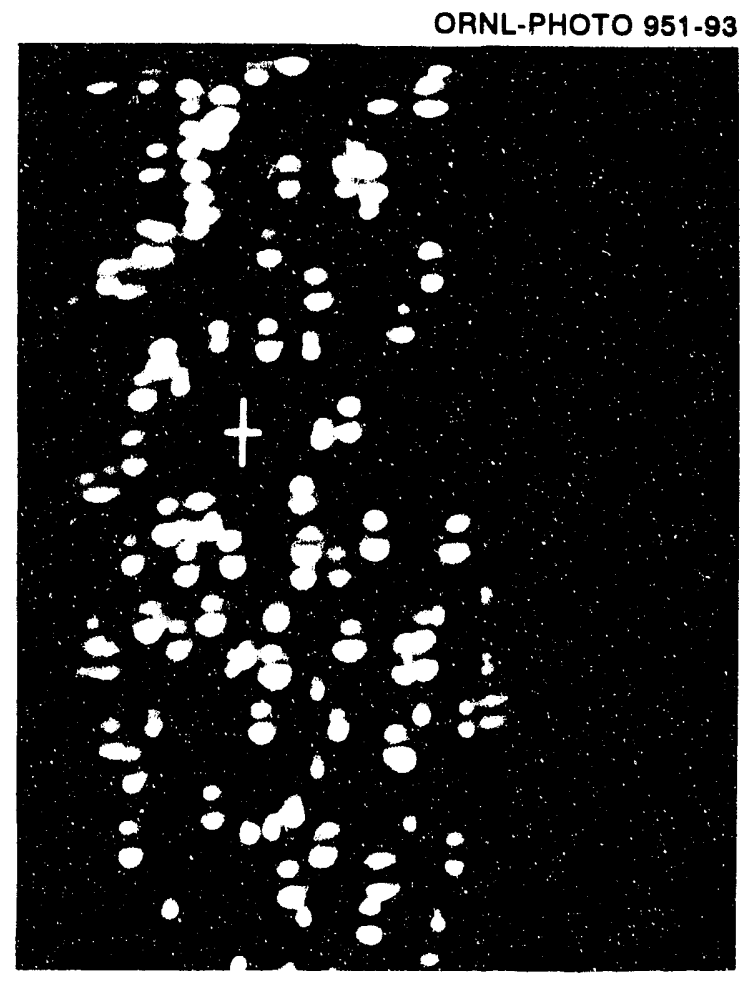

(b)

Fig. 5.3.2. An image captured with the do-it-yourself bubble reader: (a) full image and (b) magnified image. 
This approach to bubble imaging includes several novel aspects: (1) passing light through both ends of the detector, which eliminates edge glare caused by reflection of light through the wall of the cylindrical detector and imaging of the "whole" bubble, (2) a counting algorithm that will remove a bubble from the image once it is counted; thus, when two or more bubbles overlap, the top bubble after being counted can be removed leaving the partial bubble or bubbles (the curvature of the remaining partial bubble will be completed, counted, and removed from the image...etc.), and (3) the introduction of a dye into the PAG to enhance definition of an imaged bubble (the bubble will be clear and the compressed PAG surrounding the bubble will be more dense and thus darker than the rest of the detector PAG).

\subsection{DEVELOPMENT OF A COMBINATION AREA NEUTRON SPECTROMETER (CANS)}

The information gleaned from improvements to the CPND lead us to believe that superior spectral resolution and, consequently, improved neutron dose equivalent accuracy could be realized through (1) modification of the TLD component eliminating the need for a phantom, providing greater thermal neutron measuring accuracy and simulating a $4 \pi$ geometry, (2) inclusion of an additional BD to obtain better spectral resolution in the 0.01 to $1 \mathrm{MeV}$ region, and (3) determination of the effect temperature has on the shape of the energy response, $R(E)$, and how to best correct for it. As a result DOE is currently funding the development of the Combination Area Neutron Spectrometer (CANS).

\subsubsection{Redesigned TLD}

The TLD component of CANS was redesigned to capitalize on the detection of thermal and slow or epi-Cd neutrons without using a phantom. This is possible because the BD components measure the higher energy neutrons. A Harshaw card was used (two Teflon sandwiched TLD-600/700 paired elements in an Al substrate) with one pair sandwiched between $\mathrm{Cd}$ filters and the other backed by a Cd filter. The paired TLD-700 is used to subtract the incident photon contribution and the Cd-capture gammas from the TLD-600 response. The Cd-sandwiched TLD-600 responds to incident epi-Cd neutrons $(>0.414 \mathrm{eV})$ and the Cd-backed TLD-600 to incident thermal and epi-Cd neutrons. The difference in the two provides an accurate measure of the incident thermal fluence. By placing two of these units back-to-back, a $4 \pi$ geometry is simulated (Fig. 5.4.1).

\subsubsection{Additional BDs}

The region of greatest change in the fluence-to-dose equivalent conversion factor as defined by ICRP 21 is between about $0.01 \mathrm{MeV}$ and $1 \mathrm{MeV}$ (ICRP 1973). Improving the accuracy of the fluence measurements in this region will spawn a subsequent improvement in the total neutron dose equivalent accuracy. Since the BD-100R and BDS-1500 possess respective thresholds at about 0.1 and $1 \mathrm{MeV}$, adding a $\mathrm{BD}$ with a threshold at about 0.01 $\mathrm{MeV}$ (BDS-10) will facilitate measuring neutrons in the regions $<0.01 \mathrm{MeV}$, from 0.01 to $0.1 \mathrm{MeV}$, from 0.1 to $1 \mathrm{MeV}$ and from 1 to $15 \mathrm{MeV}$. Dividing this region into upper and lower regions should improve the overall spectral resolution. BDs possessing thresholds other than these are also being reinvestigated. 


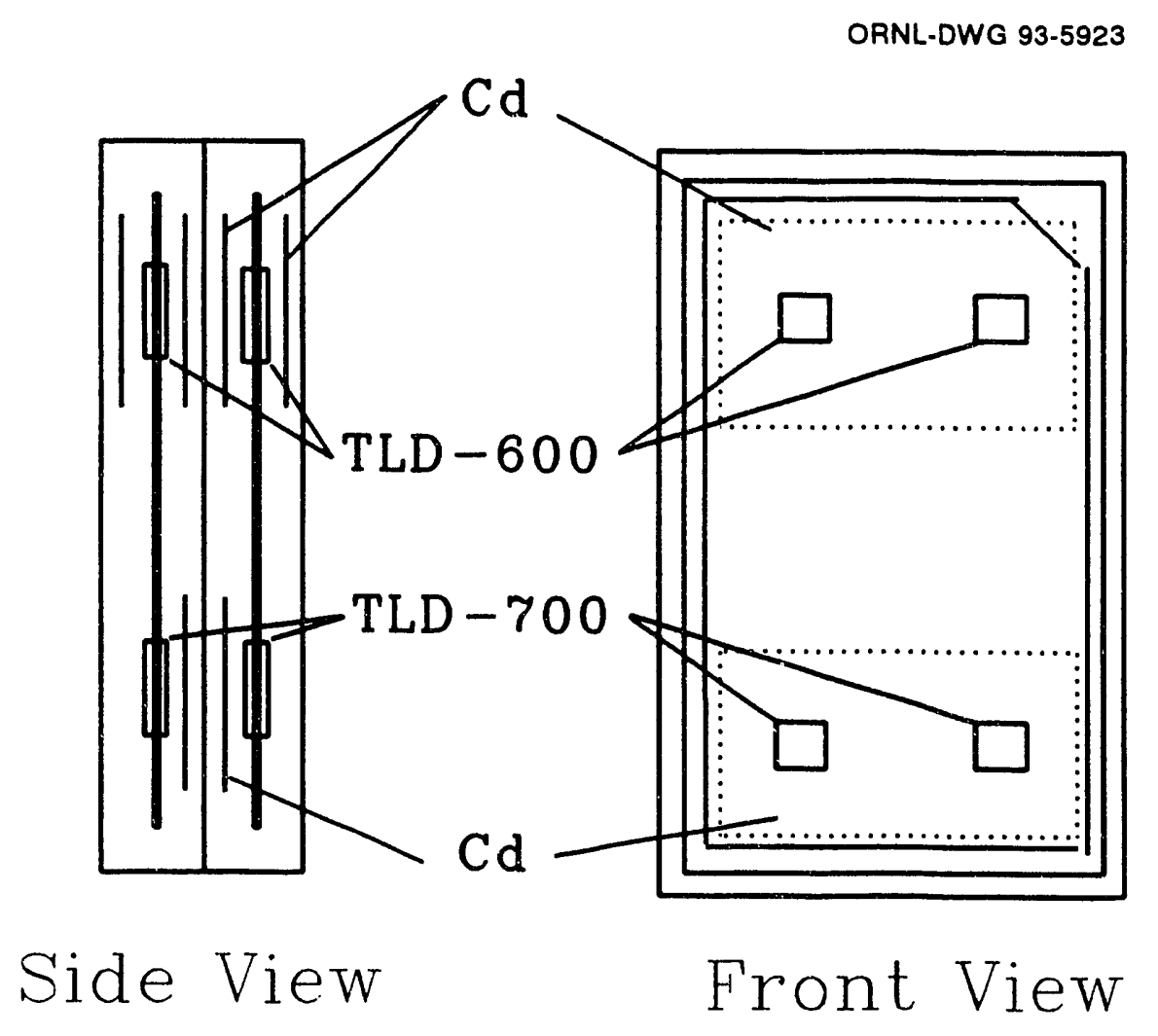

Fig. 5.4.1. Diagram of the modified TLD component of CANS. 
Because it utilizes a SHL, the BD detector will always inherently possess a degree of temperature dependence. Efforts are currently underway to conduct another set of monoenergetic neutron irradiations at Columbia Universities Radiation Accelerator Research Facility (RARAF) in New York. The experiment will focus on determining how temperature affects a $\mathrm{BDs} \mathrm{R}(\mathrm{E})$ by irradiating $\mathrm{BDs}$ to monoenergetic neutrons at various controlled temperatures, described in Sect. 4.3. This knowledge, once acquired, will allow us to make inherently more accurate measurements of neutron spectra by altering the $\mathrm{BD}$ $R(E)$ equations used in the matrix deconvolution algorithm to reflect what the $R(E) s$ are at the irradiation temperature, instead of applying a gross temperature correction factor to the integrated response, which ignores the change in $R(E)$ caused by temperature.

\subsubsection{Application to CANS}

This newly acquired knowledge will enable us to make more accurate measurements of neutron spectra at temperatures other than those at which the $R(E)$ had been determined by altering the $B D R(E)$ equations used in the matrix deconvolution algorithm to reflect the $R(E)$ at the irradiation temperature. The process will be as follows:

1. the temperature at the time of irradiation is recorded,

2. a tube correction coefficient, TCC, is applied to the response of each $\mathrm{BD}$ to mimic the response of a $1 \mathrm{bu} / 0.01 \mathrm{mSv}$ calibrated detector

3. the $R(E I)$ matrix is modified to reflect the $R(E)$ at the irradiation temperature,

4. the matrix is inverted producing equations for the $\phi_{\mathrm{EI}} \mathrm{s}$,

5. the TCC values are entered and the equations solved to yield the $\phi_{\mathrm{EI}}$,

6. application of the averaged $h_{4}$ for each EI provides the neutron dose equivalent produced in that $\mathrm{EI},\left(\mathrm{H}_{\mathrm{EI}}\right)$, and

7. the summation of the $\mathrm{H}_{\mathrm{El}} \mathrm{s}$ provides the total measured neutron dose equivalent $\left(\mathrm{H}_{\mathrm{T}}\right)$.

Applying the TCC is analogous to applying an element correction coefficient to individual TLD element readings.

Development is under way with field tests scheduled to include containment of a Texas Utilities BWR, measurements at the TOKAMAK device at Princeton Plasma Physics Laboratory, and measurement of various pure and mixed field radioisotopic spectra utilizing various shielding configurations at ORNL and NSWC.

\subsection{ALTERNATIVE REAL-TIME ACOUSTICAL PROCESSING (ARAP)}

Our vision is the development of a real-time neutron spectrometer/dosimeter. The realization of this goal will require the synthesis of all we have learned during our BD-related research and a cutting edge knowledge of electronics and micro-processors. The Alternative Real-time Acoustical Processing technique (ARAP), currently under development by the DOSAR Group, may prove to be a step toward realizing this goal. This technique will enable real-time application of the BTI's BDs. ARAP will answer the clarion call for a simple device for measuring neutron spectra and calculating dose equivalent. In our mind's eye the devices could resemble those of the artist conceptions in Figs. 5.5.1 and 5.5.2. 


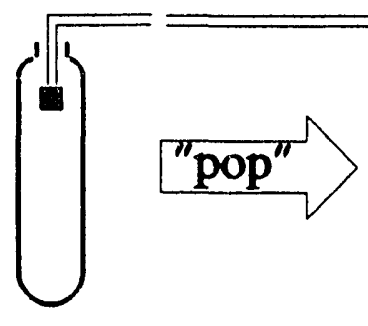

A.
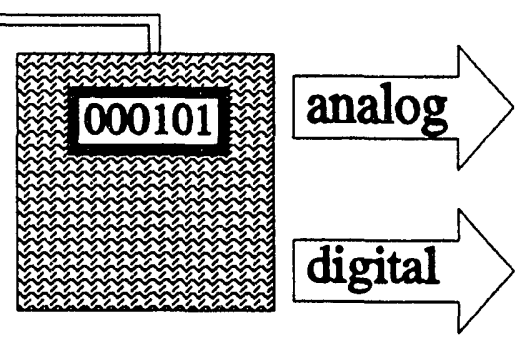

B.
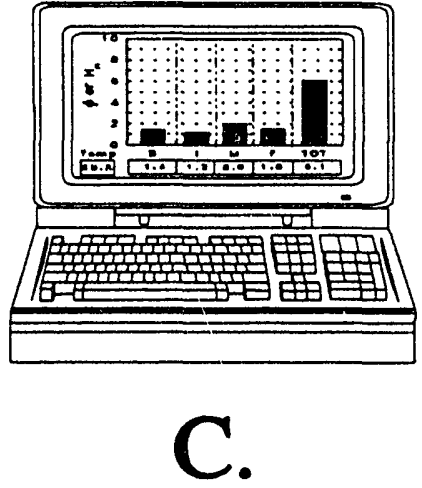

Fig. 5.5.1. Real-time spectrometry: (A) "pop" detected by a microphone; (B) counted by simple circuitry and displayed; (C) multiple detector signals come to a signal processing board in a laptop computer where they are recorded, processed, and spectral results displayed graphically. 


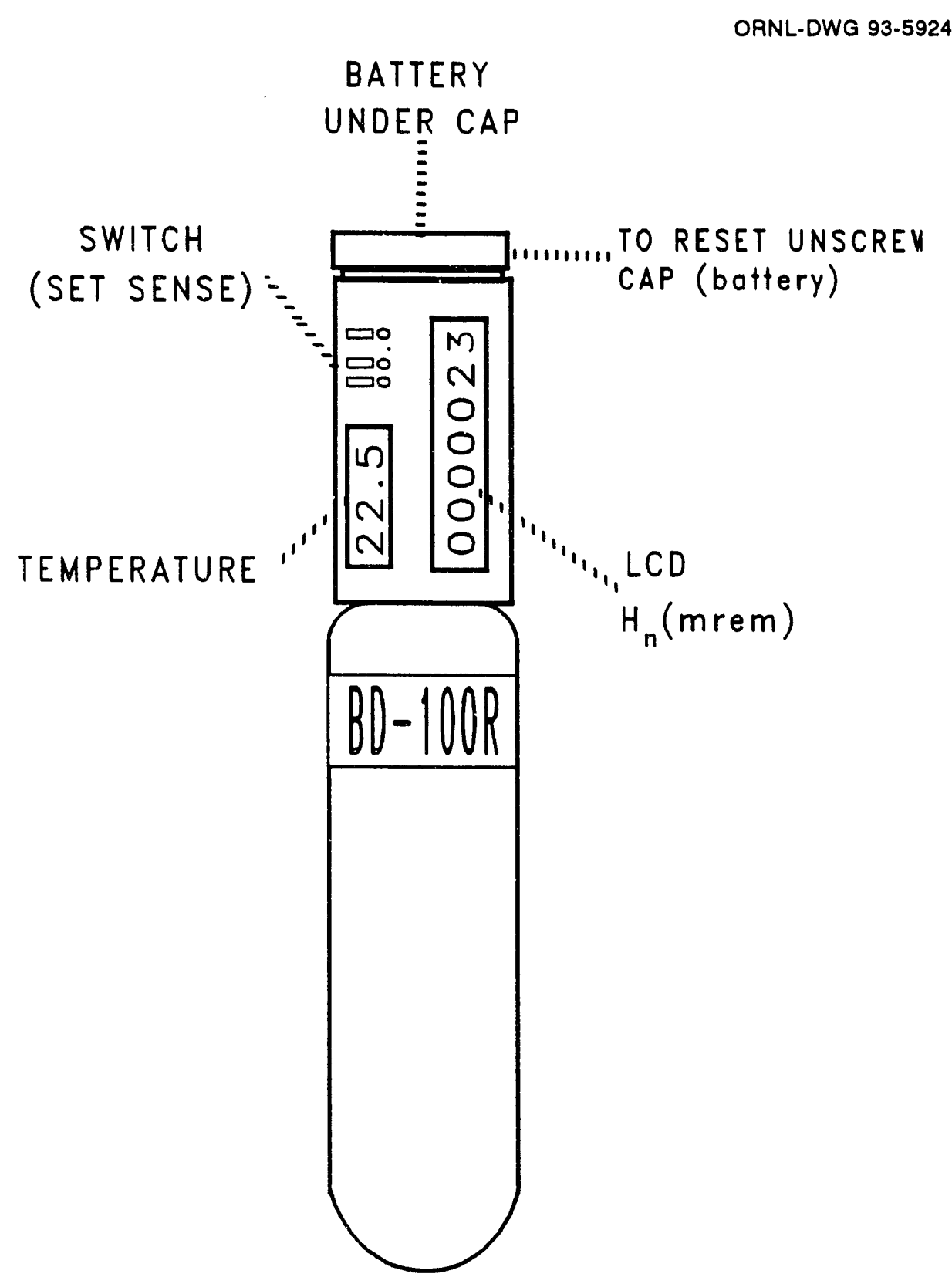

Fig. 5.5.2. Real-time temperature corrected neutron dosimeter using a BD-100R and miniature ARAP. 
It was documented by Apfel that the violent boiling process occasioned by bubble formation transmits a mechanical shock wave manifested as an audible "pop" (Roy, Apfel, and Lo 1987). The prototype real-time spectrometer, Fig. 5.5.1, includes a signal processing board loaded in a laptop computer that will receive and digitize the acoustical signal from a microphone placed inside each detector connected to it. This information will be analyzed and an algorithm will process the information as described in Sect. 5.4. Appropriate on-line modifications to the $R(E) s$ are made for temperate compensation as well as on-line calculations of the spectrum, applying the desired average $h_{\phi}$ to calculate $H_{E I}$ and $H_{T}$. Used in this way, ARAP will measure the spectrum and calculate the dose equivalent in real time. These on-line results will be displayed both numerically and as a histogram on the computer screen much as a graphic equalizer. A linear record of the data will be written to disk.

The device in Fig. 5.5.1 will provide a linear correlation of detector response and temperature for the purpose of on-line a posteriori compensation for the temperature effects experienced during measurements. An amenity of the system will be its backup features. Three means of verification or reading will be incorporated in the device:

1. LCD indication on the detector of temperature and the cumulative bubble count,

2. logging of the cumulative counts and temperature at preset time intervals, and

3. the option of traditional post-event optical counting, if the electronics fail somewhere along the way. 


\section{SUMMARY AND CONCLUSIONS}

The already good performance of the CPND to evaluate the neutron dose equivalent for a variety of neutron spectra both radioisotopic and in situ has been improved. The $\mathrm{H}_{\mathrm{T}}$ results were within $11 \%$ of the reference values (BMS based) for the in situ spectra and within $2 \%$ of the reference values for the radioisotopic spectra. The low standard deviation and bias suggest improved spectrometric and dose equivalent accuracy and precision $(\mathrm{S}=$ 0.07 and 0.01 and $\mathrm{B}=-0.03$ and 0.01 for the in situ and radioisotopic categories respectively). These results were achieved without any a priori knowledge of the neutron spectra and with a single algorithm that can be solved using a spreadsheet.

A historical overview of the development of bubble detector technology was presented. A thumbnail sketch of the currently held beliefs on the mechanisms involved in bubble formation and a description of the CPND were provided.

The aspects of the CPND which were modified and the reasoning behind them were discussed. These included

1. refinement of the BD-100R and BDS-1500 response functions,

2. reevaluation of the thermal neutron sensitivity of TLD-600,

3. redefinition of the energy intervals (EI),

4. a spectrum deconvolution matrix algorithm, and

5. the methodology for neutron dose equivalent determination.

The effectiveness of these modifications was assessed by comparing the measured results to both reference values and the original CPND performance. An overall improvement in $\mathrm{H}_{\mathrm{T}}$ accuracy over the original CPND of $2 \%$ for the in situ and $28 \%$ for the radioisotopic spectra was observed.

Some explanations were offered regarding

1. useable lifetime,

2. observed response variations,

3. temperature effects,

4. bubble growth,

5. bubble memory,

6. incompressible bubbles, and

7. theory of operation.

Some suggestions were presented for further research and application of this emerging technology. These included

1. extremity dosimetry,

2. accident-level dosimetry,

3. a do-it-yourself bubble reader for research applications,

4. development of a Combination Area Neutron Spectrometer (CANS), and

5. development of Alternative Real-Time Acoustical Processing (ARAP). 


\subsection{AREAS OF NEED}

Although the spectral results provided by the CPND and CANS are characterized by a small number of energy intervals or bins (EI) (typically four or five), this should not be viewed as a substantial deficit to their value as an effective and accurate neutron spectrometer/dosimeter. It is believed that this statement is warranted for the following reasons. Considering that there is very little difference in the $h$, between thermal energies and $10 \mathrm{keV}$ (according to ICRP 21), a single value of $h_{\phi}$ can be applied to the total $\phi$ in this region. This suggests that only one EI is needed below $0.01 \mathrm{keV}$, and consequently, that a quantification of the total number of neutrons below $0.01 \mathrm{keV}$ is adequate. Only in specialized situations do radiation environments contain neutrons above $15 \mathrm{MeV}$ (e.g., accelerators and similar devices), therefore, a single EI is all that is needed from 1 to $15 \mathrm{MeV}$. A single $h_{\uparrow}$ can then be applied to neutrons in this EI. Also, by dividing the $10 \mathrm{keV}$ to $1 \mathrm{MeV}$ region into two segments, $10 \mathrm{keV}$ to $100 \mathrm{keV}$ and $100 \mathrm{keV}$ to $1 \mathrm{MeV}$, we can improve the spectrometric resolution in this region where the change in $h_{0}$ is the greatest. This also allows application of a separate $h_{\phi}$ to the $\phi$ in each segment. Thus, we have demonstrated that by strategically defining the EIs one can preform "good" neutron dosimetry with a four-interval neutron spectrum. Recall a correction factor derived from 9-to-3 in. ratios (a two point measurement) has historically been applied to albedo dosimeters for energy corrections (Griffith et al. 1979).

What are the areas of greatest need? Are we poised on the brink of a breakthrough in neutron dosimetry? There are still a few ominous problems that must be overcome before bubble detector becomes a "household word" and full blown application of this technology becomes practical in the real world of neutron detection and dosimetry. Some areas of greatest need include

1. storage of the digitized image for a permanent record of the number bubbles in the detector, i.e., like a glow curve;

2. a reduction in the cost of detectors, which is coming down and will continue as demand increases;

3. accumulation of performance data to reinforce acceptance of this new technology by the rank and file in the dosimetry community (this will come with use);

4. broadened application, i.e., for extremities and photons;

5. a low cost reader (the latest generation available from BTI goes for about $\$ \mathbf{3 5 , 0 0 0}$ );

6. advancement towards overcoming the temperature dependence barrier and its affects on $R(E)$ (advances are being made in this area);

7. reduction in size and the geometry of the container to be more conducive to reading and to accommodate the use of multiple detectors in a compact holder; and

8. a definitive model explaining bubble formation.

\subsection{CLOSING REMARKS}

The goal of every dosimetrist should be to provide the most accurate dosimetry possible, utilizing every means within his or her ability to do so. With the probable increase of the neutron quality factor and the push within the DOE to reduce the current annual dose equivalent limit for radiation workers from $50 \mathrm{mSv}$ to $20 \mathrm{mSv}$, the ability to provide accurate neutron dosimetry at levels that are typically encountered in the workplace (i.e., 0.1 to 
$0.5 \mathrm{mSv}$ per quarter) becomes increasing critical. The history of past Personnel Dosimetry Intercomparison Studies (PDIS) conducted by the DOSAR group at ORNL, indicates that, of the dosimetry systems currently employed, scarce will be those adept enough to weather the impending storm (Sims and Dickson 1985). Although BD technology does not yet offer the perfect dose equivalent device, what technology does? With the anticipated improvements aimed at remedying its weaknesses, this technology threatens to surpass anything currently available, or that is foreseeable in the near future for quick, simple, and inexpensive neutron spectral and dosimetric measurements. It accurately measures the neutron dose equivalent received from both known and unknown neutron spectra encountered in the workplace without the necessity of an a priori knowledge of the spectra. Utilizing bubble detector technology, one can improve the quality of neutron dosimetry. If development and application continue at their present pace, bubble detector technology may become for the applied health physicist/dosimetrist what the microwave has become for the bachelor, a quick and simple means to achieving a practical end. 


\section{REFERENCES}

Alsmiller R. G., and Barish, J. 1974. "The Calculated Response of ${ }^{6} \mathrm{LiF}$ Albedo Dosimeters to Neutrons with Energies s400 MeV," Health Phys. 26:13-28.

Anderson, M. E. 1967. "Neutron Energy Spectra of ${ }^{239} \mathrm{Pu}-\mathrm{Be},{ }^{238} \mathrm{Pu}-\mathrm{F}$, and ${ }^{238} \mathrm{Pu}-{ }^{18} \mathrm{O}(\alpha, \mathrm{n})$ Sources," MLM-1422, TID-4500, UC-34 Physics, Monsanto Research Corp., Mound Laboratory, Miamisburg, Ohio.

Apfel, R. E. 1979. "The Superheated Drop Detector," Nucl. Instr. and Meth. 162:603-608. Apfel, R. E. 1987. "Neutron-Induced Vaporization of Superheated Liquids: Theory and Experiment," Mat. Res. Soc. Symp. Proc. 57:57-66.

Apfel, R. E. and Roy, S. C. 1984. "Investigation on the Applicability of Superheated Drop Detectors in Neutron Dosimetry," Nucl. Instr. and Meth. in Phys. Res. 219.582.587.

Apfel, R. E., Roy, S. C., and Lo, Y. C. 1987. "Prediction of the Minimum Neutron Energy Required to Nucleate Vapor Bubbles in Superheated Liquids," Phys. Rev. A31:3194-3198.

Block, S., Bryan, J., Prevo, C., and Montan, D. 1967. "Laboratory Sources Enhanced in $0.5 \mathrm{eV}$ to $200 \mathrm{keV}$ Neutrons for Instrument Evaluation," Health Phys. 13:1025-1031.

Buckner, M. A., Casson, W. H., and Liu, J. C. 1990. "Optimization of the New Combination Personnel Neutron Dosimeter," Health Phys. 58, Supplement 1: S64.

DOE Laboratory Accreditation Program for Personnel Dosimetry Systems 1986. Department of Energy Standard for The Performance Testing of Personnel Dosimetry Systems, U. S. Department of Energy, Assistant Secretary for Environment, Safety, and Health. Washington, D. C. 20545, DOE/EH-0027.

Eisenhauer, C. M. 1984. "Evaluation of Dose Equivalent per Unit Fluence for a $D_{2} \mathrm{O}$ Moderated ${ }^{252} \mathrm{Cf}$ Neutron Source," Radiat. Prot. Dosim. 9:63-64.

Eisenhauer, C. M., Hunt, J. B., and Schwartz, R. B. 1985. "Calibration Techniques for Neutron Personnel Dosimetry," Radiat. Prot. Dosim. 10:43-57.

Glaser, D. A. 1952. "Some Effects of Ionizing Radiation on the Formation of Bubbles in Liquids," Phys. Rev., 87:665.

Griffith, R. V., Hankins, D. E., Gammage, R. B., Tommasino, L., and Wheeler, R. V. 1979. "Recent Developments in Personnel Neutron Dosimeters-A Review," Health Phys. 36:235-260.

Harper, M. J. 1991. A Theoretical Model of Superheated Liquid Droplet Neutron Detector, Ph.D. dissertation, University of Maryland.

Hurst, G. S., Harter, J. A., Hensley, P. N., Mills, W. A, Slater, M., and Reinhardt, P. W. 1956. "Techniques of Measuring Neutron Spectra with Threshold Detectors-Tissue Dose Determination," Review of Scientific Instr. 27:153-156.

Ing, H. Mar. 11, 1991. President, Bubble Technology Industries, Chalk River, Ontario, Canada K0J 1J0, personal communication to M. A. Buckner, Health and Safety Research Div., Oak Ridge Natl. Lab.

Ing, H. and Birnboim, H. C. 1984. A Bubble-Damage Polymer Detector for Neutrons, Nucl. Tracks and Radiai. Meas. 8:285-288.

International Atomic Energy Agency (IAEA) 1985. Neutron Monitoring for Radiological Protection, IAEA Technical Report Series No. 252, International Atomic Energy Agency, Vienna.

International Commission on Radiological Protection (ICRP) 1973. Data for Protection Against Ionizing Radiation for External Sources, ICRP Publication 21, Permagon Press, Oxford. 
International Organization for Standarcization 1986. Neutron Reference Radiations for Calibrating Neutron Measuring Devices Used for Radiation Protection Purposes and for Determiraing Their Response as a Function of Neutron Energy, Draft International Standard ISO/DIS 8529, ISO, Geneva.

Ipe, N. E. and Busick, D. D. 1987. BD-100: The Chalk River Nuclear Laboratories' Neutron Bubble Detector, SLAC-PUB-4398, Stanford University, Stanford, California, USA.

Ipe, N. E., Busick, D. D., and Pollock, R. W. 1988. "Factors Affecting the Response of the Bubble Detector BD-100 and a Comparison of its Response to CR-39, ${ }^{\text {iz }}$ Radiat. Prot. Dosim., 23:135-138.

Knoll, G. F. 1979. Radiation Detection and Measurement, John Wiley and Sons, Inc.

Liu, J. C. 1989. The Development, Characterization, and Performance Evaluation of a New Combination Type Personnel Neutron Dosimeter, Ph.D. dissertation, Texas A\&M University, College Station, Texas [Also Liu, J. C. 1989. The Development, Characterization, and Performance Evaluation of a New Combination Type Personnel Neutron Dosimeter, ORNL-6593, Martin Marietta Energy Systems, Inc., Oak Ridge Natl. Lab.].

Liu, J. C. and Sims, C. S. 1990. "Characterization of the Harsh Albedo TLD and the Bubble Detectors BD-100R and BDS-1500," Radiat. Prot. Dosim., 32:21-32.

Liu, J. C. and Sims, C. S. 1990. "Performance Evaluation of a New Combination Personnel Neutron Dosimeter." Radiat. Prot. Dosim. 32:33-43.

Lo, Y. C. 1987. Characterization of a Neutron Detector Based on Superheated Drops, Technical Report 87-1, Yale University.

Lorch, E. A. 1973. "Neutron Spectra of ${ }^{241} \mathrm{Am} / \mathrm{B},{ }^{241} \mathrm{Am} / \mathrm{Be},{ }^{241} \mathrm{Am} / \mathrm{F},{ }^{242} \mathrm{Cm} / \mathrm{Be},{ }^{238} \mathrm{Pu} /{ }^{13} \mathrm{C}$, and ${ }^{252} \mathrm{Cf}$ Isotopic Neutron Sources," International Journal of Applied Radiation and Isotopes, 24:585-591.

Massand, O. P. and Venkataraman, G. 1974. "The Neutron Spectrum of Plutonium Fluoride," Nucl. Instr. and Meth. 121:405-506.

Pollock, R. W. 1989. Current Developments with Bubble Detectors, Technical Note, Siemens Gammasonics, Inc., Des Plaines, Illinois, USA.

Roy, D. Jan. 9, 1991. Technology Applications Manager, Bubble Technology Industries, Chalk River, Ontario, Canada K0J 1J0, personal communication, to M. A. Buckner, Health and Safety Research Div., Oak Ridge Natl. Lab.

Roy, S. C., Apfel, R. E., and Lo, Y. C. 1987. "Superheated Drop Detector: A Potential Tool in Neutron Research," Nucl. Instr. and Meth. A255:199-206.

Schwartz, R. B. and Hunt, J. B. 1990. "Measurement of the Energy Response of the Superheated Drop Neutron Detectors," Radiat. Prot. Dosim. 34:377-380.

Seitz, F. 1958. "On the Theory of the Bubble Chamber," Phys. Fluids 1:2-13.

Sims, C. S. and Dickson, H. W. 1985. "Neutron Dosimetry Intercomparison Studies," Radiat. Prot. Dosim. 10:331-340.

Swaja, R. E. and Sims, C. S. 1988. "Neutron Personnel Dosimetry Intercomparison Studies at the Oak Ridge National Laboratory: A Summary (1981-1935)," Health Phys. 55:549564.

Vylet, V., Swaja, R. E., Pretre, S., Valley, J. F., and Lerch, P. 1989. "On the Use of the '9to-3' Ratio with Albedo and Fission Track Neutron Personnel Dosemeters," Radiat. Frot. Dosim. 27:29-33. 
Werle, H. 1970. "Spectral Measurements on Radioactive Neutron Sources in the Energy Range of $10 \mathrm{keV}$ to $10 \mathrm{MeV}$ with Proton Recoil Proportional Counters," INR-4/70-25, Institut für Neutronenphysik and Reaktortechnik, Kernforschungszentrum, Karlsruhe, pp. 85 and 86. 


\section{Appendix}

THE SPECTRAL NEXUS: UNDERSTANDING THE RELATIONSHIP BETWEEN RESPONSE FUNCTIONS AND NEUTRON SPECTRA 
The common practice of primarily employing the average energy as the identifying feature of a neutron spectrum is, though unintentional, often misleading. Because the response curve of most dosimeters is drastically different from that of the $h_{\phi}$, it becomes very difficult for current dosimeters to measure the neutron dose equivalent of an unknown or mixed neutron field. One of the underlying difficulties stems from the rapid decrease in $h_{\phi}$ from 1 to $0.01 \mathrm{MeV}$. As the incident neutron energy decreases from 1 to $0.01 \mathrm{MeV}$, an increasingly larger number of neutrons is required to produce the same biological effect. The difference in $h_{\phi}$ in this region is as great as a factor of 33 , from $9.9 \mathrm{pSv}-\mathrm{cm}^{2}$ at $.01 \mathrm{MeV}$ to $327 \mathrm{pSv}-\mathrm{cm}^{2}$ at $1 \mathrm{MeV}$. Consequently, the same dose equivalent produced by 330.01 $\mathrm{MeV}$ neutrons would require only a single $1 \mathrm{MeV}$ neutron.

Dosimetrists rarely deal with monoenergetic neutron exposures. More typically the neutron fields encountered are unknown and polyenergetic. The exigency of this situation dictates that careful consideration of the entire spectrum is necessary. Unfortunately, and to the demise of many investigators, this importance is frequently minimized. Such minimization is often done for the sake of simplification. But, this oversimplification can spawn unwarranted inferences, contribute to the development of erroneous or false models, and inhibit the formulation of valid explanations for observed phenomena. Case in point.

Ipe et al. conducted a series of experiments for the purpose of assessing the energy dependence of the BD-100 (Ipe, Busick, and Pollock 1988). The BD-100 and BD-100R are synonymous, therefore, BD-100R will be used for the remainder of this work (Pollock 1989). The average energies (given in $\mathrm{MeV}$ ) of the sources used in the Ipe et al. experiments are 4.5 for ${ }^{239} \mathrm{PuBe}, 2.3$ for $\mathrm{PuB}, 2.15$ for ${ }^{252} \mathrm{Cf}, 0.9$ for PuF, and 0.5 for PuLi. The data acquired by Ipe et al. appear to indicate that an increase in the BD-100R sensitivity is to be expected as the incident neutron energy decreases. Since the average energies fall well within the flat region of the BD-100R response curve (i.e., the region above $150 \mathrm{keV}$, see Fig. 2.2.1), would it not seem reasonable, upon cursory examination, to expect the BD-100R response to be more or less identical for each of these sources? There must be a logical explanation for the increase in sensitivity observed by Ipe et al. Obtaining such cognizance requires a more in-depth look into what is actually occurring.

Let us consider the interrelationships of the BD-100R R(E), $h_{\phi}$, and the spectral shape as we try to understand the organic nexus existing between these elements and the observed phenomena.

\section{Response Curve and $h_{\varphi}$}

First note that, because the sensitivity of the BD-100R is the same for all neutrons above $150 \mathrm{keV}$, in this region the $\mathrm{BD}-100 \mathrm{R}$ responds more like a fluence device than it does a dose equivalent device. A simple illustration may help realize this point. Consider a $\mathrm{BD}-100 \mathrm{R}$ that receives $0.5 \mathrm{mSv}$ (50 mrem) from three monoenergetic neutron beams of energies $E_{1}=5.0 \mathrm{MeV}, \mathrm{E}_{2}=2.76 \mathrm{MeV}$, and $\mathrm{E}_{3}=513 \mathrm{keV}$. Based on an $\mathrm{h}_{4}$ of $408 \mathrm{pSv}-\mathrm{cm}^{2}$ for $E_{1}$ and $E_{2}$ and 203 pSv-cm ${ }^{2}$ for $E_{3}$, the fluences required to induce $0.5 \mathrm{mSv}$ are $1.23 \times$ $10^{6} \mathrm{~cm}^{-2}$ for $E_{1}$ and $E_{2}$ and $2.46 \times 10^{6} \mathrm{~cm}^{-2}$ for $E_{3}$. Given a sensitivity of 1 bubble-10 $\mu \mathrm{Sv}^{-1}$ ( $1 \mathrm{bu} \mathrm{mrem}^{-1}$ ) when calibrated to ${ }^{238} \mathrm{PuBe}$, the sensitivity at all three energies is $4 \times$ $10^{-5} \mathrm{bu}-\mathrm{cm}^{2}$. Therefore, 49 bubbles would be produced by a $0.5 \mathrm{mSv}$ dose equivalent delivered by neutrons of $E_{1}(5.0 \mathrm{MeV})$ and $E_{2}(2.76 \mathrm{MeV})$ and 99 bubbles by $0.5 \mathrm{mSv}$ of 
$\mathrm{E}_{3}(513 \mathrm{keV})$ neutrons. Inferentially, for neutrons above $150 \mathrm{keV}$ the response or the BD$100 \mathrm{R}$ reflects the number of neutrons traversing the device rather than the dose equivalent delivered by the neutrons, i.e., fluence indication.

\section{Spectral Nexus}

The implication of this phenomena becomes even more complex when attempting to detect an integral dose equivalent delivered by impinging neutrons that are polyenergetic, i.e., a spectrum. When measuring the same dose equivalent delivered from two different spectra, the response of the $\mathrm{BD}-100 \mathrm{R}$ will be more pronounced for the spectrum with the larger fluence above $150 \mathrm{keV}$, regardless of the spectrum's average energy.

Analysis of the response function of the $\mathrm{BD}-100 \mathrm{R}$ and a plot of the neutron energy spectra for ${ }^{238} \mathrm{PuBe}$ and unmoderated ${ }^{252} \mathrm{Cf}$ (average energies of $4 \mathrm{MeV}$ and $2.15 \mathrm{MeV}$, respectively) will illustrate this distinction more clearly, i.e., Fig. A.1. Inspection of the spectra after normalization to a $0.01 \mathrm{mSv}(1 \mathrm{mrem})$ fluence equivalent reveals that the unmoderated ${ }^{252} \mathrm{Cf}$ spectrum contains a greater number of neutrons in the energy region that corresponds to the flat segment of the BD-100R response curve than does the ${ }^{238} \mathrm{PuBe}$ spectrum; ergo a greater sensitivity to unmoderated ${ }^{252} \mathrm{Cf}$ than ${ }^{238} \mathrm{PuBe}$. Another attribute that will influence the BD-100R's response is the width of the spectrum, i.e., broad verses narrow.

The source spectra used in the Ipe et al. study, excluding ${ }^{239} \mathrm{PuBe}$ and unmoderated ${ }^{252} \mathrm{Cf}$, are characterized by fairly narrow neutron energy distributions. With each decrease in average energy a corresponding increase in the total number of neutrons or fluence is required to produce the same dose equivalent. Therefore, when measuring the same delivered dose equivalent as the average energy decreases, an increase in response would be expected.

Although the average energy of unmoderated ${ }^{252} \mathrm{Cf}(2.15 \mathrm{MeV})$ is only slightly lower than that of PuB (2.3 MeV), the difference in spectrum shape is significant. A larger fraction of the broad fission spectrum lies between $150 \mathrm{kev}$ and $1 \mathrm{MeV}$ than does the more narrow PuB spectrum. It is this greater number of neutrons per unit dose equivalent above $150 \mathrm{keV}$ that contributes the increase in sensitivity for this broad unmoderated ${ }^{252} \mathrm{Cf}$ spectrum, a more stark increase even than would be expected from a more narrow spectrum (like the other sources used by Ipe et al.) with identical average energy. The response to a ${ }^{239} \mathrm{PuBe}$ spectrum (4.5 Mev av'srage energy) would be even less than that to ${ }^{238} \mathrm{PuBe}$, therefore the increase in response to unmoderated ${ }^{252} \mathrm{Cf}$ observed by Ipe et al. would appear even more pronounced.

Thus, spectral differences manifest themselves as deviations or variations in the response of the $\mathrm{BD}-100 \mathrm{R}$ when used to measure dose equivalent from a spectrum other than the calibration spectrum, i.e., the response is spectrum dependent. A similar, yet more pronounced effect is experienced by all current neutron dosimetry techniques. 
ORNL-DWG 93-5925

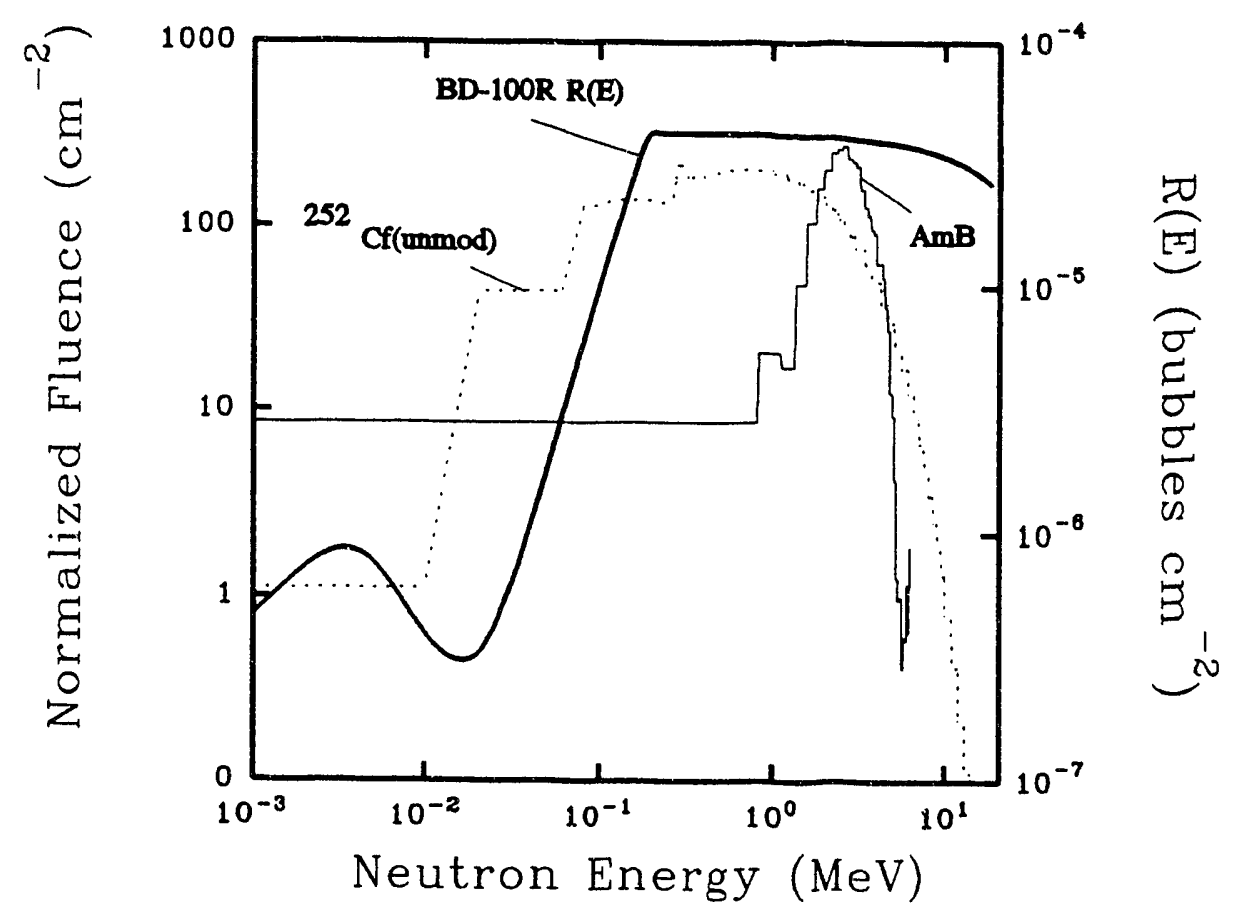

Fig. A.1 The BD-100R R(E) and ${ }^{241} \mathrm{AmBe}$ and ${ }^{252} \mathrm{Cf}$ (unmod) spectra normalized to $0.01 \mathrm{mSv}$. 


\section{When a Sv Is Not a Sv}

Because the variations in a detector's response depend on the differences between the measured and calibration spectra, the response of the $\mathrm{BD}-100 \mathrm{R}$ or any other detector may be quantified for any spectra by obtaining reference spectral information and folding it into the response function. This provides both a spectrum specific sensitivity and an answer to the question of how much the response can be expected to vary from one spectrum to another. This has been accomplished for eleven radioisotopic neutron sources obtained from the literature as noted in Table A.1. The sources are ${ }^{252} \mathrm{Cf}$ moderated and unmoderated by $\mathrm{D}_{2} \mathrm{O}\left[{ }^{252} \mathrm{Cf}\right.$ and ${ }^{252} \mathrm{Cf}$ (unmod)], ${ }^{244} \mathrm{CmBe},{ }^{241} \mathrm{AmB},{ }^{241} \mathrm{AmBe},{ }^{241} \mathrm{AmF},{ }^{241} \mathrm{AmLi},{ }^{239} \mathrm{PuBe}$, ${ }^{238} \mathrm{PuBe},{ }^{238} \mathrm{PuC}$, and ${ }^{238} \mathrm{PuF}$. The derived source sensitivities and dosimetric conversion conventions calculated are the next topic of discussion.

\section{Predicted Sensitivities in Several Radioisotopic Spectra}

Various investigators have published spectra for these sources. For the sake of comparison, values were calculated for different spectra of the same radioisotopic neutron source. A graph of the published spectrum was imaged and digitized using a video camera, digitizing board, and imaging software. The image was calibrated in both the $\mathrm{x}$ and $\mathrm{y}$ plane in concurrence with the axis of reference. Then points were selected along the curve representing the spectrum providing an $x-y$ coordinate corresponding to the selected point. This information was exported to a spreadsheet for manipulation. Computations based on In-In interpolation were preformed to determine the relative abundance of the neutrons in each spectrum from $0.025 \mathrm{eV}$ to $15 \mathrm{MeV}$ broken down into $20 \mathrm{keV}$ intervals. To normalize the spectra to a single neutron, the value for each $20 \mathrm{keV}$ interval was divided by the total number of neutrons for each reference spectrum (i.e., the sum of all the EIs); ergo, each spectrum represents the relative abundance or the fraction of single source neutron broken down into $20 \mathrm{keV}$ intervals. The ICRP $21 \mathrm{~h}, \mathrm{BD}-100 \mathrm{R} R(\mathrm{E})$, and TLD-600 R(E) were also entered into the spreadsheet and interpolated over the corresponding $20 \mathrm{keV}$ EIs. The $h_{\text {o }}$ was folded into each spectrum, i.e., the $h_{\phi}$ of each $20 \mathrm{keV}$ ICRP 21 interval was multiplied by the $\phi$ of its corresponding spectrum interval. Because the spectrum is representative of the distribution of a single source neutron, the summation of these EI dose equivalents provides the dose equivalent per each neutron emitted from the source. This is commonly known as the spectrum averaged ICRP 21 fluence-to-dose equivalent conversion factor. Dividing each $20 \mathrm{keV}$ interval by this spectrum averaged $h_{\phi}$ yields a spectrum that, when the $\mathrm{h}_{6}$ is applied, yields $0.01 \mathrm{mSv}$, i.e., a $0.01 \mathrm{mSv}$ (1 mrem) normalized spectrum. This procedure was followed for each of the sources under investigation. The response of a deter,cor can then be estimated by folding the detectors $R(E)$ into the $0.01 \mathrm{mSv}$ normalized spectrum. This yields a calculated source specific sensitivity in detector response per $0.01 \mathrm{mSv}$ (mrem). The source specific sensitivities of the TLD-600 and the BD-100R were calculated for each of the available spectra. The results of these calculations are provided in Table A.1. In addition to the source specific sensitivities, the calculated fluence and dose equivalent weighted average energies and spectrum averaged fluence-to-dose equivalent conversion factors are provided. 
Table A.1. Calculated values of $\bar{E}(\phi), \bar{E}(H), \bar{h}_{\phi}$ and BD-100R response for several radioisotopic neutron sources

\begin{tabular}{|c|c|c|c|c|c|c|}
\hline Source & Reference & $\begin{array}{l}\bar{E}(\phi)^{c} \\
(\mathrm{MeV})\end{array}$ & $\begin{array}{l}\bar{E}(H)^{d} \\
(\mathrm{MeV})\end{array}$ & $\begin{array}{c}\bar{h}_{\phi}^{e} \\
\left(10^{-10}{ }^{-}{ }^{-}-\mathrm{cm}^{2}\right)\end{array}$ & $\begin{array}{c}\text { TLD_600 } \\
\text { (mR/mrem) }\end{array}$ & $\begin{array}{c}\text { 100R } \\
\text { R(E) } \\
\text { (bu/mrem) }\end{array}$ \\
\hline${ }^{288} \mathrm{PuBe}$ & Kozlov & 5.1 & 5.12 & 4.08 & 0.38 & 0.94 \\
\hline${ }^{238} \mathrm{PuBe}(\mathrm{low})^{b}$ & Kozlov & 4.86 & 4.94 & 4.01 & 0.42 & 0.96 \\
\hline${ }^{241} \mathrm{AmBe}$ & Capgras & 4.73 & 4.82 & 4.01 & 0.42 & 0.97 \\
\hline${ }^{209} \mathrm{PuBe}$ & Capgras & 4.63 & 4.73 & 3.99 & 0.43 & 0.97 \\
\hline${ }^{241} \mathrm{AmBe}(\mathrm{low})^{b}$ & Capgras & 4.56 & 4.73 & 3.93 & 0.46 & 0.99 \\
\hline${ }^{239} \mathrm{PuBe}(\mathrm{low})^{b}$ & Capgras & 4.5 & 4.67 & 3.93 & 0.46 & 1.00 \\
\hline${ }^{244} \mathrm{CmBe}$ & Capgras & 4.5 & 4.65 & 3.94 & 0.46 & 0.99 \\
\hline PuC & Lorch & 4.48 & 4.48 & 4.09 & 0.46 & 0.95 \\
\hline${ }^{244} \mathrm{CmBe}(\mathrm{low}){ }^{b}$ & Lorch & 4.25 & 4.54 & 3.8 & 0.38 & 1.03 \\
\hline $\mathrm{AmBe}$ & ISO & 4.15 & 4.52 & 3.73 & 0.52 & 1.03 \\
\hline $\mathrm{PuC}(\mathrm{low})^{b}$ & Lorch & 3.72 & 3.8 & 3.97 & 0.56 & 1.00 \\
\hline Cf(unmod) & Lorch & 2.81 & 2.86 & 3.93 & 0.48 & 1.03 \\
\hline AmB & Lorch & 2.76 & 2.78 & 4.00 & 0.57 & 1.01 \\
\hline AmB & ISO & 2.73 & 2.79 & 3.96 & 0.54 & 1.02 \\
\hline$A m B(\text { low })^{b}$ & Lorch & 2.72 & 2.76 & 3.96 & 0.56 & 1.02 \\
\hline Cf(unm: ')(low) ${ }^{b}$ & Lorch & 2.44 & 2.61 & 3.68 & 0.68 & 1.1 \\
\hline Cf(unmod) & ISO & 2.14 & 2.47 & 3.35 & 0.85 & 1.2 \\
\hline PuF & Anderson & 1.63 & 1.67 & 3.54 & 0.77 & 1.14 \\
\hline $\mathrm{AmF}$ & Lorch & 1.61 & 1.63 & 3.69 & 0.75 & 1.12 \\
\hline $\operatorname{AmF}(10 w)^{b}$ & Lorch & 1.47 & 1.54 & 3.5 & 0.84 & 1.18 \\
\hline $\operatorname{PuF}(\text { low })^{b}$ & Anderson & 1.44 & 1.56 & 3.36 & 0.91 & 1.23 \\
\hline PuF & Massand & 1.4 & 1.47 & 3.43 & 0.88 & 1.21 \\
\hline $\operatorname{PuF}(\mathrm{low})^{b}$ & Massand & 1.4 & 1.47 & 3.43 & 0.88 & 1.21 \\
\hline $\mathrm{Cf}\left(\mathrm{D}_{2} \mathrm{O}\right)$ & iSO & 0.546 & 2.22 & 0.926 & 6.38 & 1.25 \\
\hline $\mathrm{AmLi}$ & Werle & 0.459 & 0.625 & 1.7 & 2.69 & 2.06 \\
\hline $\operatorname{AmLi}(\text { low })^{b}$ & Werle & 0.439 & 0.624 & 1.66 & 2.75 & 2.05 \\
\hline
\end{tabular}

${ }^{a}$ The data for all spectra, except those from ISO, were obtained from a digitized image of each spectrum from the referenced literature.

$b$ The fluence in the low energy range was estimated by extrapolating linearly from the value at the lowest available energy to zero at $\mathrm{E}=0 \mathrm{MeV}$ according to ISO/DIS 8529 Annex A (ISO/DIS 1986).

c $\bar{E}(\phi)$ is the fluence weighted average energy.

${ }^{d} \bar{E}(H)$ is the dose equivalent weighted average energy defined by ISO/DIS 8529 Sect. 3.19 (ISO/DIS 1986).

$e \bar{h}_{\phi}$ was derived in the manner described by ISO/DIS 8529 Sect. 3.18 using ICRP $21 h_{\phi}$.

$f$ The BD-100R response was determined by folding a $0.01 \mathrm{mSv}(1 \mathrm{mrem})$ normalized spectrum of each source into the response function $(R(E))$ of the BD-100R. 


\section{Source-Specific Correction Factors}

These calculated sensitivities can then be applied to produce correction factors as follows:

$$
C_{s}=S_{t} / S_{c}
$$

where

$\mathrm{S}_{\mathrm{t}}=$ sensitivity to spectrum being measured (bu $\left.\mathrm{mSv}^{-1}\right)$,

$\mathrm{S}_{\mathrm{c}}=$ sensitivity to calibration spectrum (bu $\mathrm{mSv}^{-1}$ ).

The calibration factors are applied to the reported dose equivalent result $\mathrm{H}_{r}$

$$
H_{r}=b u * S_{c} \text {, }
$$

where

$\mathrm{bu}=$ number of bubbles in the detector.

The variation in the sensitivity of the bubble detector to the test and calibration spectra is corrected for by using this equation,

$$
H_{c}=C_{s} * H_{r}
$$

$$
\begin{aligned}
& \text { where } \\
& \mathrm{H}_{\mathrm{c}}=\text { corrected dose equivalent response (mSv), } \\
& \mathrm{C}_{\mathrm{s}}=\text { correction factor for the spectrum of interest, } \\
& \mathrm{H}_{\mathrm{r}}=\text { raw response in } \mathrm{mSv} \text { to the spectrum of interest. }
\end{aligned}
$$


ORNL/TM-11916

\section{INTERNAL DISTRIBUTION}

1. A. B. Ahmed

2. B. A. Berven

3. J. S. Bogard

4. R. S. Bogard

5-21. M. A. Buckner

22. W. H. Casson

23. D. S. Colwell

24. K. F. Eckerman

25. C. A. England

26. J. W. Halliwell

27. M. S. Hileman

28. J. B. Hunt

29. G. D. Kerr

30. D. C. Kocher

31. C. A. Little
32. P. Y. Lu

33. K. L. McMahan

34. L. F. Miller

35. D. R. Simpson

36. D. E. Reichle

37. P. S. Rohwer

38. C. S. Sims

39. P. R. Smith

40. M. L. Souleyrette

41. Central Research Library

42. ORNL Technical Library, Y-12

43-44. Laboratory Records Dept.

45. Laboratory Records-RC

46. ORNL Patent Section

\section{EXTERNAL DISTRIBUTION}

47. Kenneth R. Alvar, LANL, MS-G761, 3390 Wellesly Ave., San Diego, CA 92122

48. Dick Amato, Bettis Atomic Power Laboratory, P.O. Box 79, West Mifflin, PA 15122 32B, BAT-2 Rm 211

49. Robert Apfel, Apfel Enterprises, Inc., 25 Science Park, STE 676, New Haven, CT 06511

50. R. K. Boake, LANL, 3390 Wellesly Ave., San Diego, CA 92122

51. Rita Borbe, INSTITUTO di RADIOLOGIA, dell' Universite, Servizio di Fisica Sanitaria, Policlinico - 06100 Perugia, ITALY

52. Rachel Carr, TU Electric, Comanche Peak, P.O. Box 10円2, Glen Rose, TX 76043

53. R. Douglas Carson, Dept. of Energy, Radiological \& Environmental Sciences Laboratory, 785 DOE Place, Idaho Falls, ID 83402-4149

54. Tom Cousins, Defense Research Establishment-Ottawa, DREO, Dept. of National Defense, 3701 Carling Avenue, Ottawa, Ontario, CANADA K1A 0Z4

55. Kenneth Crase, Westinghouse Savannah River, P.O. Box 616, Aiken, SC 29802

56. LCDR Steven W. Doremus, Naval Dosimetry Center, National Naval Medical Center, Bethesda, MD 20814-5000

57. Jerry Gilbert, Princeton University, Plasma Physics Laboratory, P.O. Box 451, Princeton, NJ 08543

58. Mark Harper, United States Naval Academy, Naval System Department, MS:11D, Annapolis, MD 21402

59. Nolan Hertel, ETC 5.160, Mechanical Engineering Dept., The University of Texas at Austin, Austin, TX 78712

60. H. Ing, Bubble Technology Industries, Chalk River, Ontario, CANADA 
61. Nisy E. Ipe, Stanford Linear Accelerator Center, P.O. Box 4349, Stanford, CA 94309

62. Eric E. Kearsley, Armed Forces Radiobiology, Research Institute (MRA)(AFRRI), Bldg. 42, Radiation Biophysics Dept., Bethesda, MD 20889-5145

63. Henry Kugel, Princeton Plasma Physics Laboratory, Princeton University, P.O. Box 451, Princeton, NJ 08544

64. John A. Leonowich, Dosimetry Research Section, Health Physics Dept., Battelle, Pacific Northwest Laboratories, Battelle Boulevard, Richland, WA 99352

65. James C. Liu, Stanford Linear Accelerator Center, Bin 48, SLAC, P.O. Box 4349, Stanford, CA 94309

66. Robert M. Loesch, Dept. of Energy, EH-40, Washington, D.C. 20545

67. P. K. Marathe, Government of India, Bhabha Atomic Research Centre, Div. of Radiological Protection, Trombay, Bombay - 400085. INDIA

68. J. C. McDonald, Battelle Pacific Northwest Laboratory., P.O. Box 999, MS P7-03, Richland, WA 99352

69. Marko Moscovitch, Associate Professor, Radiation Science Div., Dept. of Radiation Medicine, Georgetown University, School of Medicine, 3800 Reservoir Road NW, Washington, D.C. 20007-2197

70. O. Missous, University of Montpellier II, France, CASC 083, C.E.M., Montpellier 34060, FRANCE

71. Hiroyuki Murakami, Radiation Dosimetry Div., Japan Atomic Energy Research Institute, Dept. of Health Physics, Tokai, Naka-gun, Ibaraki, 319-11, JAPAN

72. Martin Nelson, United States Naval Academy, Naval System Dept., MS:11D, Annapolis, MD 21402

73. Rob Noulty, Bubble Technology Industries, Hwy. 17, Chalk River, Ontario, CANADA K0J $1 \mathrm{~J} 0$

74. Thomas Ohlhaber, Siemens Dosimetry Service, 2501 Barrington Road, Hoffman Estates, IL 60195-7372

75. Mary Ann Parkhurst, Dosimetry Technology Section, Health Physics Dept., K357, Battelle, Pacific Northwest Laboratories, Battelle Boulevard, Richland, WA 99352

76. D. Ponraju, Indira Gandhi Centre for Atomic Research, Kalpakkam, 603102 , INDIA

77. Joel Rabovsky, Office of Health, EH-41, Dept. of Energy, Washington, D.C. 20545

78. T. A. Rhea, SAIC, 800 Oak Ridge Turnpike, Oak Ridge, TN 37831

79. Gordon Riel, N60921 Supply Officer, Naval Surface Warfare Center, White Oak, Silver Spring, MD 20903-5000

80. David Roy, Bubble Technology Industries, Hwy. 17, Chalk River, Ontario, CANADA K0J1J0

81. Robert B. Schwartz, National Institute of Standards \& Technology, Bldg. 235, Gaithersburg, MD 20899

82. Leonard S. Sygitowicz, Reeco, H.P. Dept., MS 708, P.O. Box 98521, Las Vegas, NV 89193-8521

83. Jennifer E. Tanner, Battelle, P.O. Box 999, Richland, WA 99352

84. Dr. L. Tommasino, Measurement Laboratory, Italian Directorate of Nuclear Safety and Radioprotection, ENEA, Via V. Brancatl s8, 00144 Roma, ITALY

85. Hector Rene Vega-Carrillo, 3106 Duval Street \#306, Austin, TX 78705-3045 
86. Robert V. Wheeler, Landauer, 2 Science Road, Glenwood, IL 60425-1586

87. C. F. Wu, Waste Isolation Pilot Plant, Westinghouse Electric Corporation, P.O. Box 2078, Carlsbad, NM 88221

88. Joseph G. Young, Australian Radiation Laboratory, Lower Plenty Road, Yallambie, Victoria 3085, AUSTRALIA

89. Office of Assistant Manager for Energy Research and Development, DOE Oak Ridge Field Office, P.O. Box 2001, Oak Ridge, TN 37831-8600

90-99. Office of Scientific and Technical Information, P.O. Box 62, Oak Ridge, TN 37831-0062 (10-NTIS) 

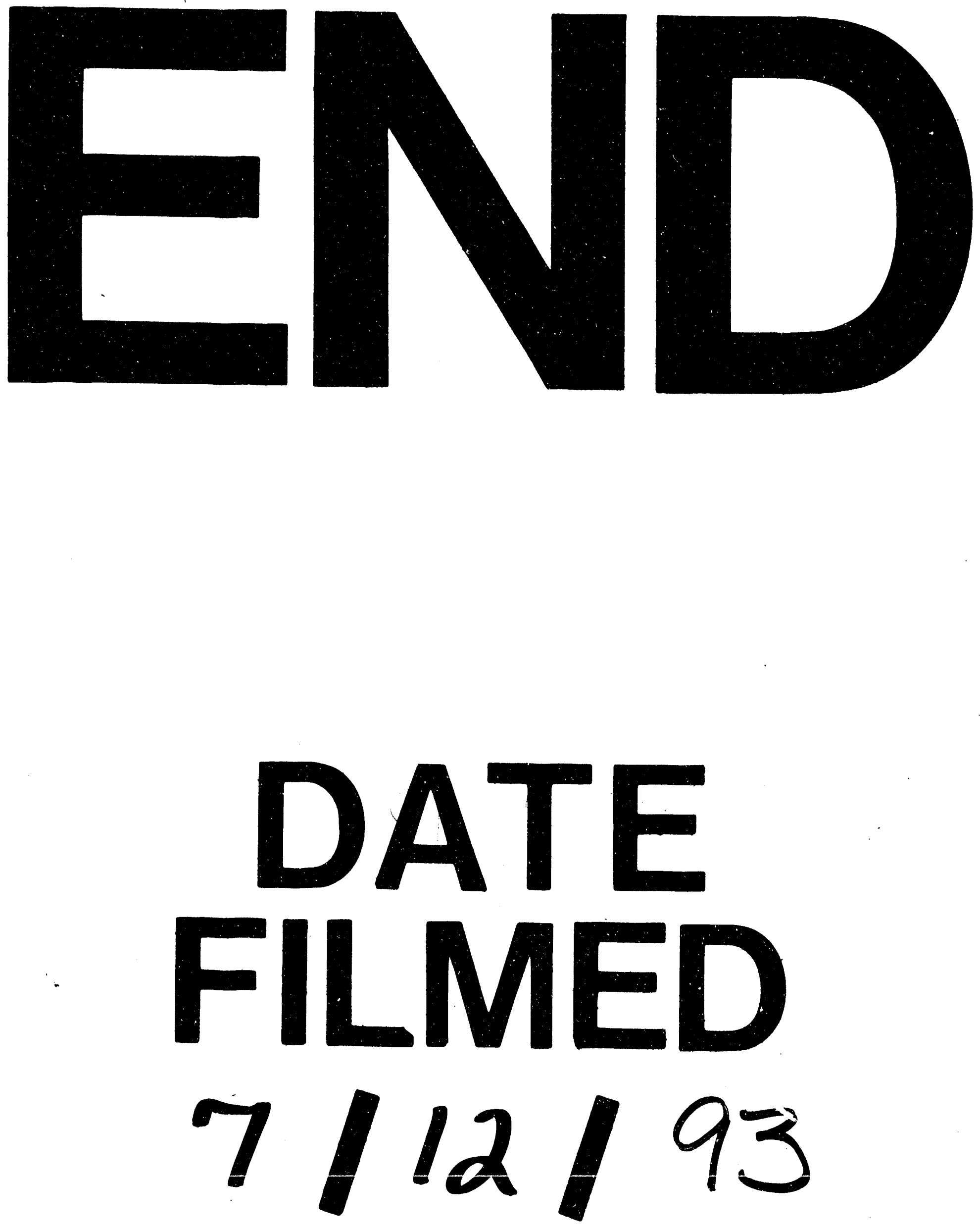
